
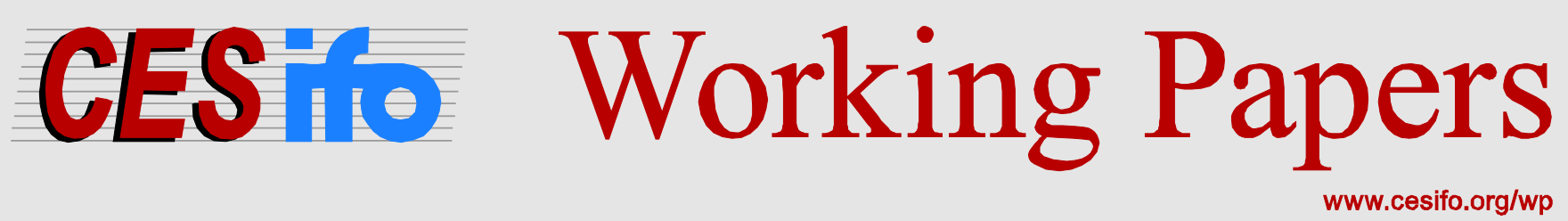

\title{
Do Banks Pass Through Credit Expansions? The Marginal Profitability of Consumer Lending During the Great Recession
}

\author{
Sumit Agarwal \\ Souphala Chomsisengphet \\ Neale Mahoney \\ Johannes Stroebel
}

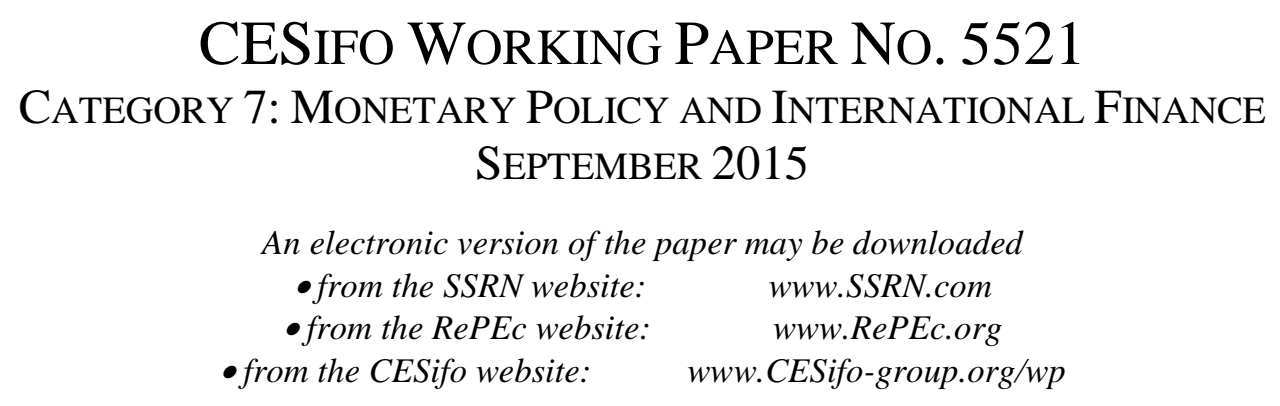




\title{
Do Banks Pass Through Credit Expansions? The Marginal Profitability of Consumer Lending During the Great Recession
}

\begin{abstract}
We examine the ability of policymakers to stimulate household borrowing and spending during the Great Recession by reducing banks' cost of funds. Using panel data on 8.5 million U.S. credit card accounts and 743 credit limit regression discontinuities, we estimate the marginal propensity to borrow (MPB) for households with different FICO credit scores. We find substantial heterogeneity, with a $\$ 1$ increase in credit limits raising total unsecured borrowing after 12 months by 59 cents for consumers with the lowest FICO scores $(\leq 660)$ while having no effect on consumers with the highest FICO scores $(>740)$. We use the same credit limit regression discontinuities to estimate banks' marginal propensity to lend (MPL) out of a decrease in their cost of funds. For the lowest FICO score households, higher credit limits quickly reduce marginal profits, limiting the pass-through of credit expansions to those households. We estimate that a 1 percentage point reduction in the cost of funds raises optimal credit limits by $\$ 127$ for consumers with FICO scores below 660 versus $\$ 2,203$ for consumers with FICO scores above 740. We conclude that banks' MPL is lowest exactly for those households with the highest MPB, limiting the effectiveness of policies that aim to stimulate the economy by reducing banks' cost of funds.
\end{abstract}

\author{
Sumit Agarwal \\ National University of Singapore \\ ushakri@yahoo.com \\ Neale Mahoney \\ University of Chicago \\ Booth School of Business / USA \\ neale.mahoney@gmail.com
}

\author{
Souphala Chomsisengphet \\ Office of the Controller of the Currency \\ souphala.chomsisengphet@occ.treas.gov
}

\author{
Johannes Stroebel \\ New York University \\ Stern School of Business / USA \\ johannes.stroebel@nyu.edu
}

September 9, 2015

For helpful comments, we are grateful to Viral Acharya, Scott Baker, Eric Budish, Alex Frankel, Erik Hurst, Anil Kashyap, Theresa Kuchler, Randall Kroszner, Marco di Maggio, Matteo Maggiori, Rick Mishkin, Jonathan Parker, Thomas Phillipon, Amit Seru, Amir Sufi, and Alessandra Voena, as well as seminar and conference participants at Berkeley Haas, NYU Stern, Columbia University, HEC Paris, BIS, Ifo Institute, Goethe University Frankfurt, SED 2015, NBER Summer Institute, and LMU Munich. We thank Regina Villasmil, Mariel Schwartz, and YinWei Soon for truly outstanding and dedicated research assistance. The views expressed are those of the authors alone and do not necessarily reflect those of the Office of the Comptroller of the Currency. 
During the Great Recession, policymakers in the U.S. and Europe sought to stimulate the economy by providing banks with lower-cost capital and liquidity. One objective of these actions was to encourage banks to expand credit to households and firms that would in turn increase their borrowing, spending, and investment. ${ }^{1}$ Perhaps because of the slow recovery, this approach has been questioned, with a number of prominent economists concluding that credit expansions were less successful than anticipated at stimulating economic activity (e.g., Taylor, 2014; Goodhart, 2015; Sufi, 2015). ${ }^{2}$ The natural question is "why?" This paper presents an explanation grounded in the micro-economics of consumer credit markets.

The effect of bank-mediated stimulus on household borrowing and spending depends on whether banks pass through credit expansions to households with a high marginal propensity to borrow (MPB). A growing body of research finds that low credit score households are the most credit constrained, suggesting that credit expansions that target these households will have the largest aggregate effects (e.g., Gross and Souleles, 2002). A separate literature shows that the low credit score segment of the consumer lending market exhibits substantial asymmetric information (e.g., Adams, Einav and Levin, 2009). As we discuss below, asymmetric information can reduce banks' incentives to expand credit, because higher credit limits lead to higher rates of default, reducing the marginal profitability of lending. These findings raise the concern that banks' marginal propensity to lend (MPL) is the lowest exactly for those households with the highest MPB, reducing the effectiveness of these policies.

We evaluate this concern by estimating heterogeneous MPBs and MPLs in the U.S. credit card market during the Great Recession. We use panel data on all credit cards issued by the 8 largest U.S. banks. These data, assembled by the Office of the Comptroller of the Currency (OCC), provide us with account-level information on contract terms, utilization, payments, and costs at the monthly level for more than 400 million credit card accounts between January 2008 and December 2014.

Our research design exploits the fact that banks sometimes set credit limits as discontinuous functions of consumers' FICO credit scores. For example, a bank might grant a $\$ 2,000$ credit limit to applicants with a FICO score below 720 and a \$5,000 credit limit to applicants with a FICO score of

\footnotetext{
${ }^{1}$ For example, when introducing the Financial Stability Plan, Geithner (2009) argued that "the capital will come with conditions to help ensure that every dollar of assistance is used to generate a level of lending greater than what would have been possible in the absence of government support." In Europe, similar schemes were put in place in order to reduce the cost of capital of those banks that expand lending to the non-financial sector and households (e.g., the "Funding for Lending" scheme of the Bank of England, and the "Targeted Longer-Term Refinancing Operation" of the ECB). See also Appendix A.

${ }^{2}$ The Wall Street Journal reports that "Fed officials have been frustrated in the past year that low interest rate policies haven't reached enough Americans to spur stronger growth the way economics textbooks say low rates should. By reducing interest rates - the cost of credit - the Fed encourages household spending, business investment and hiring, [...]. But the economy hasn't been working according to script." The Economist concludes: "[I]t seems clear that current circumstances are causing these monetary policy actions to be far less effective than they otherwise would be."
} 
720 or above. We show that other borrower and contract characteristics trend smoothly through these cutoffs, allowing us to use a regression discontinuity strategy to identify the causal impact of providing extra credit at prevailing interest rates. We identify a total of 743 credit limit discontinuities for different credit cards originated in our sample. These discontinuities are detected at all parts of the FICO score distribution, and we observe 8.5 million new credit cards issued to borrowers within 50 FICO score points of a cutoff.

Using this regression discontinuity design, we estimate substantial heterogeneity in the MPB across the FICO score distribution. For the lowest FICO score group $(\leq 660)$, a $\$ 1$ increase in credit limits raises borrowing volumes on the treated credit card by 58 cents at 12 months after origination. This effect is due to increased spending and is not explained by a shifting of borrowing across different credit cards. For the highest FICO score group ( $>740)$, we estimate a $23 \%$ effect on the treated card that is entirely explained by a shifting of borrowing across credit cards, with an increase in credit limits having no effect on total borrowing. These estimates suggest that bank-mediated stimulus will only raise aggregate borrowing if credit expansions are passed through to low FICO score households.

We next consider how banks pass through credit expansions to different households. Directly estimating a bank's MPL out of a change in its cost of funds is difficult because changes in banks' cost of funds are typically correlated with unobserved factors that also affect lending. Our approach is to build a simple model of optimal credit limits that characterizes a bank's MPL with a small number of parameters we can estimate using our credit limit quasi-experiments. ${ }^{3}$ This approach requires that bank lending responds optimally on average to a change in the cost of funds and that we can measure the incentives faced by banks. We think both assumptions are reasonable in our setting. Credit card lending is highly sophisticated and our estimates of bank incentives are fairly precise. Indeed, we show that observed credit limits are quite close to the optimal credit limits predicted by our model.

In our model, banks set credit limits at the level where the marginal revenue from a further increase in credit limits equals the marginal cost of that increase. A decrease in the cost of funds - e.g., due to an easing of monetary policy, a reduction in capital requirements, or a market intervention that reduces financial frictions - reduces the cost of extending a given unit of credit and corresponds to a downward shift in the marginal cost curve. As shown in Figure 1, such a reduction has a larger effect on credit limits when marginal revenue and marginal cost curves are relatively flat (Panel A) than when these curves are relatively steep (Panel B).

\footnotetext{
${ }^{3}$ We show that in the credit card market, it is credit limits, not interest rates, that are the primary margin of response for lenders (see Ausubel, 1991; Calem and Mester, 1995; Stavins, 1996; Stango, 2000).
} 
Figure 1: Pass-Through of Reduction in Cost of Funds into Credit Limits

(A) Flatter MC and MR

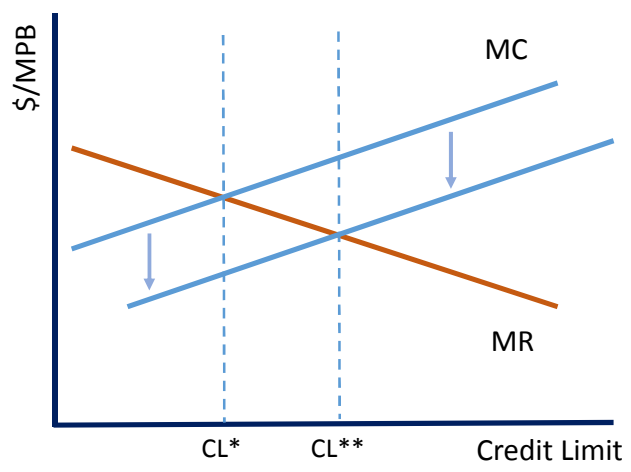

(B) Steeper MC and MR

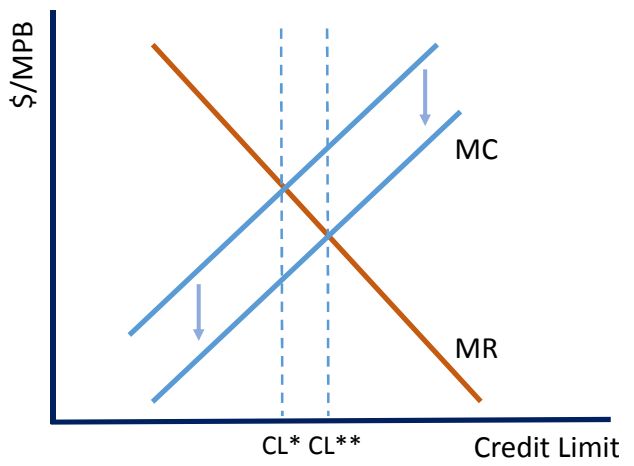

Note: Figure shows marginal cost (MC) and marginal revenue (MR) for lending to observationally identical borrowers. A reduction in the cost of funds shifts the marginal cost curve down, and raises equilibrium credit limits $\left(\mathrm{CL}^{*} \rightarrow \mathrm{CL}^{* *}\right)$. Panel A considers a case with relatively flat MC and MR curves; Panel B considers a case with steeper MC and MR curves.

What are the economic forces that determine the slope of marginal costs? One factor is the degree of adverse selection. With adverse selection, higher credit limits are disproportionately taken up by consumers with higher probabilities of default. These higher default rates raise the marginal cost of lending, thereby generating upward sloping marginal costs (see Mahoney and Weyl, 2013). Higher credit limits can also raise marginal costs holding the distribution of marginal borrowers fixed. For example, if higher debt levels have a causal effect on the probability of default - as they do in the strategic bankruptcy model of Fay, Hurst and White (2002) - then higher credit limits, which increase debt levels, will also raise default rates. As before, this raises the marginal cost of lending, generating upward sloping marginal costs. ${ }^{4}$

We use the same quasi-exogenous variation in credit limits to estimate the slope of marginal costs, allowing us to quantify the effect of asymmetric information and other factors on the MPL without untangling their relative importance. We find that the (positive) slope of the marginal cost curve is largest for the lowest FICO score borrowers, driven by steeply upward sloping marginal chargeoffs for these households. We also find that the (negative) slope of the marginal revenue curve is steeper for these households, since marginal fee revenue, which is particularly important for lending to low FICO score borrowers, is decreasing in credit limits. Taken together, these estimates imply that a 1 percentage point reduction in the cost of funds increases optimal credit limits by $\$ 127$ for borrowers with FICO scores below 660, compared with \$2,203 for borrowers with FICO scores above 740.

This negative correlation between the MPL and the MPB for households with different FICO

\footnotetext{
${ }^{4}$ This mechanism also arises in models of myopic behavior, in which consumers, faced with a higher credit limit, borrow more than they can repay because they do not fully internalize having to repay their debt in the future.
} 
scores has important implications for the effectiveness of bank-mediated stimulus. ${ }^{5}$ We find that correctly accounting for this negative correlation reduces the estimated effect of a decrease in the cost of funds on total borrowing after 12 months by $76 \%$ relative to a naive calculation that estimates this effect as the product of the average MPL and the average MPB in our data. ${ }^{6}$

We view our paper as making two main contributions. First, we think that the credit card market is important, because credit cards are the marginal source of credit for many U.S. households. According to the 2010 Survey of Consumer Finances, 68\% of households had a credit card versus 10.3\% for a home equity line of credit and $4.1 \%$ for "other" lines of credit. Moreover, credit cards were particularly important during the Great Recession when many homeowners were underwater and unable to borrow against home equity. For instance, credit cards issued to consumers with FICO scores above 740 had average borrowing volumes of $\$ 2,101$ at one year after origination, indicating that credit cards were a key source of credit even in the upper range of the FICO distribution.

Second, we believe the conceptual point that the pass-through of changes to banks' cost of funds is muted for borrowers with steeper marginal costs - e.g., because of asymmetric information - applies to a broader set of lending markets. These include small business loans, mortgages, and newlyemerging online lending markets, all of which feature significant potential for adverse selection and moral hazard (see Petersen and Rajan, 1994; Karlan and Zinman, 2009; Keys et al., 2010; Hertzberg, Liberman and Paravisini, 2015; Kurlat and Stroebel, 2015; Stroebel, 2015). Indeed, Fuster and Willen (2010) show that most of the mortgage refinancing in response to the Federal Reserve's quantitative easing programs was done by households with higher FICO scores, with limited refinancing by lower FICO score households. This pattern is consistent with evidence of significant adverse selection in the low end of the housing market (e.g., Ambrose, Conklin and Yoshida, 2015) and the connection between adverse selection and pass-through that we highlight.

Our empirical approach follows a literature that has estimated the importance of credit constraints by analyzing household responses to income shocks (e.g., Souleles, 1999; Stephens, 2003, 2008; Johnson, Parker and Souleles, 2006; Blundell, Pistaferri and Preston, 2008). ${ }^{7}$ Most closely related are Gross

\footnotetext{
${ }^{5}$ Our estimates are obtained from credit cards that were originated during an economic crisis, which is precisely the period during which stimulus is generally considered. Therefore, even if these slopes varied with aggregate economic activity, our estimates are appropriate for inferring banks' marginal propensity to lend during economic crises.

${ }^{6}$ This muted pass-through applies symmetrically to increases in the cost of funds. This means that attempts by central banks to "lean against" credit bubbles by raising interest rates may also precipitate smaller-than-average changes in credit availability for those households that borrow the most.

${ }^{7}$ Other papers include Zeldes (1989), Hsieh (2003), Agarwal, Liu and Souleles (2007), Aaronson, Agarwal and French (2012), Agarwal and Qian (2014), Baker (2013), Dobbie and Skiba (2013), Parker et al. (2013), Agarwal et al. (2015a), Bhutta and Keys (2014), Gelman et al. (2015), and Sahm, Shapiro and Slemrod (2015). See Jappelli and Pistaferri (2010) and Zinman (2014) for reviews.
} 
and Souleles (2002), who estimate MPBs using time-series variation in credit limits, and Aydin (2015), who exploits a credit limit experiment in Turkey to estimate MPBs. We view our contribution of estimating both MPBs and MPLs in the same context as a natural next step in this literature.

Our paper highlights the aggregate and distributional effects of the bank lending channel of monetary policy (Bernanke and Gertler, 1995; Kashyap and Stein, 1995) and, in particular, the effect of monetary policy on bank lending during the Great Recession (see Jiménez et al., 2012, 2014; Acharya et al., 2014). Our finding of heterogeneous MPLs out of a reduction in banks' cost of funds complements recent work by Doepke and Schneider (2006), Coibion et al. (2012), Scharfstein and Sunderam (2013), Auclert (2014), Keys et al. (2014), Di Maggio, Kermani and Ramcharan (2014) and Hurst et al. (2015), who investigate heterogeneity in the transmission of monetary policy through other channels.

Finally, we relate to a large literature that has identified declining household borrowing volumes as a proximate cause of the Great Recession (Mian and Sufi, 2010, 2012; Guerrieri and Lorenzoni, 2011; Eggertsson and Krugman, 2012; Hall, 2011; Philippon and Midrigan, 2011; Mian, Rao and Sufi, 2013; Korinek and Simsek, 2014). We provide a reason why bank-mediated credit expansions might have been less successful than anticipated in stimulating household borrowing and spending. We also estimate high MPBs out of extra credit for households with low FICO scores. This finding suggests that, at the margin, aggregate borrowing volumes were constrained by restricted credit supply - and not by a decline in credit demand driven by voluntary household deleveraging.

Our findings are subject to a number of caveats. First, while we identify one important reason why policies to reduce banks' cost of funds were relatively ineffective at raising household borrowing during the Great Recession, other forces also played a role. For instance, stress tests and higher capital requirements may have increased the cost of lending, particularly to low FICO score borrowers, and thus might have offset the policies we consider that were designed to reduce banks' cost of funds. Second, our paper does not assess the desirability of stimulating household borrowing from a macroeconomic stability or welfare perspective. For example, while extending credit to low FICO households might lead to more borrowing and consumption in the short run, we do not evaluate the consequences of the resulting increase in leverage. Finally, our results do not capture general equilibrium effects that might arise from the increased spending of low FICO score households and are not informative about the effectiveness of monetary policy through other channels, such as a redistribution from savers to borrowers, or in its role in preventing a collapse of the banking sector.

The rest of the paper proceeds as follows: Section 1 presents background on the determinants 
of credit limits and describes our credit card data. Section 2 discusses our regression discontinuity research design. Section 3 verifies the validity of this research design. Section 4 presents our estimates of the marginal propensity to borrow. Section 5 provides a model of credit limits. Section 6 presents our estimates of the marginal propensity to lend. Section 7 concludes.

\section{Background and Data}

Our research design exploits quasi-random variation in the credit limits set by credit card lenders (see Section 2). In this section, we describe the process by which banks determine these credit limits and introduce the data we use in our empirical analysis. We then describe our process for identifying credit limit discontinuities and present summary statistics on our sample of quasi-experiments.

\subsection{How Do Banks Set Credit Limits?}

Most credit card lenders use credit scoring models to make their pricing and lending decisions. These models are developed by analyzing the correlation between cardholder characteristics and outcomes like default and profitability. Banks use internally developed and externally purchased credit scoring models. The most commonly used external credit scores are called FICO scores, which are developed by the Fair Isaac Corporation. FICO scores are used by over $80 \%$ of the largest financial institutions and primarily take into account a consumer's payment history, credit utilization, length of credit history, and the opening of new accounts (see Chatterjee, Corbae and Rios-Rull, 2011). Scores range between 300 and 850, with higher scores indicating a lower probability of default. The vast majority of the population has scores between 550 and 800 .

Each bank develops its own policies and risk tolerance for credit card lending, with lower credit score consumers generally assigned lower credit limits. Setting cutoff scores is one way that banks assign credit limits. For example, banks might split their customers into groups based on their FICO score and assign each group a different credit limit (FDIC, 2007). ${ }^{8}$ This would lead to discontinuities in credit limits extended on either side of the FICO score cutoff. Alternatively, banks might use a "dualscoring matrix," with the FICO score on the first axis and another score on the second axis, and cuttoff levels on both dimensions. In this case, depending on the distribution of households over the two dimensions, the average credit limit might be smooth in either dimensions, even if both dimensions

\footnotetext{
${ }^{8}$ While it might seem more natural to set credit limits as continuous functions of FICO scores, the use of "buckets" for pricing is relatively common across many markets. For example, many health insurance schemes apply common pricing for individuals within age ranges of five years, and large retailers often set uniform pricing rules within sizable geographic areas. This suggests that the potential for increased profit from more complicated pricing rules is likely to be second-order.
} 
have cutoffs. The resulting credit supply rules can change frequently and may vary across different credit cards issued by the same bank.

\subsection{Data}

Our main data source is the Credit Card Metrics (CCM) data set assembled by the U.S. Office of the Comptroller of the Currency (OCC). ${ }^{9}$ The CCM data set has two components. The main data set contains account-level information on credit card utilization (e.g., purchase volume, measures of borrowing volume such as ADB), contract characteristics (e.g., credit limits, interest rates), charges (e.g., interest, assessed fees), performance (e.g., chargeoffs, days overdue), and borrower characteristics (e.g., FICO scores) for all credit card accounts at these banks. The second data set contains portfoliolevel information for each bank on items such as operational costs and fraud expenses across all credit cards managed by the bank. Both data sets are submitted monthly; reporting started in January 2008 and continues through the present. In the average month, we observe account-level information on over 400 million credit cards. See Agarwal et al. (2015b) for more details on these data and summary statistics on the full sample.

In addition, we merge quarterly credit bureau data to the CCM data using a unique identifier. These credit bureau data contain information on an individual's credit cards across all lenders, including information on the total number of credit cards, total credit limits, total balances, length of credit history, and credit performance measures such as whether the borrower was ever more than 90 days past due on an account. This information captures the near totality of the information on new credit card applicants that was available to lenders at account origination.

\subsection{Identifying Credit Limit Discontinuities}

In our empirical analysis, we focus on credit cards that were originated during our sample period, which started in January 2008. Our data do not contain information on the credit supply functions of banks when the credit cards were originated. Therefore, the first empirical step involves backing out these credit supply functions from the observed credit limits offered to individuals with different FICO scores. To do this, we jointly consider all credit cards of the same type (co-branded, oil and gas, affinity, student, or other), issued by the same bank, in the same month, and through the same loan channel (pre-approved, invitation to apply, branch application, magazine and internet application, or

\footnotetext{
${ }^{9}$ The OCC supervises and regulates nationally-chartered banks and federal savings associations. In 2008, the OCC initiated a request to the largest banks that issue credit cards to submit data on general purpose, private label, and small business credit cards. The purpose of the data collection was to have more timely information for bank supervision.
} 
other). It is plausible that the same credit supply function was applied to each card within such an "origination group." For each of the more than 10,000 resulting origination groups between January 2008 and November 2013, we plot the average credit limit as a function of the FICO score. ${ }^{10}$

Panels A to D of Figure 2 show examples of such plots. Since banks generally adjust credit limits at FICO cutoffs that are multiples of 5 (e.g., 650, 655, 660), we pool accounts into such buckets. Average credit limits are shown with blue lines; the number of accounts originated are shown with grey bars. Panels A and B show examples where there are no discontinuous jumps in the credit supply function. Panels C and D show examples of clear discontinuities. For instance, in Panel C, a borrower with a FICO score of 714 is offered an average credit limit of approximately $\$ 2,900$ while a borrower with a FICO score of 715 is offered an average credit limit of approximately $\$ 5,600$.

While continuous credit supply functions are significantly more common, we detect a total of 743 credit limit discontinuities between January 2008 and November 2013. We refer to these cutoffs as "credit limit quasi-experiments" and define them by the combination of origination group $\times$ FICO score. Panel E of Figure 2 shows the distribution of FICO scores at which we observe these quasiexperiments. They range from 630 to 785, with 660, 700, 720, 740, and 760 being the most common cutoffs. Panel F shows the distribution of quasi-experiments weighted by the number of accounts originated within 50 FICO points of the cutoffs, which is the sample we use for our regression discontinuity analysis. We observe more than 1 million accounts around the most prominent cutoffs. Our experimental sample has 8.5 million total accounts or about 11,400 per quasi-experiment.

\subsection{Summary Statistics}

Table 1 presents summary statistics for the accounts in our experimental sample at the time the accounts were originated. In particular, to characterize the accounts that identify our effects, we calculate the mean value for a given variable across all accounts within 5 FICO score points of the cutoff for each quasi-experiment. We then show the means and standard deviations of these values across the 743 quasi-experiments in our data. We also show summary statistics within each of the 4 FICO score groups that we use to explore heterogeneity in the data: $\leq 660,661-700,701-740$, and $>740$. These ranges were chosen to split our quasi-experiments into roughly equal-sized groups. In the entire sample, $28 \%$ of credit cards were issued to borrowers with FICO scores below $660,16 \%$ and $19 \%$ were issued to borrowers with FICO scores between 661-700 and 701-740, respectively, and 37\% of credit

\footnotetext{
${ }^{10}$ Since our data end in December 2014, we only consider credit cards originated until November 2013 to ensure that we observe at least 12 months of post-origination data.
} 
cards were issued to borrowers with FICO scores above 740 (see Appendix Figure A1).

At origination, accounts at the average quasi-experiment have a credit limit of $\$ 5,265$ and an annual percentage rate (APR) of $15.4 \%$. Credit limits increase from $\$ 2,561$ to $\$ 6,941$ across FICO score groups, while APRs decline from $19.6 \%$ to $14.7 \%$. In the merged credit bureau data, we observe utilization on all credit cards held by the borrower. At the average quasi-experiment, account holders have 11 credit cards, with the oldest account being more than 15 years old. Across these credit cards, account holders have $\$ 9,551$ in total balances and $\$ 33,533$ in credit limits. Total balances are humpshaped in FICO score, while total credit limits are monotonically increasing. In the credit bureau data, we also observe historical delinquencies and default. At the average quasi-experiment, account holders have been more than 90 days past due (90+ DPD) 0.17 times in the last 24 months. This number declines from 0.93 to 0.13 across the FICO score groups.

\section{Research Design}

Our identification strategy exploits the credit limit quasi-experiments identified in Section 1 using a fuzzy regression discontinuity (RD) research design (see Lee and Lemieux, 2010). In our setting, the "running variable" is the FICO score. The treatment effect of a \$1 change in credit limit is determined by the jump in the outcome variable divided by the jump in the credit limit at the discontinuity.

We first describe how we recover the treatment effect for a given quasi-experiment and then discuss how we aggregate across the 743 quasi-experiments in the data. For a given quasi-experiment, let $x$ denote the FICO score, $\bar{x}$ the cutoff FICO level, $c l$ the credit limit, and $y$ the outcome variable of interest (e.g., borrowing volume). The fuzzy RD estimator, a local Wald estimator, is given by:

$$
\tau=\frac{\lim _{x \downarrow \bar{x}} E[y \mid x]-\lim _{x \uparrow \bar{x}} E[y \mid x]}{\lim _{x \downarrow \bar{x}} E[c l \mid x]-\lim _{x \uparrow \bar{x}} E[c l \mid x]}
$$

The denominator is always non-zero because of the known discontinuity in the credit supply function at $\bar{x}$. The parameter $\tau$ identifies the local average treatment effect of extending more credit to people with FICO scores in the vicinity of $\bar{x}$. We follow Hahn, Todd and Van der Klaauw (2001) and estimate the limits in Equation 1 using local polynomial regressions. Let $i$ denote a credit card account and II the set of accounts within 50 FICO score points on either side of $\bar{x}$. For each quasi-experiment, we fit a local second-order polynomial regression that solves the following objective function separately for 
observations $i$ on either side of the cutoff, $d \in\{l, h\}$. We do this for two different variables, $\tilde{y} \in\{c l, y\}$.

$$
\min _{\alpha_{\tilde{y}, d}, \beta_{\tilde{y}, d}, \gamma_{\tilde{y}, d}} \sum_{i \in \mathbb{I}}\left[\tilde{y}_{i}-\alpha_{\tilde{y}, d}-\beta_{\tilde{y}, d}\left(x_{i}-\bar{x}\right)-\gamma_{\tilde{y}, d}\left(x_{i}-\bar{x}\right)^{2}\right]^{2} K\left(\frac{x_{i}-\bar{x}}{h}\right) \quad \text { for } d \in\{l, h\}
$$

Observations further from the cutoff are weighted less, with the weights given by the kernel function

$K\left(\frac{x_{i}-\bar{x}}{h}\right)$, which has bandwidth $h$. Since we are primarily interested in the value of $\alpha_{\tilde{y}, d}$, we choose the triangular kernel that has optimal boundary behavior. ${ }^{11}$ In our baseline results we use the default bandwidth from Imbens and Kalyanaraman (2011). For those quasi-experiments for which we identify an additional jump in credit limits within II, we include an indicator variable in Equation 2 that is equal to 1 for all FICO scores above this second cutoff. Given these estimates, the local average treatment effect is given by:

$$
\tau=\frac{\hat{\alpha}_{y, h}-\hat{\alpha}_{y, l}}{\hat{\alpha}_{c l, h}-\hat{\alpha}_{c l, l}}
$$

\subsection{Heterogeneity by FICO Score}

Our objective is to estimate the heterogeneity in treatment effects by FICO score (see Einav et al., 2015, for a discussion of estimating treatment effect heterogeneity across experiments). Let $j$ indicate quasiexperiments, and let $\tau_{j}$ be the local average treatment effect for quasi-experiment $j$ estimated using Equation 3. Let $\mathrm{FICO}_{k}, k=1, \ldots, 4$ be an indicator variable that takes on a value of 1 when the FICO score of the discontinuity for quasi-experiment $j$ falls into one of our FICO groups $(\leq 660,661-700$, $701-740,>740)$. We recover heterogeneity in treatment effects by regressing $\tau_{j}$ on the FICO group dummies and controls:

$$
\tau_{j}=\sum_{k \in K} \beta_{k} F I C O_{k}+X_{j}^{\prime} \delta_{X}+\epsilon_{j}
$$

In our baseline specification, the $X_{j}$ are fully interacted controls for origination quarter, bank, and a "zero initial APR" dummy that captures whether the account has a promotional period during which no interest is charged; we also include loan channel fixed effects. ${ }^{12}$ The $\beta_{k}$ are the coefficients of interest and capture the mean effect for accounts in FICO group $k$, conditional on the other covariates.

We construct standard errors by bootstrapping over the 743 quasi-experiments. In particular, we draw 500 samples of treatment effects with replacement and estimate the coefficients of interest $\beta_{k}$ in each sample. Our standard errors are the standard deviations of these estimates. Conceptually, we

\footnotetext{
${ }^{11}$ Our results are robust to using different specifications. For example, we obtain similar estimates when we run a locally linear regression with a rectangular kernel, which is equivalent to running a linear regression on a small area around $\bar{x}$.

${ }^{12}$ To deal with outliers in the estimated treatment effects from Equation 3, we winsorize the values of $\tau_{j}$ at the $2.5 \%$ level.
} 
think of the local average treatment effects $\tau_{j}$ as "data" that are drawn from a population distribution of treatment effects. We are interested in the average treatment effect in the population for a given FICO score group. Our bootstrapped standard errors can be interpreted as measuring the precision of our sample average treatment effects for the population averages.

\section{Validity of Research Design}

The validity of our research design rests on two assumptions: First, we require a discontinuous change in credit limits at the FICO score cutoffs. Second, other factors that could affect outcomes must trend smoothly through these thresholds. Below we present evidence in support of these assumptions.

\subsection{First Stage Effect on Credit Limits}

We first verify that there is a discontinuous change in credit limits at our quasi-experiments. Panel A of Figure 3 shows average credit limits at origination within 50 FICO score points of the quasiexperiments together with a local linear regression line estimated separately on each side of the cutoff. Initial credit limits are smoothly increasing except at the FICO score cutoff, where they jump discontinuously by $\$ 1,472$. The magnitude of this increase is significant relative to an average credit limit of $\$ 5,265$ around the cutoff (see Table 3). Panel A of Figure 4 shows the distribution of first stage effects from RD specifications estimated separately for each of the 743 quasi-experiments in our data. These correspond to the denominator of Equation 3. The first stage estimates are fairly similar in size, with an interquartile range of $\$ 677$ to $\$ 1,755$ and a standard deviation of $\$ 796 .^{13}$

Panel B of Figure 4 examines the persistence of the jump in the initial credit limit. It shows the RD estimate of the effect of a $\$ 1$ increase in initial credit limits on credit limits at different time horizons following account origination. The initial effect is highly persistent and very similar across FICO score groups, with a $\$ 1$ higher initial credit limit raising subsequent credit limits by $\$ 0.85$ to $\$ 0.93$ at 36 months after origination. Table 4 shows the corresponding regression estimates.

In the analysis that follows, we estimate the effect of a change in initial credit limits on outcomes at different time horizons. A natural question is whether it would be preferable to scale our estimates by the change in contemporaneous credit limits instead of the initial increase. We think the initial increase in credit limits is the appropriate denominator because subsequent credit limits are endogenously determined by household responses to the initial increase. We discuss this issue further in Section 5.4.

\footnotetext{
${ }^{13}$ For all RD graphs we control for additional discontinuous jumps in credit limits as discussed in Section 2.
} 


\subsection{Other Characteristics Trend Smoothly Through Cutoffs}

For our research design to be valid, the second requirement is that all other factors that could affect the outcomes of interest trend smoothly through the FICO score cutoff. These include contract terms, such as the interest rate (Assumption 1), characteristics of borrowers (Assumption 2), and the density of new accounts (Assumption 3). Because we have 743 quasi-experiments, graphically assessing the validity of our identifying assumptions for each experiment is not practical. Therefore, we show results graphically that pool across all of the quasi-experiments in the data, estimating a single pooled treatment effect and pooled local polynomial. In Table 3 we present summary statistics on the distribution of these treatment effects across the 743 individual quasi-experiments.

\section{Assumption 1: Credit limits are the only contract characteristic that changes at the cutoff.}

The interpretation of our results requires that credit limits are the only contract characteristic that changes discontinuously at the FICO score cutoffs. For example, if the cost of credit also changed at our credit limit quasi-experiments, an increase in borrowing around the cutoff might not only result from additional access to credit at constant cost, but could also be explained by lower borrowing costs.

Panel C of Figure 3 shows the average APR around our quasi-experiments. APR is defined as the initial interest rate for accounts with a positive interest rate at origination, and the "go to" rate for accounts which have a zero introductory APR. ${ }^{14}$ As one would expect, the APR is declining in the FICO score. Importantly, there is no discontinuous change in the APR around our credit limit quasiexperiments. ${ }^{15}$ Table 3 shows that, for the average (median) experiment, the APR increases by 1.7 basis points (declines by 0.5 basis points) at the FICO cutoff; these changes are economically tiny relative to an average APR of $15.4 \%$. Panel E of Figure 3 shows that the length of the zero introductory APR period for the 248 quasi-experiments with a zero introductory APR. The length of the introductory period is increasing in FICO score but there is no jump at the credit limit cutoff. ${ }^{16}$

\section{Assumption 2: All other borrower characteristics trend smoothly through the cutoff.}

\footnotetext{
${ }^{14}$ The results look identical when we remove experiments for accounts with an initial APR of zero.

${ }^{15}$ We initially identified a few instances where APR also changed discontinuously at the same cutoff as we detected a discontinuous change in credit limits. These quasi-experiments were dropped in our process of arriving at the sample of 743 quasi-experiments that are the focus of our empirical analysis.

${ }^{16} \mathrm{~A}$ related concern is that while contract characteristics other than credit limits are not changing at the cutoff for the bank with the credit limit quasi-experiment, they might be changing at other banks. If this were the case, the same borrower might also be experiencing discontinuous changes in contract terms on his other credit cards, which would complicate the interpretation of our estimates. To test whether this is the case, for every FICO score where we observe at least one bank discontinuously changing the credit limit for one card, we define a "placebo experiment" as all other cards that are originated around the same FICO score at banks without an identified credit limit quasi-experiment. The right column of Figure 3 shows average contract characteristics at all placebo experiments. All characteristics trend smoothly through the FICO score cutoff at banks with no quasi-experiments.
} 
We next examine whether borrowers on either side of the FICO score cutoff looked similar on observables in the credit bureau data when the credit card was originated. Panels A and B of Figure 5 show the total number of credit cards and the total credit limit on those credit cards, respectively. Both are increasing in FICO score, and there is no discontinuity around the cutoff. Panel C shows the age of the oldest credit card account for consumers, capturing the length of the observed credit history. We also plot the number of payments for each consumer that were 90 or more days past due (DPD), both over the entire credit history of the borrower (Panel D), as well as in the 24 months prior to origination (Panel E). These figures, and the information in Table 3, show that there are no discontinuous changes around the cutoff in any of these (and other unreported) borrower characteristics.

\section{Assumption 3: The number of originated accounts trends smoothly through the cutoff.}

Panel F of Figure 5 shows that the number of accounts trends smoothly through the credit score cutoffs. This addresses two potential concerns with the validity of our research design. First, RDs are

invalid if individuals are able to precisely manipulate the forcing variable. In our setting, the lack of manipulation is unsurprising. Since the banks' credit supply functions are unknown, individuals with FICO scores just below a threshold are unaware that marginally increasing their FICO scores would lead to a significant increase in their credit limits.

An additional concern in our setting is that banks might use the FICO score cutoff to make extensive margin lending decisions. For example, if banks relaxed some other constraint once individuals crossed a FICO score threshold, more accounts would be originated for households with higher FICO scores, but households on either side of the FICO score cutoff would differ along that other dimension. While we did not observe any changes in observable characteristics around the FICO score cutoffs, the fact that we see no jump in the number of accounts originated also makes it unlikely that banks select borrowers based on characteristics unobservable to the econometrician. The absence of a jump in the number of originated accounts also means that consumers did not respond to different credit limits in their decision whether to open a credit card account. Again, this is unsurprising, as consumers generally learn about their final credit limit only after they have been sent their approved credit card.

\section{Borrowing and Spending}

Having established the validity of our research design, we turn to estimating the causal impact of an increase in credit limits on borrowing and spending, focusing on how these effects vary across the FICO score distribution. 


\subsection{Average Borrowing and Spending}

We start by presenting basic summary statistics on credit card utilization. The left column of Table 2 shows average borrowing and cumulative spending by FICO score group at different time horizons after account origination. To characterize the credit cards that identify the causal estimates, we restrict the sample to accounts within 5 FICO score points of a credit limit quasi-experiment.

Average daily balances (ADB) on the "treated" credit cards are hump-shaped in FICO score. ${ }^{17}$ At 12 months after origination, ADB increase from $\$ 1,260$ for the lowest FICO score group $(\leq 660)$, to more than $\$ 2,150$ for the middle FICO score groups, before falling to $\$ 2,101$ for the highest FICO score group $(>740)$. ADB are fairly flat over time for the lowest FICO score group but drop sharply for accounts with higher FICO scores. Total balances across all credit cards are between $\$ 10,500$ and $\$ 12,500$ for accounts with FICO scores above 660 , and do not vary substantially with the time since the treated card was originated; for accounts with FICO scores below 660 total balances are about $\$ 6,000 .^{18}$ Despite large differences in credit limits by FICO score, purchase volume over the first 12 months since origination is fairly similar, ranging from $\$ 2,514$ to $\$ 2,943$ across FICO score groups. Higher FICO score borrowers spend somewhat more on their cards over longer time horizons, but even at 60 months after origination, cumulative purchase volume ranges between $\$ 4,390$ and $\$ 6,095$ across FICO score groups.

\subsection{Marginal Propensity to Borrow (MPB)}

We next exploit our credit limit quasi-experiments to estimate the marginal propensity to borrow out of an increase in credit limits. The top row of Figure 6 shows the effect of a quasi-exogenous increase in credit limits on ADB on the "treated" credit card. Panel A shows the effect on ADB at 12 months after account origination in the pooled sample of all quasi-experiments. ADB increase sharply at the discontinuity but otherwise trend smoothly in FICO score.

Panel B decomposes this effect, showing the impact of a \$1 increase in credit limits on ADB at different time horizons after account origination and for different FICO score groups. Panel A of

\footnotetext{
${ }^{17} \mathrm{ADB}$ are defined as the arithmetic mean of end-of-day balances over the billing cycle. This is the borrowing volume on which credit card borrowers pay interest. If borrowers do not carry over balances from the previous month, and repay end-of-month balances within a grace period, they are not charged interest for that month. See Agarwal et al. (2015b).

${ }^{18}$ In the OCC data, we observe ADB as a clean measure of interest-bearing borrowing volume. In the credit bureau data, we observe the account balances at the point the banks report them to the credit bureau. These account balances will include interest-bearing debt, but can also include balances that are incurred during the credit card cycle, but which are repaid at the end of the cycle, and are therefore not considered debt. This explains why the level of credit bureau account balances is higher than the amount of total credit card borrowing that households report, for example, in the Survey of Consumer Finances. We discuss below why this does not affect our interpretation of marginal increases in total balances as a marginal increase in total credit card borrowing.
} 
Table 5 shows the corresponding RD estimates. Higher credit limits generate a sharp increase in ADB on the treated credit card for all FICO score groups. Within 12 months, the lowest FICO score group raises ADB by 58 cents for each additional dollar in credit limits. This effect is decreasing in FICO score, but even borrowers in the highest FICO score group increase their ADB by approximately 23 cents for each additional dollar in credit limits. For the lowest FICO score group, the increase in ADB is quite persistent, declining by less than $20 \%$ between the first and fourth year. This is consistent with these low FICO score borrowers using the increase in credit to fund immediate spending and then "revolving" their debt in future periods. For the higher FICO score groups, the MPB drops more rapidly over time.

The middle row of Figure 6 examines the effects on account balances across all credit cards held by the consumer, using the merged credit bureau data. The reason to look at this broader measure of borrowing is to account for balance shifting across cards. For example, a consumer who receives a higher credit limit on a new credit card might shift borrowing to this card to take advantage of a low introductory interest rate. This would result in an increase in borrowing on the treated card but no increase in overall balances. The response of total borrowing across all credit cards is the primary object of interest for policymakers wanting to stimulate household borrowing and spending.

Panel C of Figure 6 shows the effect on total balances across all credit cards at 12 months after origination pooled across all quasi-experiments. Panel D shows the RD estimates of the effect of a $\$ 1$ increase in credit limits on total balances across all cards for different time horizons and FICO score groups. Panel B of Table 5 shows the corresponding RD estimates. For all but the highest FICO score group, the marginal increase in borrowing on the treated card corresponds to an increase in overall borrowing. ${ }^{19}$ Indeed, we cannot reject the null hypothesis that the increase in ADB translates one-forone into an increase in total balances. The one exception the highest FICO score group for which we find evidence of significant balance shifting. At one year after origination, these consumers exhibit a 23\% MPB on the treated card but essentially zero MPB across all their accounts (the statistically insignificant point estimate is $-5 \%)$. This is not because the high FICO score group does not borrow:

\footnotetext{
${ }^{19}$ The fact that we observe total credit card balances and not total ADB in the credit bureau data (see footnote 18) does not affect our interpretation of the marginal increase in balances as a marginal increase in borrowing. In particular, one might worry that the causal response of balances in the credit bureau data picks up an increase in credit card spending, without an increase in total credit card borrowing. Such a response, which would not generate a stimulative effect on the economy, could result if people switched their method of payment from cash to credit cards. However, in our setting this is unlikely to be a concern. Among high FICO score borrowers, we observe no treatment effect on balances across all cards, suggesting that neither spending nor borrowing was affected by the increase in credit limits. For lower FICO score borrowers, the increase in balances across all credit cards maps one-for-one into the observed increase in ADB on the treated credit card, again showing that we are not just picking up a shifting of payment methods from cash to credit cards. This confirms that the change in total balances across all cards picks up the change in total borrowing across these cards.
} 
they have sizable ADB on the treated credit card (Table 2). Instead, it is likely due to the fact that the high FICO score group has on average $\$ 44,813$ in credit limits across all of their cards (Table 1), indicating these households are not credit constrained on the margin.

The increase in borrowing on both the treated card and across all credit cards is suggestive that higher credit limits raise overall spending. However, at least in the short run, consumers could increase their borrowing volumes by paying off their debt at a slower rate without spending more. To examine whether the increase in borrowing is indeed due to higher spending rather than slower debt repayment, the bottom row of Figure 6 estimates the effect of higher credit limits on cumulative purchase volume on the treated card. Panel C of Table 5 shows the corresponding estimates. Over the first year, the higher borrowing levels on the treated card are almost perfectly explained by increased purchase volume. For the lowest FICO score group, a $\$ 1$ increase in credit limits raises cumulative purchase volume over the first year by 56 cents, $\mathrm{ADB}$ on the treated card by 58 cents, and ADB across all cards by 59 cents. For the highest FICO score group, the increase in cumulative purchase volume is 22 cents, which is almost identical to the 23 cents increase in treated card ADB.

Over longer time horizons, the cumulative increase in purchase volume outstrips the rise in ADB. This is consistent with larger effects on overall spending than borrowing. Since we do not have information on purchase volume across all credit cards or cash spending, we cannot rule out that the additional purchase volume over longer time horizons results from shifts in the payment method.

Overall, the quasi-experimental variation in credit limits provides evidence of a large average MPB and substantial heterogeneity across FICO score groups. For the lowest FICO group $(\leq 660)$, we find that a $\$ 1$ increase in credit limits raises total borrowing by 59 cents at 12 months after origination. This effect is explained by more spending rather than less pay-down of debt. For the highest FICO group ( $>740$ ), we estimate a $23 \%$ effect on the treated credit card that is entirely explained by balance shifting, with a $\$ 1$ increase in credit limits having no effect on total borrowing. While these estimates are not representative of the entire population, they correspond to the set of applicants for new credit cards. This is the population most likely to respond to credit expansions, and is thus of particular relevance to policymakers hoping to stimulate borrowing and spending through the banking sector.

Our findings suggest that the effects of bank-mediated stimulus on borrowing and spending will depend on whether credit expansions reach those low FICO score borrowers with large MPBs. On the other hand, extending extra credit to low FICO score households who are more likely to default might well conflict with other policy objectives, such as reducing the riskiness of bank balance sheets. 


\section{$5 \quad$ A Model of Optimal Credit Limits}

In this section we present a model of optimal credit limits. We use this model to examine the effect of a change in the cost of funds on credit limits and to examines how primitives, such the degree of asymmetric information, create heterogeneity in this effect. In Section 6 we estimate the key parameters of this model, allowing us to characterize banks' marginal propensity to lend (MPL) to borrowers with different FICO scores.

We view this approach of estimating the MPL as superior to looking directly at the correlation between banks' cost of funds and their credit supply decisions. For instance, an approach that uses time-series variation in the cost of funds is problematic because large changes in banks' cost of funds generally occur at the same time as changes in economic activity that also affect banks' willingness to lend. ${ }^{20}$ Similarly, an approach that uses cross-sectional variation is problematic because cross-bank differences in the cost of funds are likely to be related to the strength of bank balance sheets, and the strength of bank balance sheets may have a direct impact on banks' appetite to extend credit to consumers with different risk profiles.

\subsection{Credit Limits as the Primary Margin of Adjustment}

In principle, banks could respond to a decline in the cost of funds by adjusting any number of contract terms, including credit limits, interest rates, rewards, and fees. We follow the empirical literature on contract pricing in credit markets and restrict our analysis to a single dimension of adjustment (see Einav, Jenkins and Levin, 2012). In choosing to focus on credit limits, and not interest rates, we build on a large prior literature, starting with Ausubel (1991), that documents the stickiness of credit card interest rates to changes in the cost of funds (see Appendix Figure A2). ${ }^{21}$

Many explanations for this interest rate stickiness have been proposed, including limited interest rate sensitivity by borrowers, collusion by credit card lenders, default externalities across credit card lenders, and an adverse selection story whereby lower interest rates disproportionately attract borrowers with higher default rates (Ausubel, 1991; Calem and Mester, 1995; Stavins, 1996; Stango, 2000; Parlour and Rajan, 2001). While we think determining why interest rates are sticky is an interesting question, we take this feature of the market as given in this study. Importantly, while we focus on the

\footnotetext{
${ }^{20}$ During our sample period we observe one drop of the federal funds rate, between August 2008 and November 2008 (see Appendix Figure A2). This was a time period when banks were also updating their outlooks about future loan performance.

${ }^{21}$ Additional evidence in support of this choice comes from Agarwal et al. (2015b). In their model, when fees are nonsalient, a decline in fee revenue is passed through into interest rates at the exact same rate as a decline in the cost of funds. Their finding that the decline in fee revenue brought about by the 2009 CARD Act was not offset by higher interest rates is therefore consistent with limited pass through into interest rates of a decline in the cost of funds.
} 
pass-through to credit limits, our conceptual point is likely relevant for any pass-through to interest rates that might occur. For instance, if lower interest rates attract worse borrowers, then pass-through into interest rates of declines in the cost of funds will also be limited.

\subsection{Model Setup}

Consider a one-period lending problem in which a bank chooses a credit limit CL for a group of observably identical borrowers, such as all consumers with the same FICO score, to maximize profits. Let $q(C L)$ describe how the quantity of borrowing depends on the credit limit, and let $M P B=q^{\prime}(C L)$ indicate the consumers' marginal propensity to borrow out of a credit expansion.

Banks earn revenue from interest charges and fees. Let $r$ denote the interest rate, which is fixed and determined outside of the model. Let $F(C L) \equiv F(q(C L), C L)$ denote fee revenue, which can depend on credit limits directly and indirectly through the effect of credit limits on borrowing.

The main costs for the bank are the cost of funds and chargeoffs. The bank's cost of funds, $c$, can be thought of as a refinancing cost but more broadly captures anything that affects the banks' cost of lending, including capital requirements and financial frictions. Let $C(C L) \equiv C(q(C L), C L)$ denote chargeoffs, which can also depend directly and indirectly on credit limits. ${ }^{22}$ The objective for the bank is to choose a credit limit to maximize profits. ${ }^{23}$

$$
\max _{C L} q(C L)(r-c)+F(C L)-C(C L) .
$$

The optimal credit limit sets marginal profits to zero, or, equivalently, sets marginal revenue equal to marginal cost:

$$
\underbrace{q^{\prime}(C L) r+F^{\prime}(C L)}_{=M R(C L)}=\underbrace{q^{\prime}(C L) c+C^{\prime}(C L)}_{=M C(C L)} .
$$

We assume that marginal revenue crosses marginal cost "from above," i.e., $M R(0)>M C(0)$ and $M R^{\prime}(C L)<M C^{\prime}(C L)$, so we are guaranteed to have an interior optimal credit limit.

We are interested in the effect on borrowing of a decrease in the cost of funds, which is given by the total derivative $-\frac{d q}{d c}$. This can be decomposed into the product of the marginal propensity to lend

\footnotetext{
22"Chargeoffs" refer to an expense incurred on the lender's income statement when a debt is considered long enough past due to be deemed uncollectible. For an open-ended account such as a credit card, regulatory rules usually require a lender to charge off balances after 180 days of delinquency.

${ }^{23}$ The model abstracts from the extensive margin decision of whether or not to offer a credit card. To capture this margin, the model could be extended to include a fixed cost of originating and maintaining a credit card account. In such a model, borrowers would only receive a credit card if expected profits exceeded this fixed cost.
} 
(MPL) and the marginal propensity to borrow (MPB):

$$
-\frac{d q}{d c}=\underbrace{-\frac{d C L}{d c}}_{=\mathrm{MPL}} \times \underbrace{\frac{d q}{d C L}}_{=\mathrm{MPB}}
$$

In Section 4, we estimated the MPB directly using the quasi-experimental variation in credit limits. We next discuss how we use our variation to estimate the MPL.

\subsection{Pass-Through of a Decrease in the Cost of Funds}

A decrease in the cost of funds reduces the marginal cost of extending each unit of credit and can be thought of as a downward shift in the marginal cost curve. Since equilibrium credit limits are determined by the intersection of marginal revenue and marginal cost (see Equation 6), the slopes of marginal revenue and marginal costs determine the resulting change in equilibrium credit limits. To see this, consider Figure 1 from the introduction. In Panel A, where marginal cost and marginal revenue are relatively flat, a given downward shift in the marginal cost curve leads to a large increase in equilibrium credit limits. In Panel B, where marginal cost and marginal revenue are relatively steep, the same downward shift in the marginal cost curve leads to a smaller increase in credit limits.

Mathematically, the effect on credit limits of a decrease in the cost of funds can be derived by applying the implicit function theorem to the first order conditions shown in Equation 6:

$$
M P L=-\frac{d C L}{d c}=-\frac{q^{\prime}(C L)}{M R^{\prime}(C L)-M C^{\prime}(C L)}
$$

The numerator is the marginal propensity to borrow $\left(q^{\prime}(C L) \equiv M P B\right)$ and scales the size of the effect because a given decrease in the per-unit cost of funds induces a larger shift in marginal costs when credit card holders borrow more on the margin. The denominator is the slope of marginal profits $M P^{\prime}(C L)=M R^{\prime}(C L)-M C^{\prime}(C L)$. The existence assumption, $M R^{\prime}(C L)<M C^{\prime}(C L)$, guarantees the denominator is negative and thus implies positive pass-through, MPL $>0$. The MPL is decreasing as the downward sloping marginal profits curve becomes steeper. Economically, we view the MPB and the slope of marginal profits as "sufficient statistics" that capture the effect on pass-through of a number underlying features of the credit card market without requiring strong assumptions on the underlying model of consumer behavior (see, Chetty, 2009, for more on this approach).

Perhaps the most important of these features is asymmetric information, which includes both 
adverse selection and moral hazard. ${ }^{24}$ Since banks can adjust credit limits based on observable borrower characteristics, they determine the optimal credit limit separately for each group of observably identical borrowers. By selection we therefore mean selection on information that the lender cannot observe or is prohibited from using by law. With adverse selection, higher credit limits disproportionally raise borrowing among households with a greater probability of default, increasing the marginal cost of extending more credit. This could occur because forward-looking households, who anticipate defaulting in the future, strategically increase their borrowing. Alternatively, it could occur because there are some households that are always more credit constrained, and these households borrow more today and have a higher probability of default in the future. Regardless of the channel, adverse selection translates into a more positively sloped marginal cost curve, a more negatively sloped marginal profit curve, and less pass-through. ${ }^{25}$

Higher credit limits could also affect marginal costs holding the composition of marginal borrowers fixed. For instance, in Fay, Hurst and White's (2002) model of consumer bankruptcy, the benefits of filing for bankruptcy are increasing in the amount of debt while the costs of filing are fixed. The implication is that higher credit limits, which raise debt levels, lead to higher default probabilities, a more positively sloped marginal cost curve, and a lower rate of pass-through. This mechanism is sometimes called moral hazard because the borrower does not fully internalize the cost of their decisions when choosing how much to borrow and whether to default. However, a positive effect of credit limits on borrowing does not require strategic behavior on the part of the borrower. For example, myopic consumers might borrow heavily out of an increase in credit limits, not because they anticipate defaulting next period, but because they down-weight the future. ${ }^{26}$

The slope of marginal revenue is equally significant in determining the MPL, and revenue from fees (e.g., annual fees, late fees) is a key determinant of the slope of marginal revenue. In particular, fee revenue does not scale one-for-one with credit card utilization. On the margin, an increase in credit limits might increase fee revenue (e.g., by raising the probability a consumer renews her card and pays next year's annual fee) but not by a large amount. A decline in marginal fee revenue at higher credit limits would translate into a more negatively sloped marginal revenue curve, a more negatively

\footnotetext{
${ }^{24}$ See Einav, Finkelstein and Cullen (2010) and Mahoney and Weyl (2013) for a more in-depth discussion of how the slope of marginal costs parameterizes the degree of asymmetric information in a market.

${ }^{25}$ In principle, selection could also be advantageous, with higher credit limits disproportionally raising borrowing among households with a lower default probability. In this case, more advantageous selection would translate into a less negatively sloped marginal profit curve, and more pass-through.

${ }^{26}$ If greater debt levels reduce the rate of default - e.g., because increased credit access allows households to "ride out" temporary negative shocks without needing to default - an increase in credit limits would result in lower default probabilities, a less negatively sloped marginal profit curve, and more pass-through.
} 
sloped marginal profits curve, and less pass-through.

In Section 6, we directly estimate heterogeneity in the slope of marginal costs, marginal revenue, and marginal profits by FICO score. This approach allows us to quantify the joint effect of a broad set of factors such as moral hazard and adverse selection on pass-through without requiring us to untangle their relative importance.

\subsection{Empirical Implementation}

Taking the model to the data involves three additional steps. First, our model of optimal credit limits has one period, while our data are longitudinal with monthly outcomes for each account. To align the data with the model, we aggregate the monthly data for each outcome into discounted sums over various horizons, using a monthly discount factor of 0.996, which translates into an annual discount factor of $0.95 .{ }^{27}$ With these aggregated data, the objective function for the bank is to set initial credit limits to maximize the discounted flow of profits, which is a one period problem. ${ }^{28}$

A second issue involves the potential divergence between expected and realized profits. In our model, marginal profits can be thought of as the expectation of marginal profits when the bank sets initial credit limits. In the data, we do not observe these expected marginal profits but instead observe the marginal profits realized by the bank. The simplest way to take our model to the data is to assume that expected and realized marginal profits were the same during our time period. We show in Section 6 that realized marginal profits at prevailing credit limits were indeed very close to zero, suggesting that banks' expectations during our time period were approximately correct. We think this is not surprising, given the sophisticated, data-driven nature of credit card underwriting, with lenders using randomized trials to continuously learn about the degree of selection and the profitability of adjusting credit limits and other contract terms (e.g., Agarwal, Chomsisengphet and Liu, 2010).

Third, we need to estimate the slopes of outcomes, such as the discounted flow of marginal profits, with respect to a change in credit limits. Our approach to estimating these slopes closely follows the approach used in recent empirical papers on selection in health insurance markets (e.g., Einav, Finkelstein and Cullen, 2010; Cabral, Geruso and Mahoney, 2014; Hackmann, Kolstad and Kowalski, 2015). Conceptually, our approach starts with the observation that each quasi-experiment provides us

\footnotetext{
${ }^{27}$ In 2009, the weighted average cost of capital for the banking sector was 5.86\%; in 2010 it was 5.11\%, and in 2011 it was $4.27 \%$ (http: / / pages. stern. nyu. edu/ adamodar/). Our results are not sensitive to the choice of discount factor.

${ }^{28}$ While initial credit limits are highly persistent (see Section 3.1), credit limits can be changed following origination, which affects the discounted sums. We assume that banks set initial credit limits in a dynamically optimal way, taking into account their ability to adjust credit limits in the future. The envelope theorem then allows us to consider the optimization problem facing a bank at card origination without specifying the dynamic process of credit limit adjustment.
} 
with two moments. For example, we can recover marginal profits at the prevailing credit limit using our credit limit regression discontinuities and we can calculate average profits per dollar of credit limits by dividing total profits by the prevailing credit limit. With two moments, we can then identify any two-parameter curve for marginal profits, such as a linear specification that allows for a separate intercept and slope.

Our baseline specification is to assume that marginal profits, and other outcomes, are linear in credit limits. This specification is advantageous because it allows for internally consistent aggregation across outcomes; for instance, linear marginal costs and linear marginal revenue imply linear marginal profits. The linear specification in also particularly transparent because the slope is captured by a single parameter that can be recovered in closed form. Specifically, if marginal profits are given by $M P(C L)=\alpha+\beta C L$, then average profits per dollar of credit limits are given by $A P(C L)=$

$\frac{\int_{X=0}^{C L} \alpha+\beta X d X}{C L}=\alpha+\frac{1}{2} \beta C L$, and the slope of marginal profits is therefore $\beta=\frac{2(M P(C L)-A P(C L))}{C L}$. Intuitively, if marginal profits are much smaller than average profits $(M P(C L) \ll A P(C L))$, the marginal profitability of lending must be rapidly declining in credit limits and marginal profits must be steeply downward sloping $\left(M P^{\prime}(C L)=\beta<0\right)$. Alternative, if marginal profits are fairly similar to average profits $(M P(C L) \approx A P(C L))$, then marginal profits must be relatively flat $\left(M P^{\prime}(C L)=\beta \approx 0\right)$.

\section{Marginal Propensity to Lend}

In Section 5, we showed how the MPL is determined by the negative ratio of the MPB and the slope of marginal profits. In this section, we use the quasi-experimental variation in credit limits to estimate how the slope of marginal profits varies across the FICO score distribution. We then combine these slopes with our estimates of the MPB from Section 4 to estimate heterogenous MPL.

\subsection{Average Utilization and Profitability}

To provide context, we first present basic facts on the profitability of the credit cards in our sample. We define profits for a credit card account as the difference between total revenue and total costs. Total revenue is the sum of interest charge revenue, fee revenue, and interchange income. We observe interest charge revenue and fee revenue for each account in our data. Interchange fees are charged to merchants for processing credit card transactions and scale proportionally with spending. Following Agarwal et al. (2015b), we calculate interchange income for each account as $2 \%$ of purchase volume.

Total costs are the sum of chargeoffs, the cost of funds, rewards and fraud expenses, and operational costs such as costs for debt collection, marketing, and customer acquisition. We observe 
chargeoffs for each account in our data. ${ }^{29}$ We observe the cost of funds at the bank-month level in the portfolio data and construct an account-level measure of the cost of funds by apportioning these costs based on each account's share of ADB. We calculate that reward and fraud expenses are $1.4 \%$ of purchase volume and operational costs are $3.5 \%$ of ADB in the portfolio data, and construct account-level values by applying these percentages to account-level purchase volume and ADB. See Agarwal et al. (2015b) for additional discussion.

The middle section of Table 2 shows cumulative total costs and its components by FICO score group at different time horizons after account origination. As before, we restrict the sample to credit cards originated within 5 FICO score points of a credit limit quasi-experiment. Cumulative total costs rise fairly linearly over time and are hump-shaped in FICO score. At 48 months after origination, cumulative total costs are $\$ 588$ for the lowest FICO group $(\leq 660)$, slightly more than $\$ 800$ for the middle groups, and $\$ 488$ for the highest FICO group ( $>740)$. Cumulative chargeoffs generally account for more than half of these costs, although they are more important for lower FICO scores accounts and become relatively more important at longer time horizons. The cumulative cost of funds declines from approximately $10 \%$ of total costs at 12 months after origination to approximately $5 \%$ at 60 months after origination.

The right section of Table 2 shows cumulative total revenue and profits. Cumulative revenue, like cumulative costs, grows fairly linearly over time. However, while cumulative costs are humpshaped in FICO score, cumulative revenue is decreasing. For instance, at 48 months after origination, cumulative total revenue is more than $\$ 900$ for the two lowest FICO groups, $\$ 863$ for second highest FICO group, and \$563 for accounts in the highest FICO group. Excluding the first year, interest charges make up approximately two-thirds of cumulative total revenue; fee revenue accounts for approximately one-quarter and is particularly important for the lowest FICO score group. Both interest charges and fees are somewhat less important for the highest FICO group. For these accounts, interchange income is relatively more important, contributing approximately one-fifth of total revenue.

The data on revenue and costs combine to produce average profits that are U-shaped in FICO score. At 48 months, cumulative profits are $\$ 365$ for the lowest FICO score group, \$126 and \$55 for the middle two FICO groups, and $\$ 75$ for accounts with the highest FICO score. Cumulative profits within a FICO score group increase fairly linearly over time.

\footnotetext{
${ }^{29}$ We use the term "chargeoffs" to indicate gross chargeoffs minus recoveries, which are both observed in our data.
} 


\subsection{Marginal Probability of Default}

We begin our analysis of pass-through by examining the causal effect of an increase in credit limits on the probability of delinquency and default. ${ }^{30}$ A large effect on default probabilities, all else equal, corresponds to more upward sloping marginal costs. Intuitively, this occurs because higher default probabilities not only raise chargeoffs for marginal lending but also raise chargeoffs from inframarginal lending, thereby leading to higher marginal chargeoffs, more upward sloping marginal costs, and a lower rate of pass-through. ${ }^{31}$

Figure 7 shows that an increase in credit limits has a large effect on the probability of delinquency for the lower FICO score account holders and virtually no effect for the accounts with the highest FICO scores. Panel A shows the effect on the probability that the account is at least 60 days past due $60+$ DPD), and Panel B shows the effect on the probability that the account is at least 90 days past due (90+ DPD). For the lowest FICO group, a $\$ 1,000$ increase in credit limits raises the probability of moderate delinquency (60+ DPD) within 4 years by 1.21 percentage points, on a base of $16.5 \%$, and raises the probability of a more serious delinquency (90+ DPD) within 4 years by 1.16 percentage points, on a base of $14.5 \%$. The effect is less than two-thirds as large for accounts with an intermediate FICO score and close to zero for accounts in the highest FICO group. Table 6 shows the corresponding estimates. Appendix Figure A3 shows RD plots for the pooled sample of all quasi-experiments.

While the effect of higher credit limits on the probability of delinquency is intuitive and straightforward to estimate, it is not a sufficient statistic for pass-through. First, the effect needs to be dollarized to capture its influence on marginal profits. Second, the estimate does not capture the effect of selection. For instance, if borrowers with a higher default probability increase borrowing more strongly when credit limits increase, marginal costs can be upward sloping with no effect on the probability of default. For these reasons, we next estimate the slope of marginal profits, which is more directly informative for the MPL.

\footnotetext{
${ }^{30}$ When a credit card borrower stops making at least the minimum monthly payment, the account is considered delinquent, or "past due." The regulator requires banks to "charge off" the account balance if an account is severely delinquent, or more than 180 days past due. This requires them to record the outstanding receivables as a loss. Although banks charge off severely delinquent accounts, the underlying debt obligations remain legally valid and consumers remain obligated to repay the debts. As discussed above, our measure of the impact of delinquency on profits is the amount of chargeoffs net any recoveries. We analyze the impact of higher credit limits both on intermediate delinquency stages (the probabilities of being more than 60 or more than 90 days past due), as well as on chargeoffs, which are a key driver of marginal profits.

${ }^{31}$ Mathematically, if we allow total chargeoffs for lending to a borrower to be given $C(C L)=d(C L) q(C L)$, where $d(C L)$ is a default indicator and $q(C L)$ the amount of borrowing, then the slope of marginal chargeoffs is given by $C^{\prime \prime}(C L)=2 d^{\prime}(C L) M P B(C L)+d^{\prime \prime}(C L) q(C L)+d(C L) M P B^{\prime}(C L)$. Since $2 M P B(C L)>0$, a higher probability of default $\left(d^{\prime}(C L)\right)$ corresponds to a large slope of marginal chargeoffs $\left(C^{\prime \prime}(C L)\right)$. The effect is increasing in the MPB because an increase in the probability of default has a large impact when the marginal amount borrowed is larger.
} 


\subsection{Slope of Marginal Profits and Components}

The top row of Figure 8 considers the effect of increasing credit limits on marginal costs and marginal chargeoffs. For each FICO group, the grey bars on the left show the marginal effect of a $\$ 1$ increase in credit limits at prevailing equilibrium credit limits; the black bars on the right show the response of those marginal effects to a $\$ 1,000$ increase in credit limits. The capped vertical lines show $95 \%$ confidence intervals constructed by bootstrapping over quasi-experiments. The estimates are based on cumulative outcomes over a 4-year horizon, although we will show robustness of our conclusions to considering different time horizons. Columns 1 to 4 of Table 7 show the corresponding estimates, and Panels A and B of Appendix Figure A4 present the standard RD plots for the pooled sample of all quasi-experiments.

Marginal costs at prevailing credit limits decrease sharply by FICO score. For the lowest FICO score borrowers $(\leq 660)$, a $\$ 1$ increase in credit limits raises cumulative costs over 4 years by 29.6 cents, mainly due to a 21.6 cent increase in chargeoffs. For the highest FICO score group ( $>740)$, a $\$ 1$ increase in credit limits raises cumulative costs by a much smaller 6.0 cents, with a 3.7 cent increase in chargeoffs. As discussed in Section 5, what matters for pass-through, though, is not the level of marginal costs at the prevailing credit limits, but what happens to these marginal costs as credit limits are increased. For the lowest FICO score group, marginal costs are steeply upward sloping, with a $\$ 1,000$ increase in credit limits raising marginal costs by 7.5 cents, or about one-quarter of the baseline marginal effect. The upward slope is driven by higher marginal chargeoffs, which rise by 8.0 cents for a $\$ 1,000$ increase in credit limits. For the higher FICO score groups, a $\$ 1,000$ increase in credit limits has virtually no effect on marginal costs and marginal chargeoffs. These results are consistent with less selection and a smaller direct effect of credit limits on default probabilities at higher FICO score levels.

The middle row of Figure 8 examines the effect of increasing credit limits on cumulative marginal revenue and cumulative marginal fee revenue. The plots are constructed identically to the plots for costs and chargeoffs. Columns 5 to 8 of Table 7 show the corresponding estimates, and Panels C and D of Appendix Figure A4 present the standard RD plots for the pooled sample of all quasi-experiments. Marginal revenue at prevailing credit limits, shown by the grey bars, is decreasing in FICO score. For the lowest FICO score group, a $\$ 1$ increase in credit limits raises revenue by 23.8 cents. For the highest FICO score group, a $\$ 1$ increase in credit limits raises revenue by 5.5 cents.

Marginal revenue is steeply downward sloping for low FICO scores borrowers and much flatter 
for borrowers with higher FICO scores. For the lowest FICO score group, a $\$ 1,000$ increase in credit limits reduces marginal revenue by 12.9 cents, or about one-half of the baseline 23.8 cents marginal effect. The majority of this decline is due to a drop in marginal fee revenue. ${ }^{32}$ For the second lowest FICO score group, a \$1,000 increase in credit limits decreases marginal revenue by only 3.9 cents, and the decrease is virtually zero for accounts with higher FICO scores. The steeper slope of marginal revenue at low FICO scores is consistent with Table 2, which shows that fee revenue is particularly important for accounts with low FICO scores. Since fee revenue does not scale with credit limits, a natural implication is that marginal fee revenue declines more for low FICO score accounts, where it is more important on average.

The bottom row of Figure 8 bring these results together into an analysis of cumulative marginal profits at 48 months since account origination. ${ }^{33}$ Columns 9 and 10 of Table 7 show the corresponding estimates and Panel E of Appendix Figure A4 presents the standard RD plot for the pooled sample of all quasi-experiments. Marginal profits at prevailing credit limits, shown with the grey bars, are virtually zero for the lowest and highest FICO groups (0.2 cents and -0.4 cents, respectively) and slightly negative for the middle FICO groups ( -3.3 cents and -2.9 cents, respectively), indicating that credit limits during our time period were approximately optimal ex post. While not the primary focus of our research, the implication is that banks were not forgoing profitable lending opportunities in the credit card market during our time period. This result provides support for the "no good risks" explanation for limited credit supply during the Great Recession and pushes against the argument that financial frictions prevented banks from exploiting profitable consumer lending opportunities. ${ }^{34}$

The slope of marginal profits is strongly negative for the lowest FICO score borrowers and becomes less negatively sloped at higher FICO scores. For the lowest FICO score group, a $\$ 1,000$ increase in credit limits reduces cumulative marginal profits over 48 months by 13.6 cents, driven by both lower marginal revenue and higher marginal costs. In response to a $\$ 1,000$ increase in credit limits, marginal profits decline by 4.1 and 2.4 cents for the middle FICO groups, and by 0.2 cents for the group with the highest FICO scores.

\footnotetext{
${ }^{32}$ Marginal fee revenue can, in principle, be negative. For instance, a higher credit limit that reduces the frequency of over-limit fees is modeled as negative marginal fee revenue in our framework.

${ }^{33}$ We estimate the effect on marginal profits directly rather than constructing it as the difference between marginal revenue and marginal cost. Estimating this effect directly maximizes statistical power but means that the effects do not aggregate perfectly, i.e., our point estimates for the slopes of marginal revenue and marginal cost do not combine to deliver the point estimate for the slope of marginal profit.

${ }^{34}$ This is consistent with claims by James Chessen, the chief economist of the American Banker's Association, who explained reduced lending volumes by arguing that, "it's a very risky time for any lender because the probability of loss is greater, and they are being prudent in their approach to lending." (Wall Street Journal, 2009).
} 


\subsection{Marginal Propensity to Lend (MPL)}

The final step in our analysis is to use the estimates above to calculate the MPL in response to a decline in the cost of funds, which is given by the negative ratio of the cumulative MBP and the slope of cumulative marginal profits, measured over the same horizon: $M P L=-\frac{M P B}{M P^{\prime}(C L)}$ (see Section 5).

Figure 9 shows the effect on credit limits of a permanent 1 percentage point decrease in the cost of funds by FICO score group. For each FICO score group, we show estimates using data on cumulative profits and ADB over time horizons of 12, 24,36, and 48 months after origination. The capped vertical lines show $95 \%$ confidence intervals constructed by bootstrapping over quasi-experiments. ${ }^{35}$

The plot shows a sharp increase in the MPL by FICO score. For the lowest FICO score group, a 1 percentage point decrease in the cost of funds raises credit limits by $\$ 127$ when we use discounted flows over 48 months to estimate the MPB and the slope of marginal profits. For consumers in the highest FICO score group, the increase is an order of magnitude larger at $\$ 2,203$. The estimates are stable to measuring cumulative profits and ADB over different horizons. We use the 48 month values as our preferred specification. ${ }^{36}$

\subsection{Effect on Aggregate Borrowing}

The effect of a decline in the cost of funds on aggregate borrowing is given by the product of MPL and MPB. ${ }^{37}$ Panel A of Figure 10 shows the effect of a 1 percentage point decrease in the cost of funds on credit limits by FICO score. Panel B shows the MPB across all cards at 12 months after origination by FICO score, which captures the short-term effect on borrowing. Table 8 shows the corresponding estimates.

MPL and MPB are strongly negatively correlated, with the highest MPL occurring for the accounts with the lowest MPB. The bottom panel of Table 8 quantifies the importance of this negative correlation by estimating the impact on aggregating borrowing under alternative assumptions. The first row shows a version of this calculation where the negative correlation is not taken into account, and the effect on borrowing is given by the weighted average MPL $\times$ weighted average MPB, where we

\footnotetext{
${ }^{35}$ In particular, we draw 500 sets of experiments with replacement, and calculate $M P L=\frac{M P B}{-M P^{\prime}(C L)}$ using this bootstrap sample. This procedure effectively allows the standard errors of the numerator and denominator to be correlated.

${ }^{36}$ Using cumulative flows over different time horizons involves a tradeoff. On the one hand, it allows us to better capture potential life-cycle effects of credit card profitability. On the other hand, focusing on longer time horizons requires us to restrict the analysis to accounts that were originated in the early part of our panel, which reduces the number of quasiexperiments we can exploit. Reassuringly, our effects are robust to the choice of time horizon.

${ }^{37}$ This approach to calculating the effect on aggregate borrowing abstracts away from the existence of spending multipliers or other general equilibrium effects, such as the possibility that additional spending from extra credit might reduce the rate of default of other borrowers.
} 
weight FICO score groups by the total number of accounts within each FICO group in the full sample (see Section 1.4). The second row accounts for this correlation by first calculating MPL $\times$ MPB for each FICO group and then averaging across the FICO groups. The point estimate for MPB is sometimes slightly negative for the highest FICO group. Therefore, the third row shows our preferred version of the calculation where we account for the correlation but bottom-code the MPB at zero. At a 12 month horizon, accounting for the correlation reduces the effect on aggregate borrowing by $76 \%$, relative to the naive estimate. Over longer time horizons, accounting for this correlation reduces the effect by between $44 \%$ and $76 \%$.

\section{Conclusion}

The effectiveness of bank-mediated stimulus in raising household borrowing depends on whether banks pass through credit expansions to households that want to borrow. We use panel data on all credit cards issued by the 8 largest U.S. banks together with 743 credit limit regression discontinuities to estimate the heterogeneity in banks' marginal propensity to lend (MPL) to different households, and heterogeneity in these households' marginal propensity to borrow (MPB).

We find large differences in MPB across the FICO score distribution, with a $\$ 1$ increase in credit limits raising total borrowing at 12 month after account origination by 59 cents for households with the lowest FICO scores $(\leq 660)$ while having no effect on households with the highest FICO scores (> 740). Banks' MPLs are negatively correlated with these MPBs, with a 1 percentage point reduction in the cost of funds raising optimal credit limits by $\$ 127$ dollars for households with FICO scores below 660 versus $\$ 2,203$ for households with FICO scores above 740 . This is explained by steeper sloping marginal profits for lower FICO score borrowers. Banks pass through credit expansion least to households that want to borrow the most, reducing the effectiveness of bank-mediated stimulus. 


\section{References}

Aaronson, Daniel, Sumit Agarwal, and Eric French. 2012. "The Spending and Debt Response to Minimum Wage Hikes." American Economic Review, 102(7): 3111-3139.

Acharya, Viral V, Tim Eisert, Christian Eufinger, and Christian W Hirsch. 2014. "Real Effects of the Sovereign Debt Crisis in Europe: Evidence from Syndicated Loans." CEPR Discussion Paper.

Adams, William, Liran Einav, and Jonathan Levin. 2009. "Liquidity Constraints and Imperfect Information in Subprime Lending." American Economic Review, 99(1): 49-84.

Agarwal, Sumit, and Wenlan Qian. 2014. "Consumption and Debt Response to Unanticipated Income Shocks: Evidence from a Natural Experiment in Singapore." American Economic Review, 104(12): 4205-30.

Agarwal, Sumit, Chunlin Liu, and Nicholas S. Souleles. 2007. “The Reaction of Consumer Spending and Debt to Tax Rebates-Evidence from Consumer Credit Data." Journal of Political Economy, 115(6).

Agarwal, Sumit, Gene Amromin, Souphala Chomsisengphet, Tomasz Piskorski, Amit Seru, and Vincent Yao. 2015a. "Mortgage Refinancing, Consumer Spending, and Competition: Evidence from the Home Affordable Refinancing Program." NBER Working Paper.

Agarwal, Sumit, Souphala Chomsisengphet, and Chunlin Liu. 2010. "The Importance of Adverse Selection in the Credit Card Market: Evidence from Randomized Trials of Credit Card Solicitations." Journal of Money, Credit and Banking, 42(4): 743-754.

Agarwal, Sumit, Souphala Chomsisengphet, Neale Mahoney, and Johannes Stroebel. 2015b. "Regulating Consumer Financial Products: Evidence from Credit Cards." Quarterly Journal of Economics, 130.

Ambrose, Brent W, James Conklin, and Jiro Yoshida. 2015. "Reputation and Exaggeration: Adverse Selection and Private Information in the Mortgage Market." Working paper.

Auclert, Adrien. 2014. "Monetary Policy and the Redistribution Channel." MIT mimeo.

Ausubel, Lawrence M. 1991. "The Failure of Competition in the Credit Card Market." American Economic Review, 81(1): 50-81.

Aydin, Deniz. 2015. “The Marginal Propensity to Consume out of Liquidity.” Working Paper.

Baker, Scott R. 2013. “Debt and the Consumption Response to Household Income Shocks." Working Paper.

Bernanke, Ben S., and Mark Gertler. 1995. "Inside the Black Box: The Credit Channel of Monetary Policy Transmission." Journal of Economic Perspectives, 9(4): 27-48.

Bhutta, Neil, and Benjamin J. Keys. 2014. “Interest Rates and Equity Extraction During the Housing Boom." Working Paper.

Blundell, Richard, Luigi Pistaferri, and Ian Preston. 2008. "Consumption Inequality and Partial Insurance." American Economic Review, 1887-1921.

Cabral, Marika, Michael Geruso, and Neale Mahoney. 2014. "Does Privatized Health Insurance Benefit Patients or Producers? Evidence from Medicare Advantage." NBER Working Paper.

Calem, Paul S., and Loretta J. Mester. 1995. "Consumer Behavior and the Stickiness of Credit-Card Interest Rates." American Economic Review, 85(5): 1327-1336. 
Chatterjee, Satyajit, Dean Corbae, and Jose-Victor Rios-Rull. 2011. "Credit Scoring and Competitive Pricing of Default Risk." Working Paper.

Chetty, Raj. 2009. "Sufficient Statistics for Welfare Analysis: A Bridge Between Structural and Reduced-Form Methods." Annual Review of Economics, 1: 451-487.

Coibion, Olivier, Yuriy Gorodnichenko, Lorenz Kueng, and John Silvia. 2012. "Innocent Bystanders? Monetary Policy and Inequality in the US." NBER Working Paper.

Di Maggio, Marco, Amir Kermani, and Rodney Ramcharan. 2014. "Monetary Policy Pass-Through: Household Consumption and Voluntary Deleveraging." Columbia Business School Research Paper.

Dobbie, Will, and Paige Marta Skiba. 2013. "Information Asymmetries in Consumer Credit Markets: Evidence from Payday Lending." American Economic Journal: Applied Economics, 5(4): 256-282.

Doepke, Matthias, and Martin Schneider. 2006. "Inflation and the Redistribution of Nominal Wealth." Journal of Political Economy, 114(6): 1069-1097.

Eggertsson, Gauti B., and Paul Krugman. 2012. "Debt, Deleveraging, and the Liquidity Trap: A Fisher-Minsky-Koo Approach." Quarterly Journal of Economics, 127(3): 1469-1513.

Einav, Liran, Amy Finkelstein, and Mark R. Cullen. 2010. "Estimating Welfare in Insurance Markets Using Variation in Prices." Quarterly Journal of Economics, 125(3): 877-921.

Einav, Liran, Mark Jenkins, and Jonathan Levin. 2012. "Contract Pricing in Consumer Credit Markets." Econometrica, 80(4): 1387-1432.

Einav, Liran, Theresa Kuchler, Jonathan Levin, and Neel Sundaresan. 2015. "Assessing Sale Strategies in Online Markets Using Matched Listings." American Economic Journal: Microeconomics, 7(2): 215-47.

Fay, Scott, Erik Hurst, and Michelle J. White. 2002. "The Household Bankruptcy Decision." American Economic Review, 92(3): 706-718.

FDIC. 2007. "Scoring and Modeling." Federal Deposit Insurance Corporation (FDIC) Credit Card Activities Manual.

Fuster, Andreas, and Paul Willen. 2010. “\$1.25 Trillion is Still Real Money: Some Facts About the Effects of the Federal Reserve's Mortgage Market Investments." FRB of Boston Public Policy Discussion Paper, 10(4).

Geithner, Timothy. 2009. "Secretary Geithner Introduces Financial Stability Plan."

Gelman, Michael, Shachar Kariv, Matthew D. Shapiro, Dan Silverman, and Steven Tadelis. 2015. "How Individuals Smooth Spending: Evidence from the 2013 Government Shutdown Using Account Data." NBER Working Paper.

Goodhart, Charles. 2015. "Why Monetary Policy has been Comparatively Ineffective?" The Manchester School, 83: 20-29.

Gross, David B, and Nicholas S. Souleles. 2002. “Do Liquidity Constraints and Interest Rates Matter for Consumer Behavior? Evidence from Credit Card Data." Quarterly Journal of Economics, 117(1): 149-185.

Guerrieri, Veronica, and Guido Lorenzoni. 2011. "Credit Crises, Precautionary Savings, and the Liquidity Trap." NBER Working Paper. 
Hackmann, Martin B., Jonathan T. Kolstad, and Amanda E. Kowalski. 2015. "Adverse Selection and an Individual Mandate: When Theory Meets Practice." American Economic Review, 105(3): 1030-1066.

Hahn, Jinyong, Petra Todd, and Wilbert Van der Klaauw. 2001. "Identification and Estimation of Treatment Effects with a Regression-Discontinuity Design." Econometrica, 69(1): 201-209.

Hall, Robert E. 2011. “The Long Slump.” American Economic Review, 101(2): 431-69.

Hertzberg, Andrew, Andres Liberman, and Daniel Paravisini. 2015. “Adverse Selection and Maturity Choice in Consumer Credit Markets: Evidence from an Online Lender." Working Paper.

Hsieh, Chang-Tai. 2003. "Do Consumers React to Anticipated Income Changes? Evidence from the Alaska Permanent Fund." American Economic Review, 93(1): 397-405.

Hurst, Erik, Benjamin J. Keys, Amit Seru, and Joseph Vavra. 2015. "Regional Redistribution Through the US Mortgage Market." NBER Working Paper.

Imbens, Guido, and Karthik Kalyanaraman. 2011. "Optimal Bandwidth Choice for the Regression Discontinuity Estimator." Review of Economic Studies.

Jappelli, Tullio, and Luigi Pistaferri. 2010. "The Consumption Response to Income Changes." Annual Review of Economics, 2: 479-506.

Jiménez, Gabriel, Steven Ongena, José-Luis Peydró, and Jesús Saurina. 2012. "Credit Supply and Monetary Policy: Identifying the Bank Balance-Sheet Channel with Loan Applications." American Economic Review, 102(5): 2301-26.

Jiménez, Gabriel, Steven Ongena, José-Luis Peydró, and Jesús Saurina. 2014. “Hazardous Times for Monetary Policy: What Do Twenty-Three Million Bank Loans Say About the Effects of Monetary Policy on Credit Risk-Taking?" Econometrica, 82(2): 463-505.

Johnson, David S., Jonathan A. Parker, and Nicholas S. Souleles. 2006. "Household Expenditure and the Income Tax Rebates of 2001." American Economic Review, 96(5): 1589-1610.

Karlan, Dean, and Jonathan Zinman. 2009. “Observing Unobservables: Identifying Information Asymmetries with a Consumer Credit Field Experiment." Econometrica, 77(6): 1993-2008.

Kashyap, Anil K., and Jeremy C. Stein. 1995. "The Impact of Monetary Policy on Bank Balance Sheets." Carnegie-Rochester Conference Series on Public Policy, 42: 151-195.

Keys, Benjamin J., Tanmoy Mukherjee, Amit Seru, and Vikrant Vig. 2010. “Did Securitization Lead to Lax Screening? Evidence from Subprime Loans." Quarterly Journal of Economics, 125(1): 307-362.

Keys, Benjamin J., Tomasz Piskorski, Amit Seru, and Vincent Yao. 2014. "Mortgage Rates, Household Balance Sheets, and the Real Economy." NBER Working Paper.

Korinek, Anton, and Alp Simsek. 2014. "Liquidity Trap and Excessive Leverage." NBER Working Paper.

Kurlat, Pablo, and Johannes Stroebel. 2015. "Testing for Information Asymmetries in Real Estate Markets." Review of Financial Studies, 28: 2429-2461.

Lee, David S., and Thomas Lemieux. 2010. "Regression Discontinuity Designs in Economics." Journal of Economic Literature, 48(2): 281-355.

Mahoney, Neale, and E. Glen Weyl. 2013. "Imperfect Competition in Selection Markets." Working Paper. 
Mian, Atif, and Amir Sufi. 2010. "Household Leverage and the Recession of 2007-09." IMF Economic Review, 58(1): 74-117.

Mian, Atif, and Amir Sufi. 2012. "What Explains High Unemployment? The Aggregate Demand Channel." NBER Working Paper.

Mian, Atif, Kamalesh Rao, and Amir Sufi. 2013. "Household Balance Sheets, Consumption, and the Economic Slump." Quarterly Journal of Economics, 128(4): 1687-1726.

Parker, Jonathan A., Nicholas S. Souleles, David S. Johnson, and Robert McClelland. 2013. "Consumer Spending and the Economic Stimulus Payments of 2008." American Economic Review, 103(6): 2530-2553.

Parlour, Christine A., and Uday Rajan. 2001. "Competition in Loan Contracts." American Economic Review, 91(5): pp. 1311-1328.

Petersen, Mitchell A., and Raghuram G. Rajan. 1994. "The Benefits of Lending Relationships: Evidence from Small Business Data." Journal of Finance, 49(1): 3-37.

Philippon, Thomas, and Virgiliu Midrigan. 2011. "Household Leverage and the Recession." NBER Working Paper.

Sahm, Claudia, Matthew D. Shapiro, and Joel Slemrod. 2015. "Balance-Sheet Households and Stimulus: Lessons from the Payroll Tax Cut and Its Expiration." Working Paper.

Scharfstein, David S., and Adi Sunderam. 2013. “Concentration in Mortgage Lending, Refinancing Activity and Mortgage Rates." NBER Working Paper.

Souleles, Nicholas S. 1999. "The Response of Household Consumption to Income Tax Refunds." American Economic Review, 947-958.

Stango, Victor. 2000. "Competition and Pricing in the Credit Card Market." Review of Economics and Statistics, 82(3): 499-508.

Stavins, Joanna. 1996. “Can Demand Elasticities Explain Sticky Credit Card Rates?" New England Economic Review, Jul: 43-54.

Stephens, Melvin. 2003. ""3rd of tha Month": Do Social Security Recipients Smooth Consumption Between Checks?" American Economic Review, 93(1): 406-422.

Stephens, Melvin. 2008. "The Consumption Response to Predictable Changes in Discretionary Income: Evidence from the Repayment of Vehicle Loans." Review of Economics and Statistics, 90(2): 241252.

Stroebel, Johannes. 2015. "Asymmetric Information About Collateral Values." Journal of Finance, Forthcoming.

Sufi, Amir. 2015. “Out of Many, One? Household Debt, Redistribution and Monetary Policy during the Economic Slump." Andrew Crockett Memorial Lecture, BIS.

Taylor, John B. 2014. "The Role of Policy in the Great Recession and the Weak Recovery." American Economic Review, 104(5): 61-66.

Wall Street Journal. 2009. "Lending Declines as Bank Jitters Persist."

Zeldes, Stephen P. 1989. "Consumption and Liquidity Constraints: An Empirical Investigation." Journal of Political Economy, 97(2): 305-46. 
Zinman, Jonathan. 2014. "Household Debt: Facts, Puzzles, Theories, and Policies." NBER Working Paper. 


\section{Figure 2: Credit Limit Quasi-Experiments: Examples and Summary Statistics}

(A) Origination Group without Quasi-Experiments

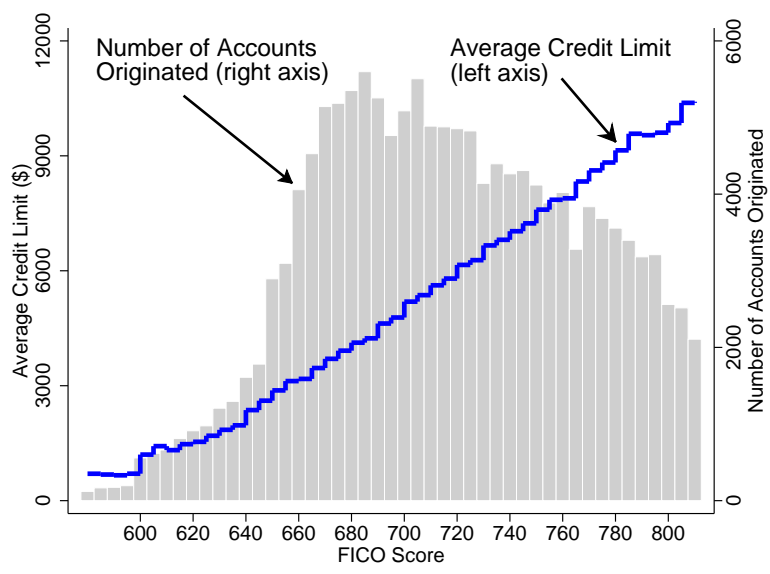

(C) Origination Group with Quasi-Experiments

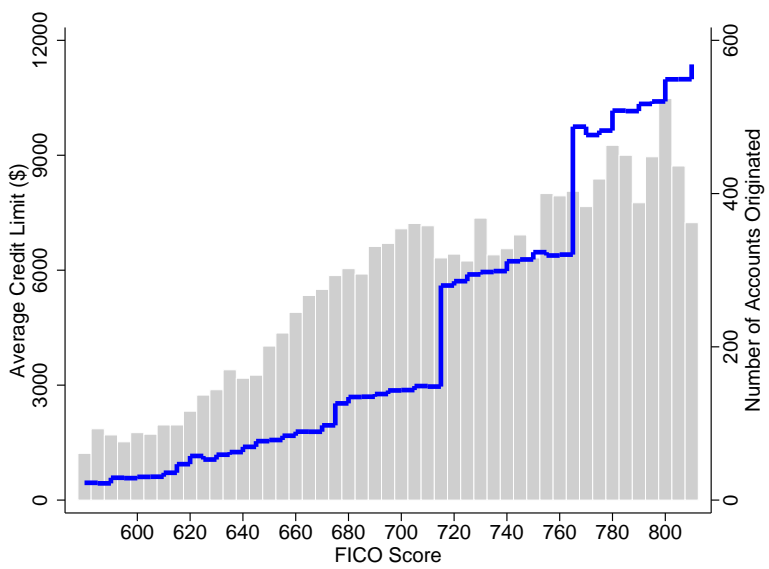

(E) FICO Score Cutoffs for Quasi-Experiments

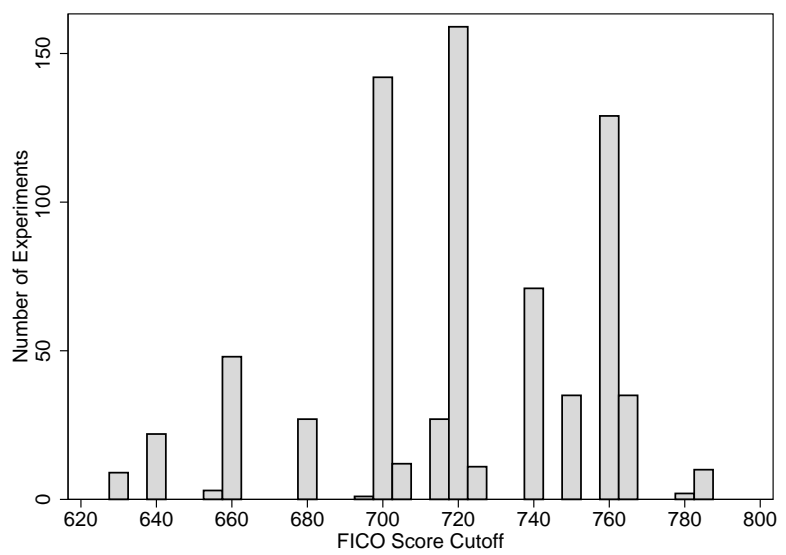

(B) Origination Group without Quasi-Experiments

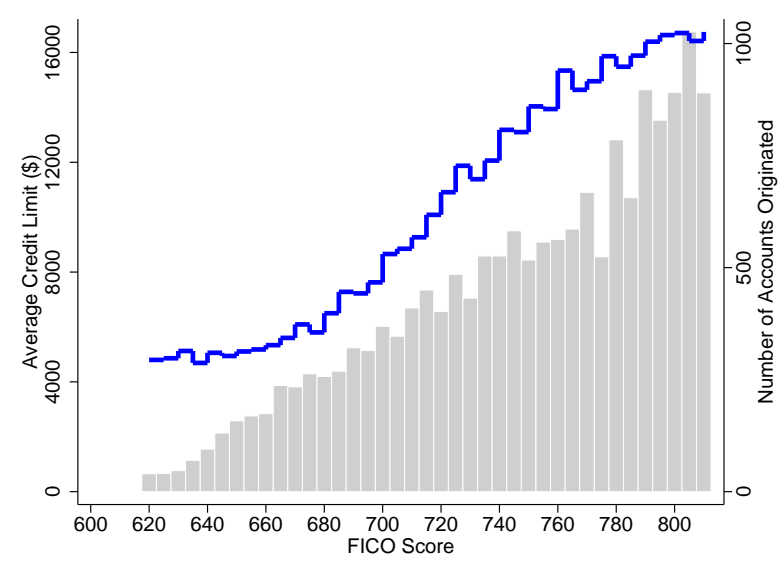

(D) Origination Group with Quasi-Experiments

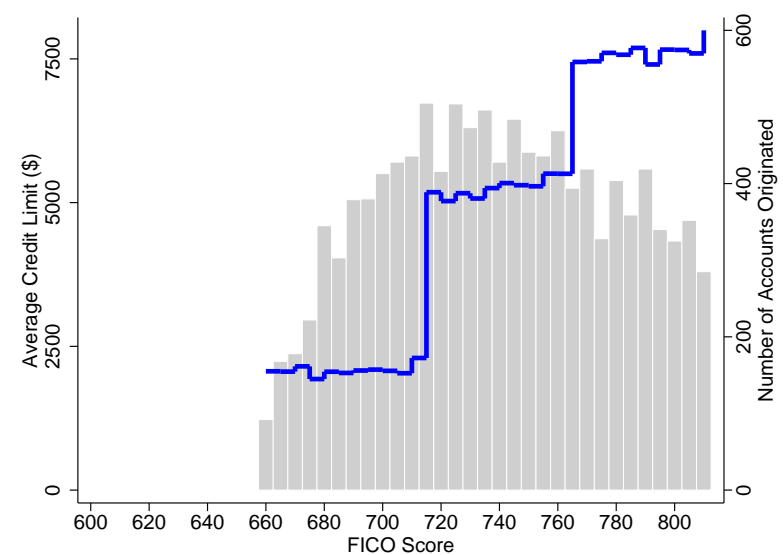

(F) Number of Accounts Near Quasi-Experiments

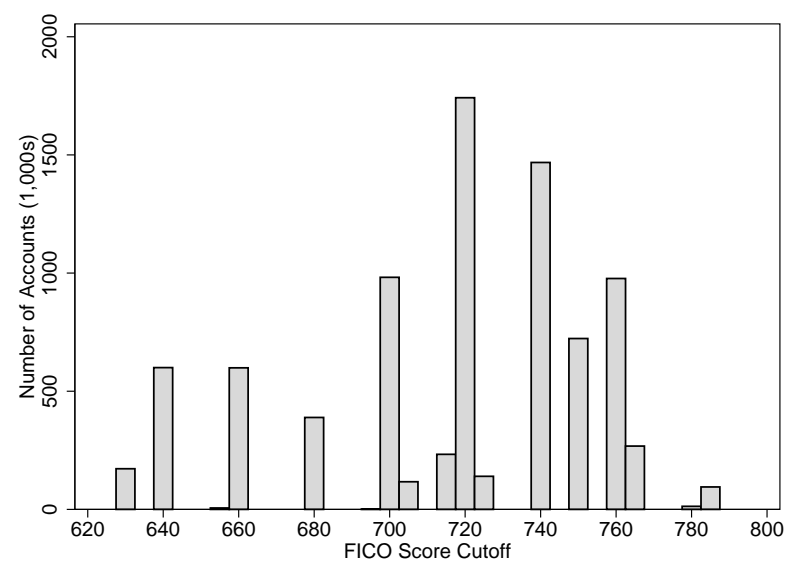

Note: Panels A to D show examples of average credit limits by FICO score for accounts in "origination groups" with and without credit limit quasi-experiments. Origination groups are defined as all credit cards of the same product-type originated by the same bank in the same month through the same loan channel. The horizontal axis shows FICO score at origination. The blue line plots the average credit limit for accounts in FICO buckets of 5 (left axis); grey bars show the total number of accounts originated in those buckets (right axis). Panels E and F show summary statistics for the quasi-experiments. Panel E plots the number of quasi-experiments at each FICO score cutoff. Panel F plots the number of accounts within 50 FICO score points of these quasi-experiments for each FICO score cutoff. 


\section{Figure 3: Credit Limits and Cost of Credit around Credit Limit Quasi-Experiments}

(A) Credit Limits around Quasi-Experiments

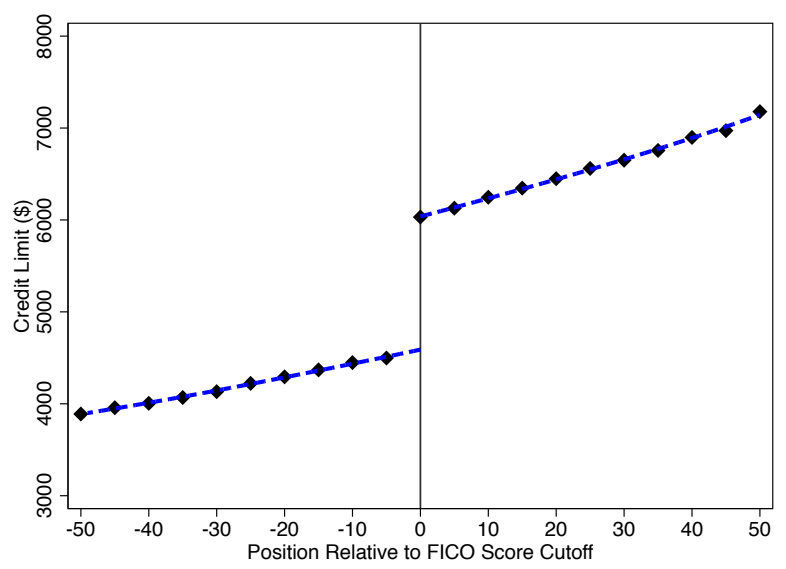

(C) APR around Quasi-Experiments

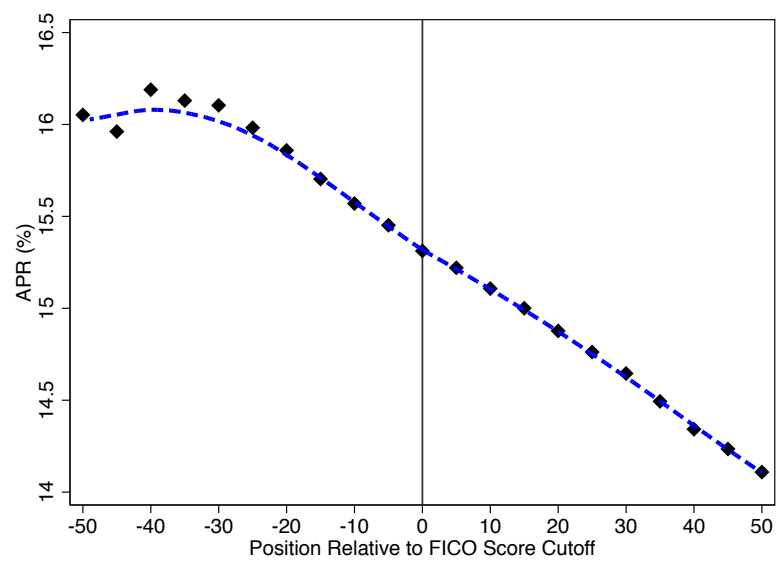

(E) Zero Intro APR around Quasi-Experiments

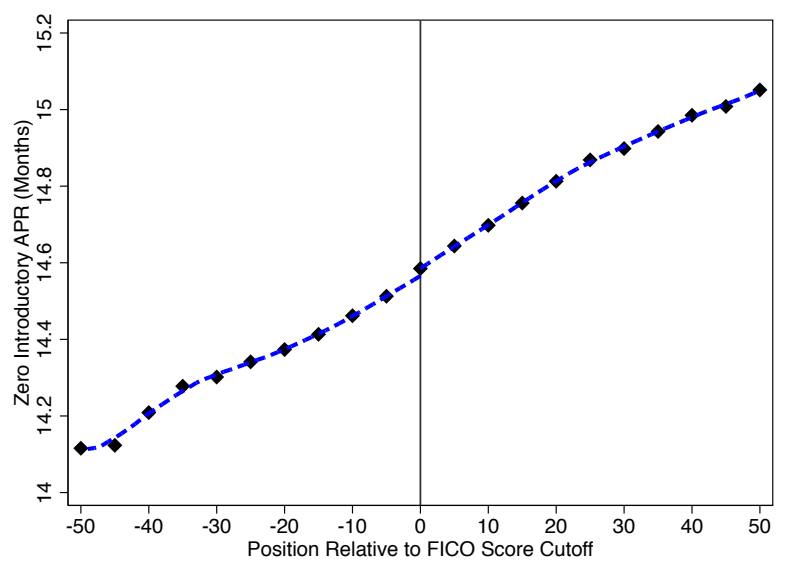

(B) Credit Limits around Placebo Experiments

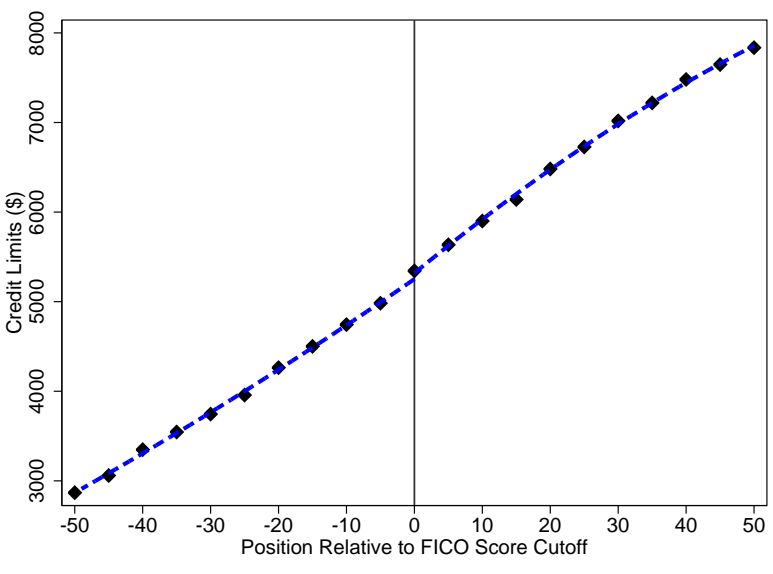

(D) APR around Placebo Experiments

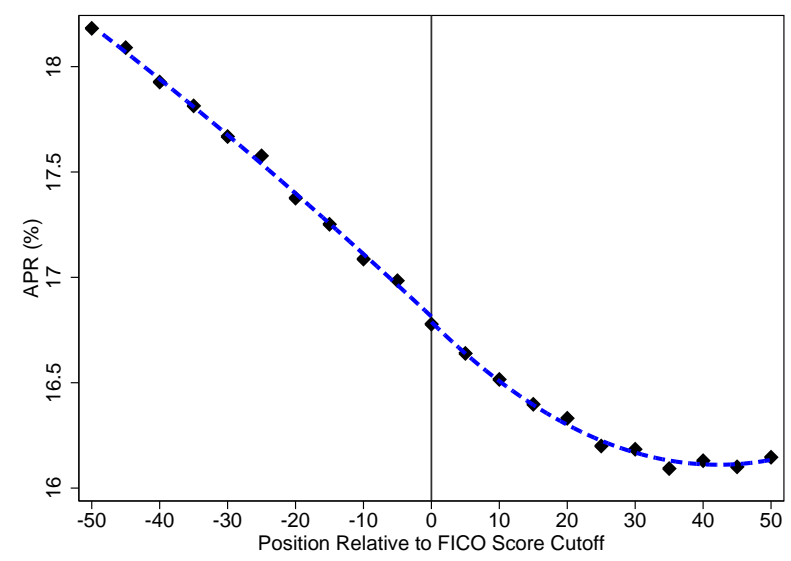

(F) Zero Intro APR around Placebo Experiments

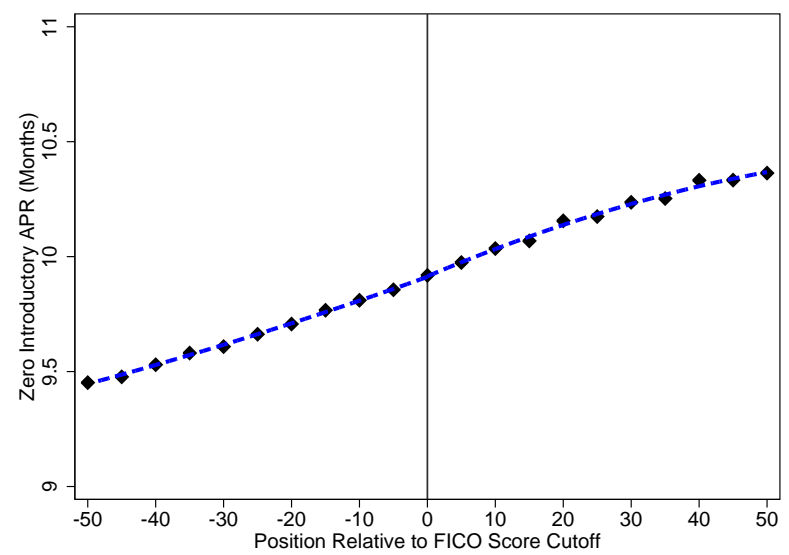

Note: Figure plots average credit limits (Panels A and B), average APR (Panels C and D), and average number of months with zero introductory APR (Panels E and F; limited to originations with zero introductory APR). The left column plots these outcomes around our 743 pooled quasi-experiments. We also control for other quasi-experiments within 50 FICO points in the same origination group. The right column plots the same outcomes around the same FICO score cutoffs but for "placebo experiments" originated in the same month as the quasi-experiments in the left column but for origination groups with no quasi-experiments at that FICO score. The horizontal axis shows FICO score at origination, centered at the FICO score cutoff. Scatter plots show means of outcomes for 5-point FICO score buckets. Blue lines show predicted values from second-order local polynomial regressions estimated separately on either side of the cutoff using the Imbens and Kalyanaraman (2011) optimal bandwidth. 
Figure 4: Effect of FICO Score Cutoff on Credit Limits

(A) Distribution of First-Stage Coefficients

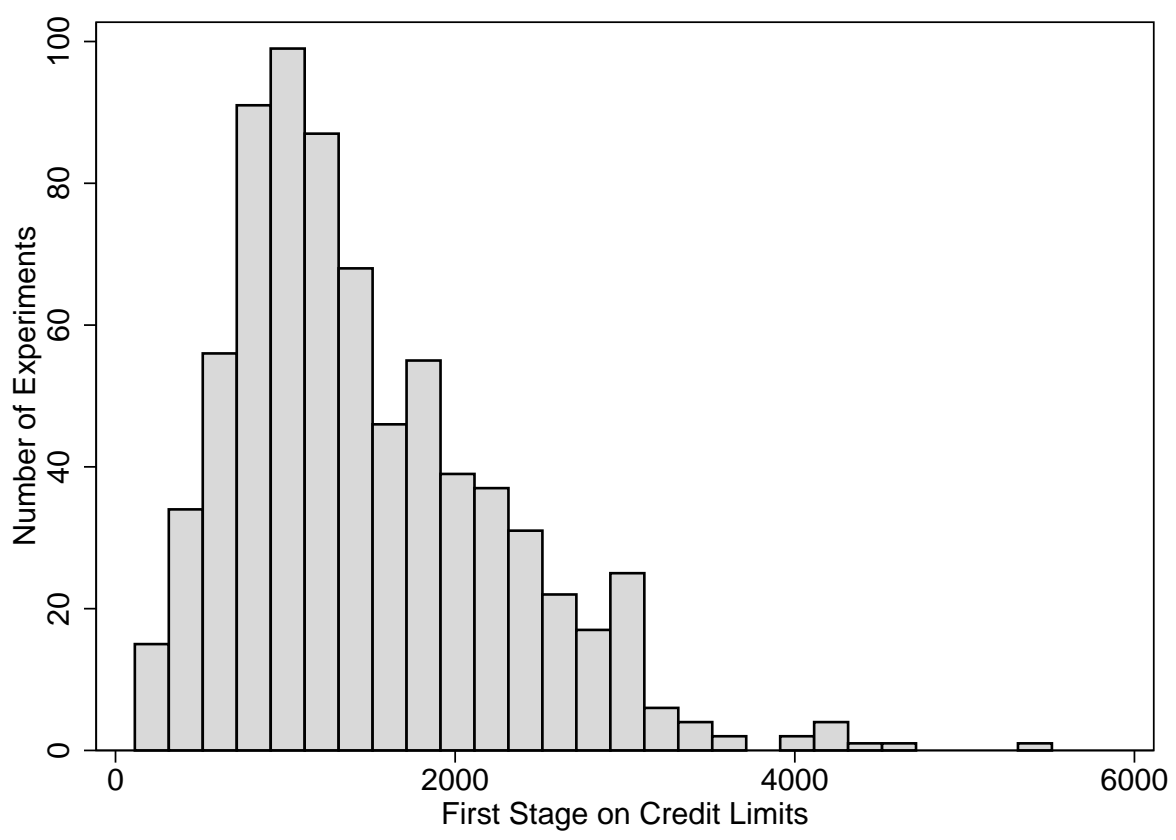

(B) Persistence of a $\$ 1$ Increase in Credit Limits

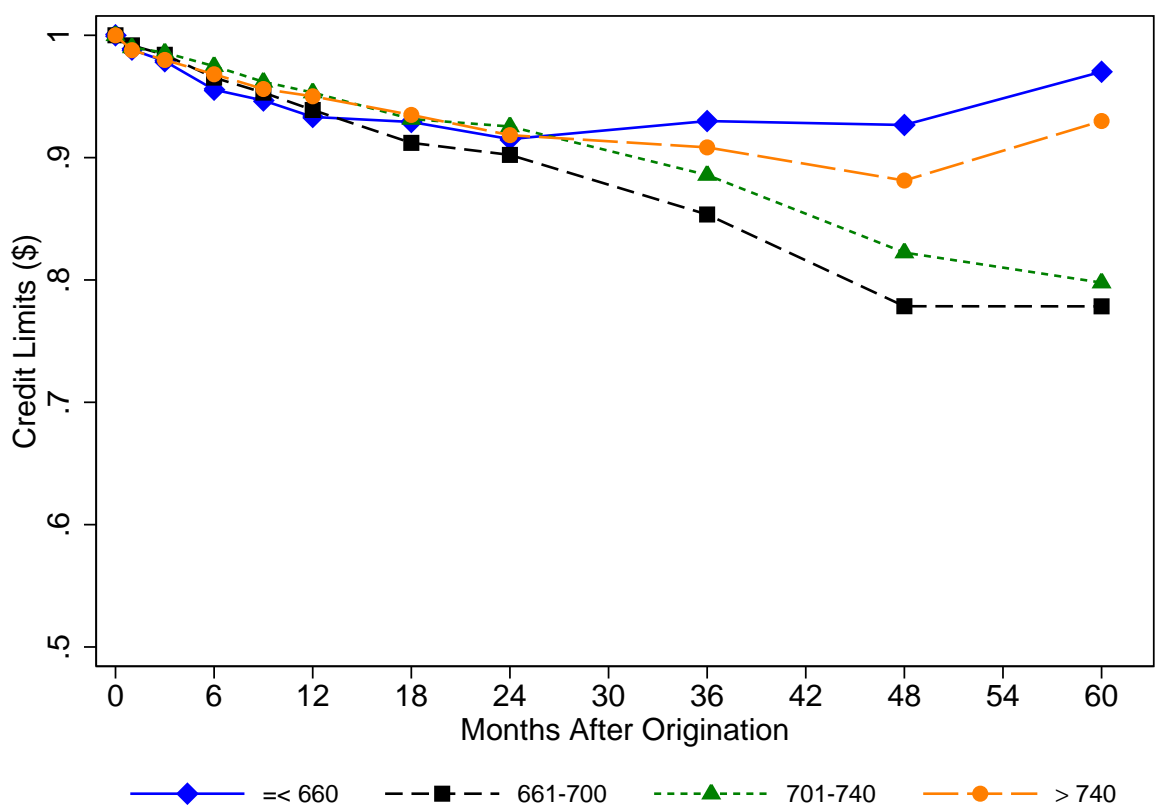

Note: Panel A shows the distribution of credit limit increases at the FICO score cutoffs across our 743 credit limit quasi-experiments. Panel B shows regression discontinuity estimates of the effect of a $\$ 1$ increase in initial credit limits on credit limits at different time horizons after account origination. Estimates are shown for FICO score groups, defined at account origination. The corresponding estimates are shown in Table 4. 
Figure 5: Initial Borrower Characteristics around Credit Limit Quasi-Experiments

(A) Number of Credit Card Accounts

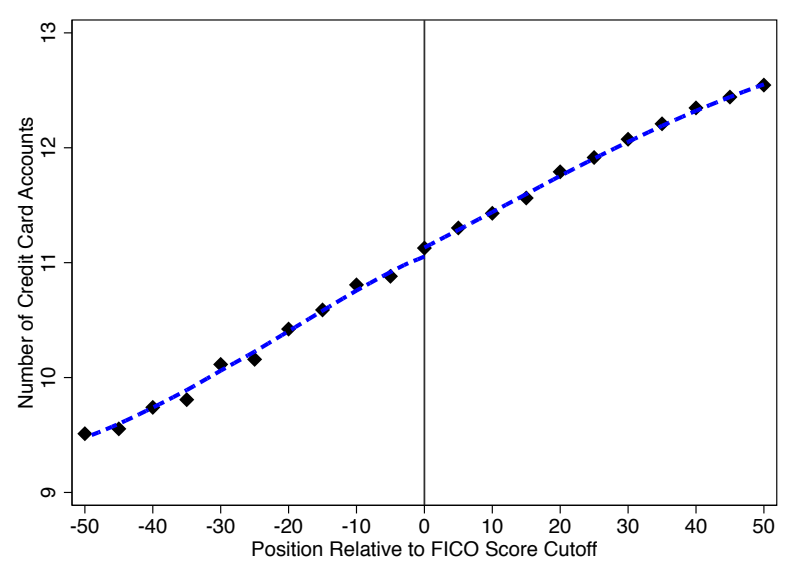

(C) Age of Oldest Account (Years)

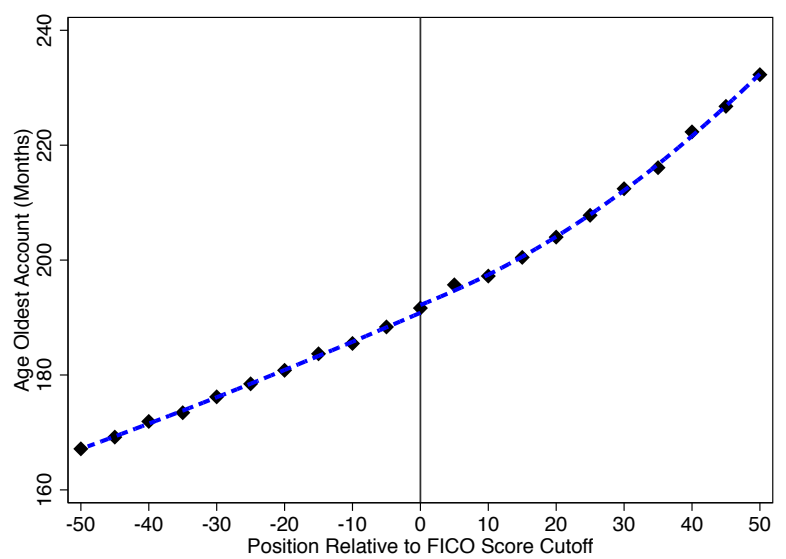

(E) Number of Payments 90+ DPD (Past 24 Months)

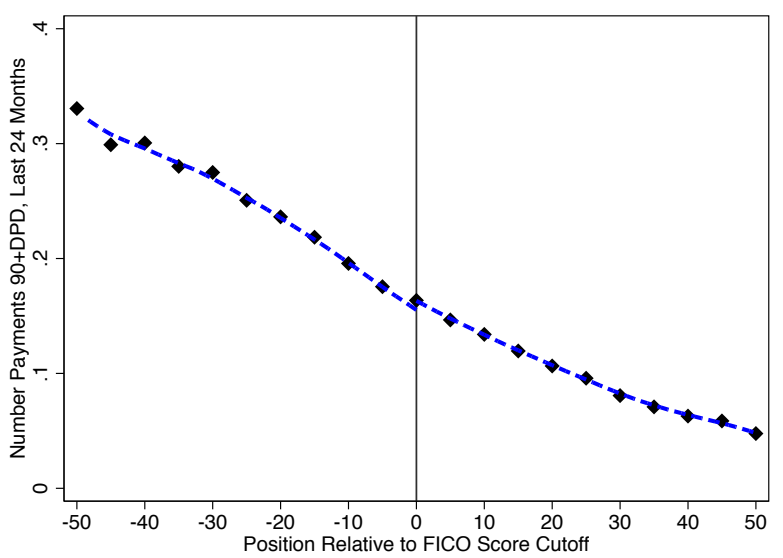

(B) Total Credit Limit (\$)

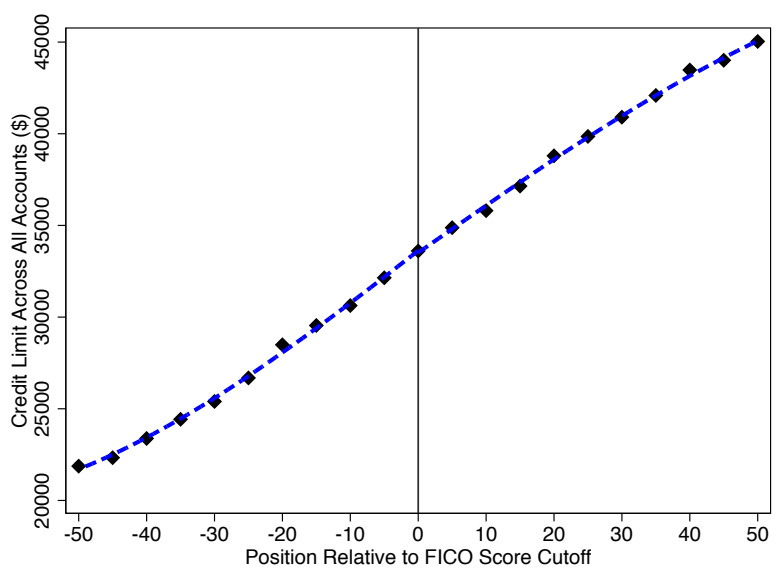

(D) Number of Payments 90+ DPD (Ever)

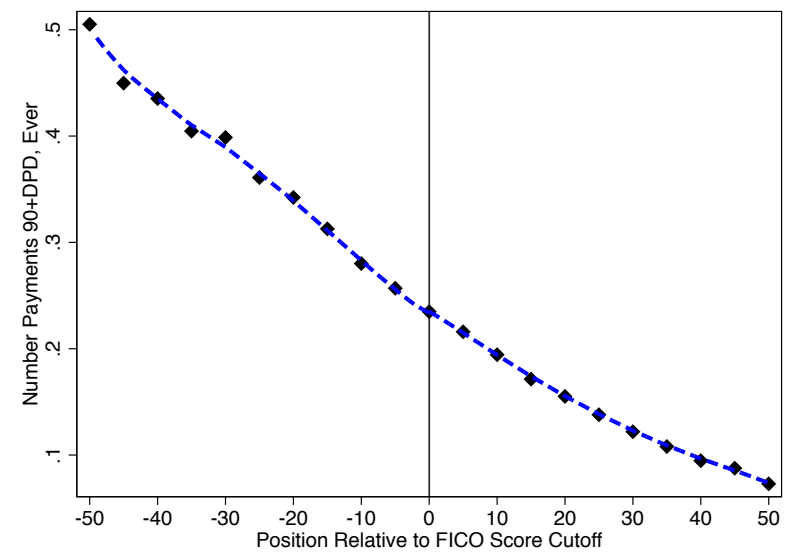

(F) Total Number of Accounts Opened

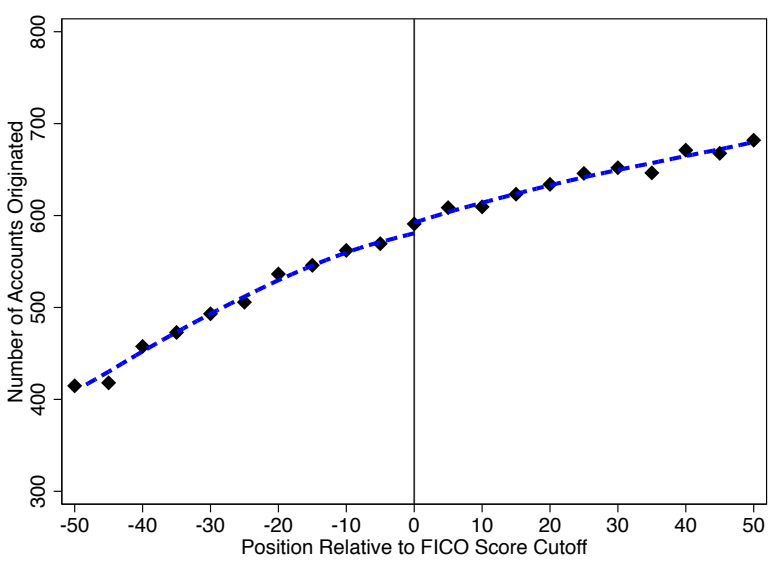

Note: Figure plots average borrower characteristics around our 743 pooled credit limit quasi-experiments. The horizontal axis shows FICO score at origination, centered at the FICO score cutoff. The vertical axis shows the number of credit card accounts (Panel A), total credit limit across all credit card accounts (Panel B), age of the oldest account (Panel C), number of payments ever 90+ days past due (Panel D), number of payments 90+ days past due in last 24 months (Panel E), and the total number of accounts opened in the origination group where we observe the credit limit quasi-experiment (Panel F). All borrower characteristics are as reported to the credit bureau at account origination. Scatter plots show means of outcomes for 5-point FICO score buckets. Blue lines show predicted values from second-order local polynomial regressions estimated separately on either side of the cutoff using the Imbens and Kalyanaraman (2011) optimal bandwidth. 
Figure 6: Marginal Propensity to Borrow

(A) ADB At 12 Months (\$)

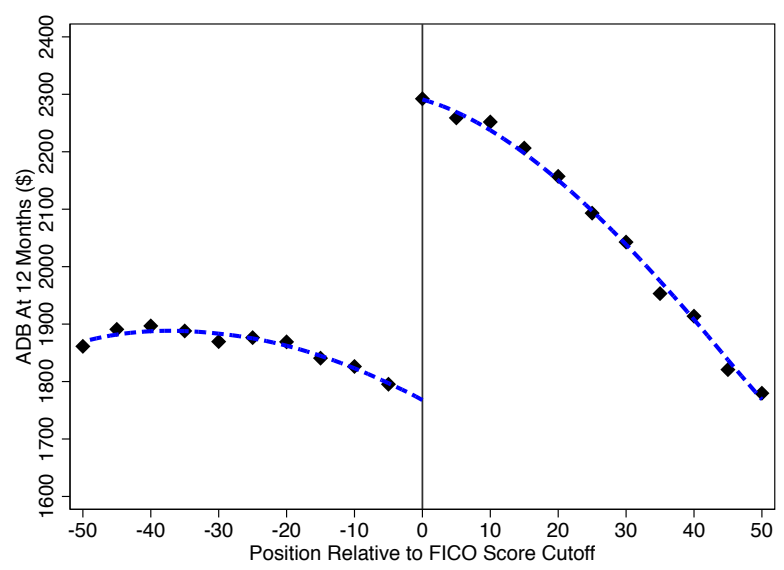

(C) Balances Across All Cards At 12 Months (\$)

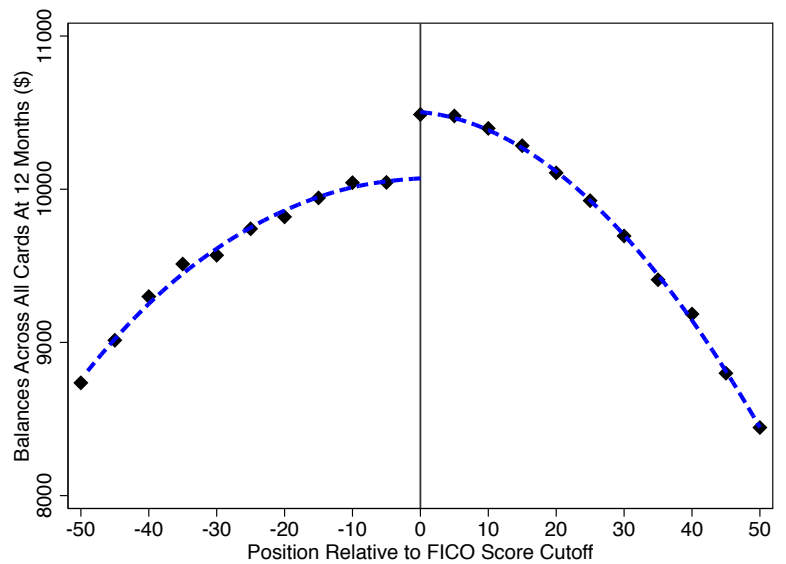

(E) Cumulative Purchase Volume At 12 Months (\$)

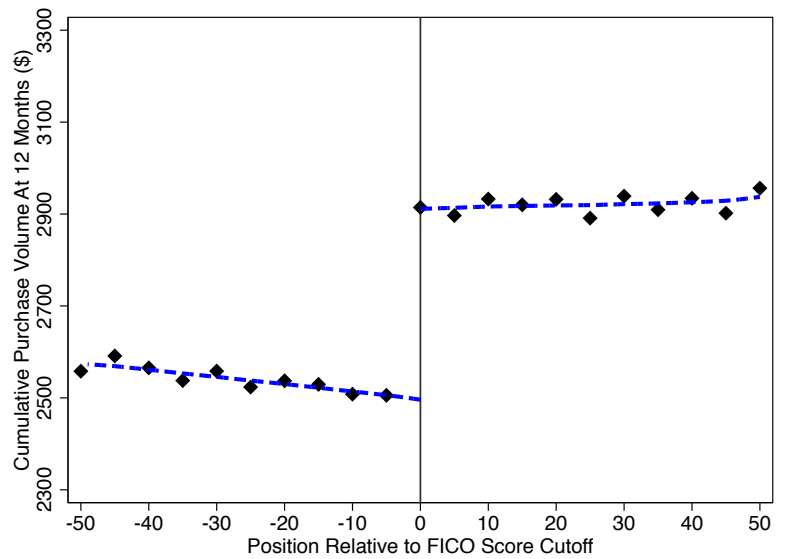

(B) $\operatorname{ADB}(\$)$

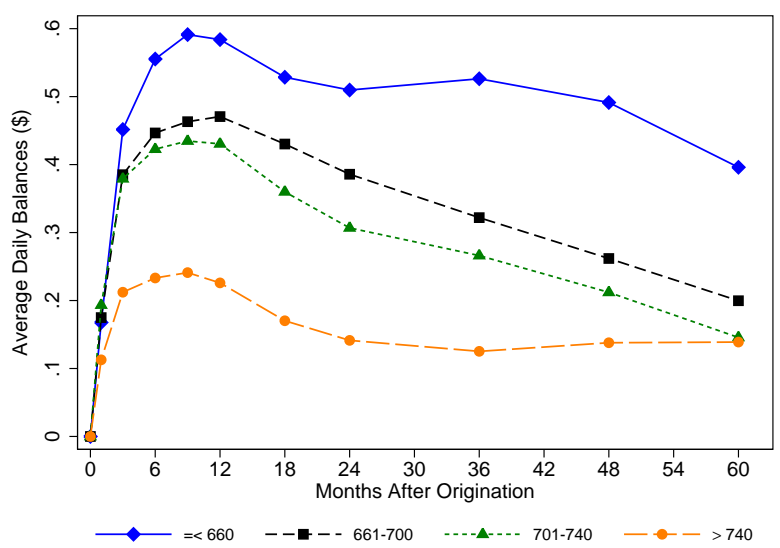

(D) Balances Across All Cards (\$)

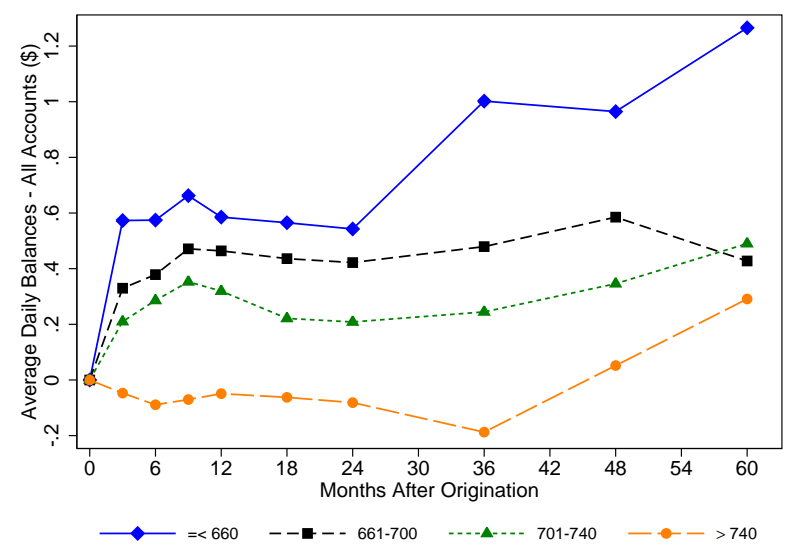

(F) Cumulative Purchase Volume (\$)

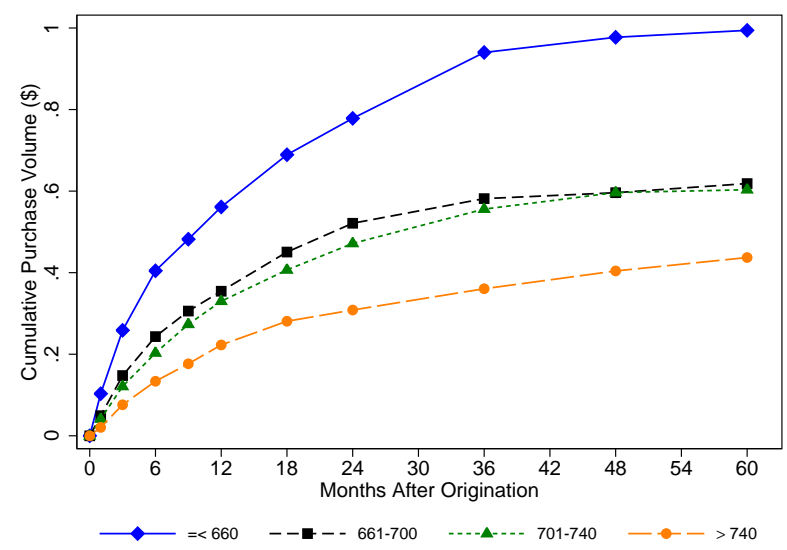

Note: Figure shows the effects of credit limits on borrowing and spending. The top row shows effects on average daily balances on the treated credit card. The middle row shows effects on total balances aggregated across all credit cards held by the account holder. The bottom row shows effect on cumulative purchase volume on the treated card. The left column shows changes in the outcome variable after 12 months around our 743 pooled credit limit quasi-experiments; these plots are constructed as described in Figure 3. The right column shows regression discontinuity estimates of the effect of $\$ 1$ increase in credit limits for different FICO score groups and different time horizons after account origination. FICO score groups are determined by FICO score at account origination. The corresponding estimates are shown in Table 5. 
Figure 7: Probability of Delinquency

(A) Probability 60+ Days Past Due (\%)

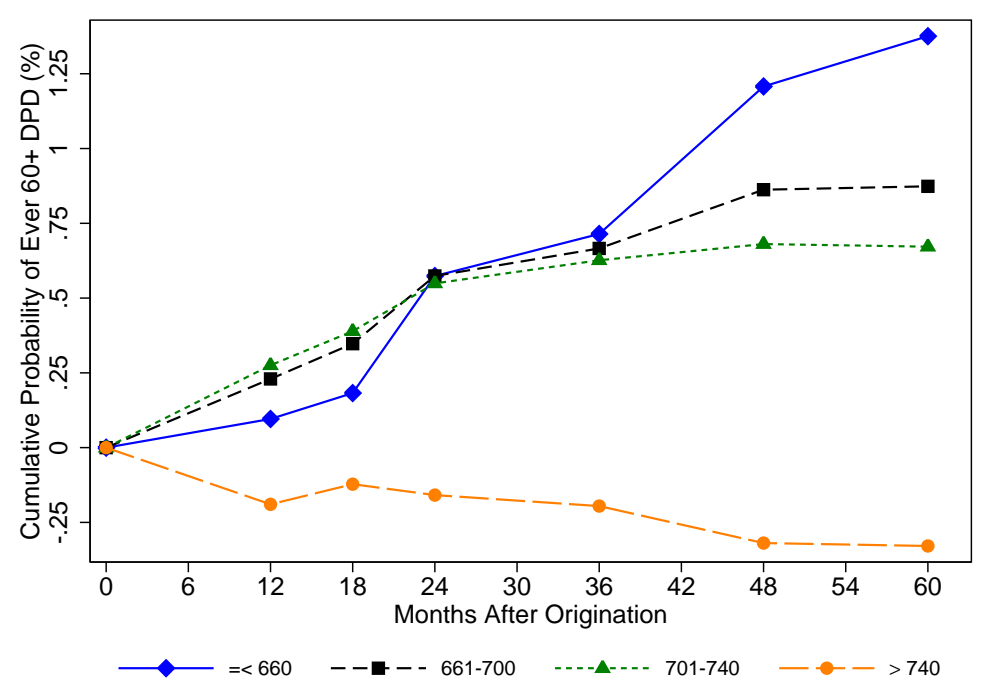

(B) Probability 90+ Days Past Due (\%)

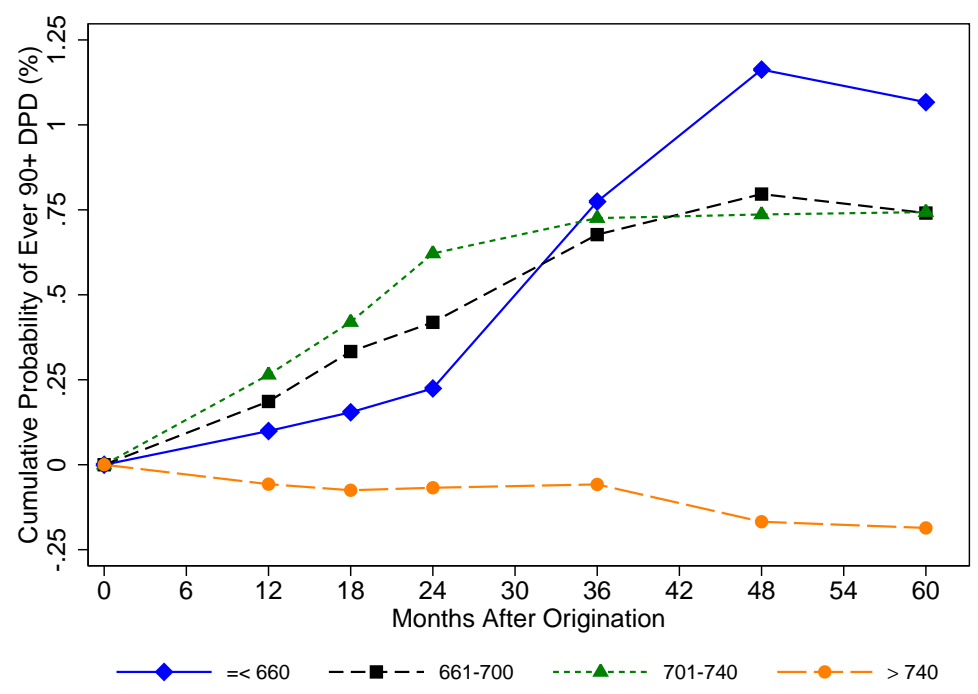

Note: Figure shows the effects of $\$ 1,000$ increase in credit limits on the probability of delinquency for different FICO score groups and different time horizons after account origination. Panel A shows effects on the probability of an account being more than 60 days past due (60+ DPD) within the time horizon, Panel B on the probability of being more than 90 days past due (90+ DPD) within the time horizon. FICO score groups are determined by FICO score at account origination. The corresponding estimates are shown in Table 6. 


\section{Figure 8: Marginal Effects and Response of Marginal Effects to a $\$ 1 \mathrm{~K}$ Increase in Credit Limits}

(A) Marginal Total Costs

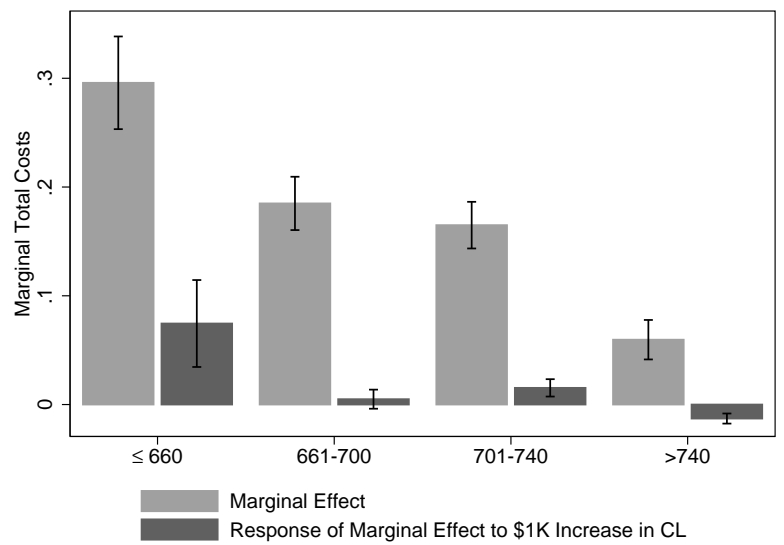

(C) Marginal Total Revenue

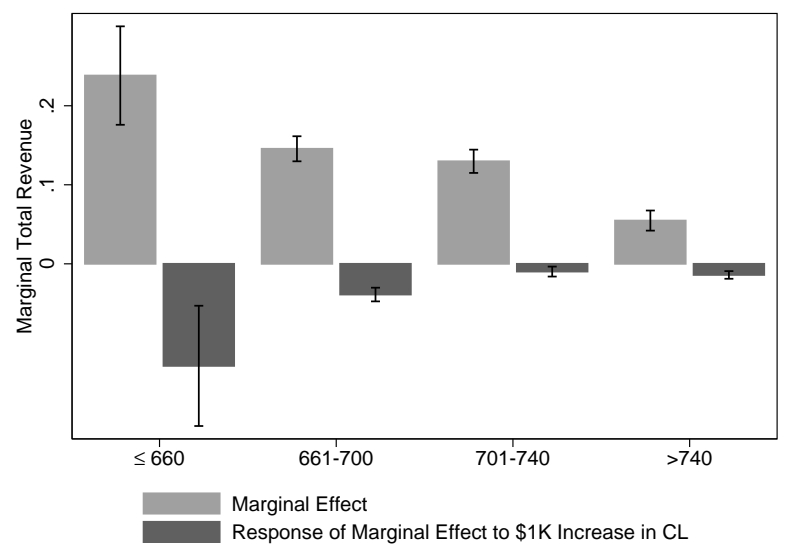

(B) Marginal Chargeoffs

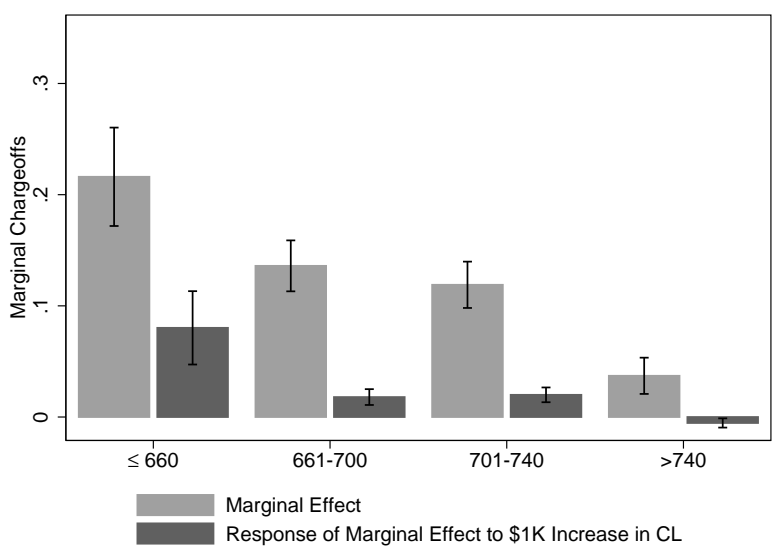

(D) Marginal Fee Revenue

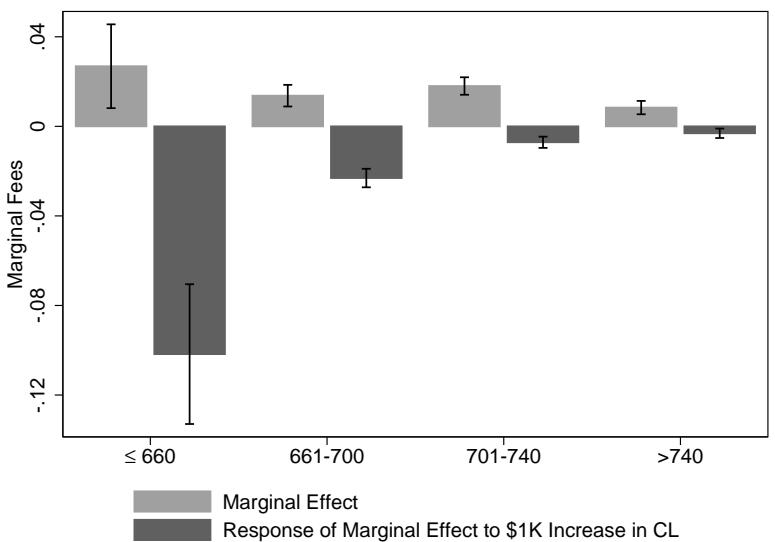

(E) Marginal Profits

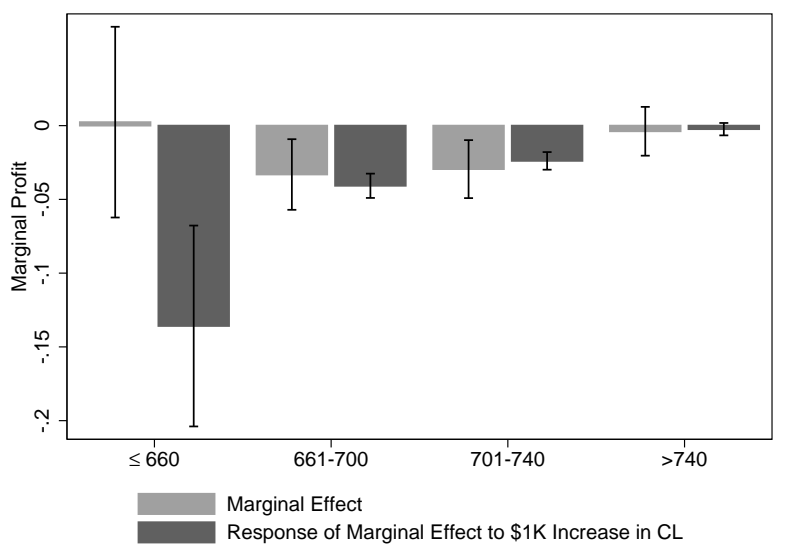

Note: Figure shows marginal effects and the effect of a $\$ 1,000$ increase in credit limits on marginal effects by FICO score group. We show these effects for total costs, chargeoffs (which are an important component of total costs), total revenue, fee revenue (which is an important component of total revenue) and profits (which is defined as total revenue minus total costs). We measure these variables cumulatively over a time horizon of 48 months after account origination. For each measure, the grey bars shows the RD estimate of the marginal effect of a $\$ 1$ increase in credit limits at the prevailing equilibrium credit limit. The black bars show the impact of $\$ 1,000$ increase in credit limits on this marginal effect. Vertical bars show $95 \%$ confidence intervals, constructed by bootstrapping across quasiexperiments. FICO score groups are determined by FICO score at account origination. The corresponding estimates are shown in Table 7. 
Figure 9: Marginal Propensity to Lend (MPL)

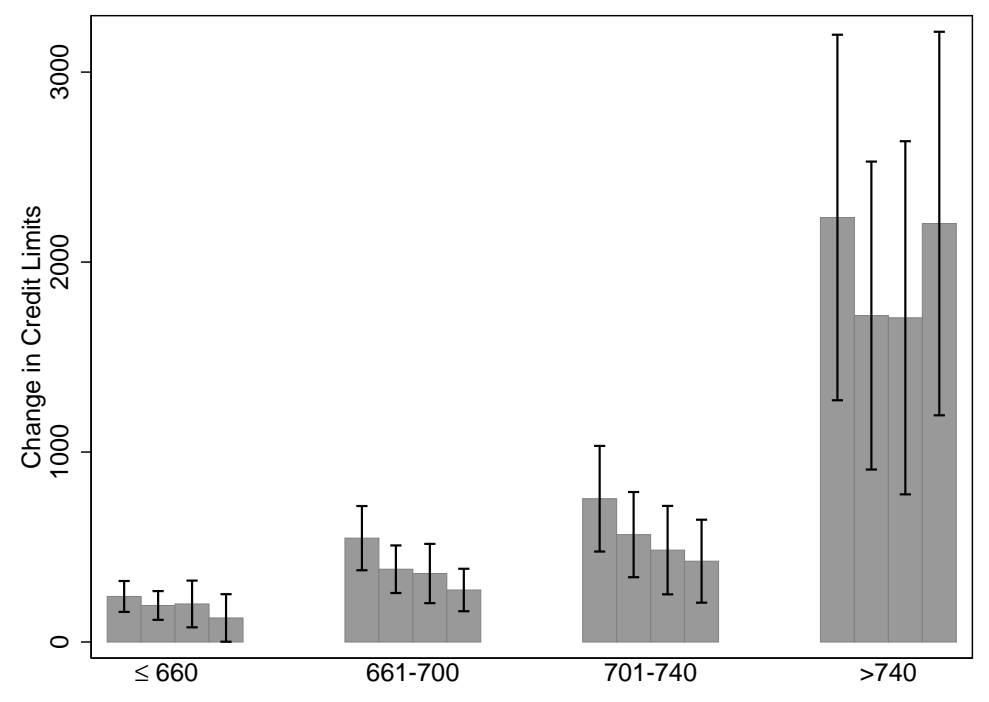

Note: Figure shows the implied effect of a 1 percentage point reduction in the cost of borrowing on credit limits by FICO score group. Estimates are produced using Equation 8. For each FICO score group, we show the implied increase in credit limits when measuring both the slope of marginal profits and marginal borrowing over the first 12, 24, 36, and 48 months following origination. Vertical bars show $95 \%$ confidence intervals, constructed by bootstrapping across quasiexperiments. FICO score groups are determined by FICO score at account origination. The corresponding estimates are shown in Table 8.

Figure 10: Correlation between MPL and MPB

(A) MPL

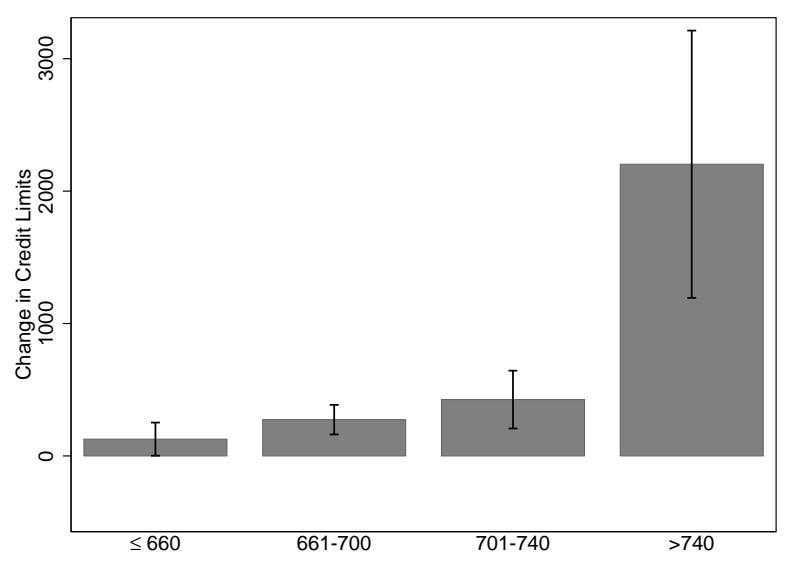

(B) MPB Across All Cards: At 12 Months

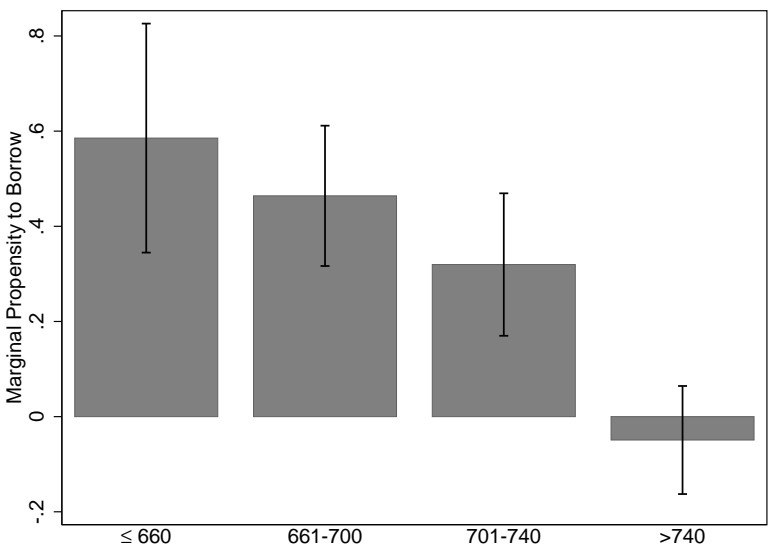

Note: Panel A shows the implied effect of a 1 percentage point reduction in the cost of borrowing on credit limits by FICO score group. The effects are calculated using the marginal profits estimates shown in Figure 8 and Table 7. Panel $\mathrm{B}$ shows the effect of a $\$ 1$ increase in credit limits on borrowing across all cards by FICO group. The corresponding estimates are shown in Table 8 . Vertical bars show 95\% confidence intervals, constructed by bootstrapping across quasi-experiments. FICO score groups are determined by FICO score at account origination. 
Table 1: Quasi-Experiment-Level Summary Statistics, At Origination

\begin{tabular}{|c|c|c|c|c|c|}
\hline & Average & S.D & & Average & S.D \\
\hline \multicolumn{3}{|c|}{ Credit Limit on Treated Card (\$) } & \multicolumn{3}{|c|}{ Total Balances Across All Credit Card Accounts (\$) } \\
\hline Pooled & 5,265 & 2,045 & Pooled & 9,551 & 3,469 \\
\hline$\leq 660$ & 2,561 & 674 & $\leq 660$ & 5,524 & 2,324 \\
\hline $661-700$ & 4,324 & 1,090 & $661-700$ & 9,956 & 2,680 \\
\hline $701-740$ & 4,830 & 1,615 & $701-740$ & 10,890 & 3,328 \\
\hline$>740$ & 6,941 & 1,623 & $>740$ & 9,710 & 3,326 \\
\hline \multicolumn{3}{|c|}{ APR on Treated Card (\%) } & \multicolumn{3}{|c|}{ Credit Limit Across All Credit Card Accounts (\$) } \\
\hline Pooled & 15.38 & 3.70 & Pooled & 33,533 & 14,627 \\
\hline$\leq 660$ & 19.63 & 5.43 & $\leq 660$ & 12,856 & 5,365 \\
\hline $661-700$ & 14.50 & 3.65 & $661-700$ & 26,781 & 7,524 \\
\hline $701-740$ & 15.35 & 3.11 & $701-740$ & 32,457 & 8,815 \\
\hline$>740$ & 14.70 & 2.52 & $>740$ & 44,813 & 12,828 \\
\hline \multicolumn{3}{|c|}{ Number of Credit Card Accounts } & \multicolumn{3}{|c|}{ Number Times 90+ DPD In Last 24 Months } \\
\hline Pooled & 11.00 & 2.93 & Pooled & 0.17 & 0.30 \\
\hline$\leq 660$ & 7.13 & 1.18 & $\leq 660$ & 0.93 & 0.31 \\
\hline $661-700$ & 10.22 & 1.68 & $661-700$ & 0.41 & 0.16 \\
\hline $701-740$ & 11.12 & 2.34 & $701-740$ & 0.29 & 0.10 \\
\hline$>740$ & 12.63 & 2.92 & $>740$ & 0.13 & 0.08 \\
\hline \multicolumn{3}{|c|}{ Age Oldest Account (Months) } & \multicolumn{3}{|c|}{ Number Accounts Currently 90+DPD } \\
\hline Pooled & 190.1 & 29.1 & Pooled & 0.03 & 0.03 \\
\hline$\leq 660$ & 162.0 & 26.3 & $\leq 660$ & 0.10 & 0.05 \\
\hline $661-700$ & 180.1 & 19.9 & $661-700$ & 0.02 & 0.02 \\
\hline $701-740$ & 184.7 & 24.0 & $701-740$ & 0.02 & 0.02 \\
\hline$>740$ & 208.6 & 25.7 & $>740$ & 0.01 & 0.01 \\
\hline
\end{tabular}

Note: Table shows quasi-experiment-level summary statistics at the time of account origination, both pooled across our 743 quasi-experiments and split by FICO score groups. At the pooled level, for each quasi-experiment, we calculate the mean value for a given variable across all of the accounts within 5 FICO score points of the cutoff. We then show the means and standard deviations of these values across our 743 quasi-experiments. We follow the same procedure to obtain the means and standard deviations by FICO score group. 
Table 2: Quasi-Experiment-Level Summary Statistics, Post Origination

\begin{tabular}{|c|c|c|c|c|c|c|c|c|c|c|c|c|c|c|}
\hline & \multicolumn{4}{|c|}{ FICO Score Group } & & \multicolumn{4}{|c|}{ FICO Score Group } & & \multicolumn{4}{|c|}{ FICO Score Group } \\
\hline & $\leq 660$ & $661-700$ & $701-740$ & $>740$ & & $\leq 660$ & $661-700$ & $701-740$ & $>740$ & & $\leq 660$ & $661-700$ & $701-740$ & $>740$ \\
\hline \multicolumn{5}{|l|}{ Credit Limit (\$) } & \multicolumn{5}{|c|}{ Cumulative Total Costs (\$) } & \multicolumn{5}{|c|}{ Cumulative Total Revenue (\$) } \\
\hline After 12 Months & 2,652 & 4,370 & 4,964 & 6,980 & After 12 Months & 122 & 172 & 169 & 147 & After 12 Months & 233 & 192 & 181 & 175 \\
\hline After 24 Months & 2,414 & 4,306 & 4,946 & 7,071 & After 24 Months & 281 & 451 & 433 & 304 & After 24 Months & 474 & 503 & 439 & 347 \\
\hline After 36 Months & 2,301 & 4,622 & 5,047 & 7,005 & After 36 Months & 459 & 710 & 644 & 395 & After 36 Months & 740 & 793 & 663 & 449 \\
\hline After 48 Months & 2,252 & 4,525 & 4,985 & 6,944 & After 48 Months & 588 & 845 & 808 & 488 & After 48 Months & 953 & 971 & 863 & 563 \\
\hline After 60 Months & 2,290 & 4,449 & 4,601 & 6,839 & After 60 Months & 712 & 962 & 901 & 583 & After 60 Months & 1,148 & 1,126 & 965 & 669 \\
\hline \multicolumn{5}{|l|}{ ADB (\$) } & \multicolumn{5}{|c|}{ Cumulative Chargeoffs (\$) } & \multicolumn{5}{|c|}{ Cumulative Interest Charge Revenue (\$) } \\
\hline After 12 Months & 1,260 & 2,160 & 2,197 & 2,101 & After 12 Months & 47 & 67 & 61 & 35 & After 12 Months & 106 & 61 & 52 & 42 \\
\hline After 24 Months & 1,065 & 1,794 & 1,719 & 1,524 & After 24 Months & 178 & 259 & 245 & 124 & After 24 Months & 297 & 295 & 243 & 159 \\
\hline After 36 Months & 1,164 & 1,734 & 1,481 & 1,343 & After 36 Months & 306 & 443 & 403 & 190 & After 36 Months & 484 & 520 & 420 & 243 \\
\hline After 48 Months & 1,079 & 1,501 & 1,260 & 1,064 & After 48 Months & 403 & 552 & 524 & 261 & After 48 Months & 625 & 669 & 578 & 340 \\
\hline After 60 Months & 1,050 & 1,465 & 1,097 & 1,084 & After 60 Months & 483 & 634 & 602 & 322 & After 60 Months & 760 & 794 & 657 & 429 \\
\hline \multicolumn{5}{|c|}{ Total Balances Across All Cards (\$) } & \multicolumn{5}{|c|}{ Cumulative Prob 60+ DPD (\$) } & \multicolumn{5}{|c|}{ Cumulative Fee Revenue (\$) } \\
\hline After 12 Months & 6,155 & 10,546 & 11,411 & 10,528 & After 12 Months & $6.4 \%$ & $4.1 \%$ & $3.6 \%$ & $1.6 \%$ & After 12 Months & 73 & 79 & 79 & 74 \\
\hline After 24 Months & 5,919 & 10,521 & 11,307 & 10,703 & After 24 Months & $12.0 \%$ & $9.3 \%$ & $8.2 \%$ & $3.8 \%$ & After 24 Months & 129 & 129 & 121 & 101 \\
\hline After 36 Months & 6,387 & 10,716 & 11,702 & 11,267 & After 36 Months & $15.1 \%$ & $12.2 \%$ & $10.9 \%$ & $5.2 \%$ & After 36 Months & 192 & 173 & 157 & 116 \\
\hline After 48 Months & 6,698 & 10,437 & 11,665 & 11,137 & After 48 Months & $16.5 \%$ & $13.6 \%$ & $12.2 \%$ & $5.9 \%$ & After 48 Months & 254 & 199 & 187 & 126 \\
\hline After 60 Months & 7,566 & 10,591 & 11,972 & 12,490 & After 60 Months & $17.2 \%$ & $14.4 \%$ & $12.9 \%$ & $6.2 \%$ & After 60 Months & 364 & 310 & 211 & 101 \\
\hline \multicolumn{5}{|c|}{ Cumulative Purchase Volume (\$) } & \multicolumn{5}{|c|}{ Cumulative Cost of Funds (\$) } & \multicolumn{5}{|l|}{ Cumulative Profits (\$) } \\
\hline After 12 Months & 2,679 & 2,579 & 2,514 & 2,943 & After 12 Months & 14 & 16 & 16 & 15 & After 12 Months & 111 & 21 & 12 & 30 \\
\hline After 24 Months & 3,583 & 3,966 & 3,910 & 4,653 & After 24 Months & 23 & 29 & 28 & 25 & After 24 Months & 194 & 56 & 9 & 46 \\
\hline After 36 Months & 3,987 & 4,834 & 4,724 & 5,525 & After 36 Months & 28 & 38 & 36 & 31 & After 36 Months & 281 & 91 & 23 & 59 \\
\hline After 48 Months & 4,223 & 5,253 & 5,162 & 5,897 & After 48 Months & 31 & 43 & 41 & 34 & After 48 Months & 365 & 126 & 55 & 75 \\
\hline After 60 Months & 4,390 & 5,509 & 5,424 & 6,095 & After 60 Months & 33 & 46 & 44 & 36 & After 60 Months & 436 & 164 & 63 & 87 \\
\hline
\end{tabular}

Note: Table shows quasi-experiment-level summary statistics at different horizons after account origination by FICO score group. For each quasi-experiment, we calculate the mean value for a given variable across all of the accounts within 5 FICO score points of the cutoff. We then show the means and standard deviations of these values across the available quasi-experiments. Since later quasi-experiments are observed for shorter periods of time only, the set of experiments contributing to the averages across different horizons is not constant. FICO score groups are defined at account origination. 
Table 3: Validity of Research Design: Discontinuous Increase at FICO Cutoff

\begin{tabular}{lcccc}
\hline & \multicolumn{2}{c}{ Distribution of Jump Across Quasi-Experiments } \\
\cline { 2 - 4 } & Average & Median & Standard Devation & Baseline \\
\hline Credit Limit & 1,472 & 1,282 & 796 & 5,265 \\
APR (\%) & 0.017 & -0.005 & 0.388 & 15.38 \\
Months to Rate Change & 0.027 & 0.016 & 0.800 & 13.37 \\
Number of Credit Card Accounts & 0.060 & 0.031 & 0.713 & 11.00 \\
Total Credit Limit - All Accounts & 151 & 28 & 33,533 \\
Age Oldest Account (Months) & 1.034 & 0.378 & 11.072 & 190.11 \\
Number Times 90+ DPD - Last 24 Months & 0.010 & 0.002 & 0.111 & 0.169 \\
Number Accounts 90+ DPD - At Origination & 0.001 & 0.001 & 0.017 & 0.026 \\
Number Accounts 90+DPD - Ever & 0.004 & 0.003 & 0.095 & 0.245 \\
Number of Accounts Originated & 10.21 & 4.38 & 47.61 & 580.12 \\
\hline
\end{tabular}

Note: Table shows the reduced-form discontinuous increase ("jump") in outcomes variables at the FICO score cutoff, corresponding to the numerator of Equation 3. All variables are measured at account origination, allowing us to inspect the validity of the research design. We present the average, median, and standard deviation of this jump across our 743 quasiexperiments. We also present the average value of the variable at the cutoff ("baseline"), allowing us to judge the economic significance of any differences.

Table 4: Persistence of Credit Limit Effect

\begin{tabular}{|c|c|c|c|c|c|}
\hline & \multicolumn{5}{|c|}{ Months After Account Origination } \\
\hline & 12 & 24 & 36 & 48 & 60 \\
\hline \multicolumn{6}{|l|}{ FICO } \\
\hline \multirow[t]{3}{*}{$\leq 660$} & 0.93 & 0.92 & 0.93 & 0.93 & 0.97 \\
\hline & $(0.01)$ & $(0.02)$ & $(0.03)$ & $(0.05)$ & (0.09) \\
\hline & {$[0.00]$} & {$[0.00]$} & {$[0.00]$} & {$[0.00]$} & {$[0.00]$} \\
\hline \multirow[t]{3}{*}{$661-700$} & 0.94 & 0.90 & 0.85 & 0.78 & 0.78 \\
\hline & $(0.01)$ & $(0.01)$ & $(0.02)$ & $(0.03)$ & (0.07) \\
\hline & {$[0.00]$} & {$[0.00]$} & {$[0.00]$} & {$[0.00]$} & [0.00] \\
\hline \multirow[t]{3}{*}{$701-740$} & 0.95 & 0.93 & 0.89 & 0.82 & 0.80 \\
\hline & $(0.01)$ & $(0.01)$ & $(0.01)$ & $(0.03)$ & $(0.06)$ \\
\hline & {$[0.00]$} & {$[0.00]$} & {$[0.00]$} & {$[0.00]$} & [0.00] \\
\hline \multirow[t]{3}{*}{$>740$} & 0.95 & 0.92 & 0.91 & 0.88 & 0.93 \\
\hline & $(0.01)$ & $(0.01)$ & $(0.02)$ & $(0.03)$ & (0.08) \\
\hline & {$[0.00]$} & {$[0.00]$} & {$[0.00]$} & {$[0.00]$} & {$[0.00]$} \\
\hline
\end{tabular}


Table 5: Marginal Propensity to Borrow

\begin{tabular}{|c|c|c|c|c|c|}
\hline & \multicolumn{5}{|c|}{ Months After Account Origination } \\
\hline & 12 & 24 & 36 & 48 & 60 \\
\hline \multicolumn{6}{|c|}{ Panel A: Average Daily Balance } \\
\hline \multicolumn{6}{|c|}{ FICO } \\
\hline \multirow[t]{3}{*}{$\leq 660$} & 0.58 & 0.51 & 0.53 & 0.49 & 0.40 \\
\hline & $(0.03)$ & $(0.03)$ & $(0.03)$ & $(0.05)$ & $(0.05)$ \\
\hline & {$[0.00]$} & {$[0.00]$} & {$[0.00]$} & {$[0.00]$} & {$[0.00]$} \\
\hline \multirow[t]{3}{*}{$661-700$} & 0.47 & 0.39 & 0.32 & 0.26 & 0.20 \\
\hline & $(0.01)$ & $(0.01)$ & $(0.02)$ & $(0.02)$ & $(0.03)$ \\
\hline & {$[0.00]$} & {$[0.00]$} & {$[0.00]$} & {$[0.00]$} & {$[0.00]$} \\
\hline \multirow[t]{3}{*}{$701-740$} & 0.43 & 0.31 & 0.27 & 0.21 & 0.15 \\
\hline & $(0.01)$ & $(0.01)$ & $(0.02)$ & $(0.02)$ & $(0.03)$ \\
\hline & {$[0.00]$} & {$[0.00]$} & {$[0.00]$} & {$[0.00]$} & {$[0.00]$} \\
\hline \multirow[t]{3}{*}{$>740$} & 0.23 & 0.14 & 0.13 & 0.14 & 0.14 \\
\hline & $(0.01)$ & $(0.02)$ & $(0.02)$ & $(0.02)$ & $(0.03)$ \\
\hline & {$[0.00]$} & {$[0.00]$} & {$[0.00]$} & {$[0.00]$} & {$[0.00]$} \\
\hline \multicolumn{6}{|c|}{ Panel B: Total Balance Across All Cards } \\
\hline \multicolumn{6}{|c|}{ FICO } \\
\hline \multirow[t]{3}{*}{$\leq 660$} & 0.59 & 0.54 & 1.00 & 0.96 & 1.27 \\
\hline & $(0.12)$ & $(0.19)$ & $(0.26)$ & $(0.41)$ & $(0.63)$ \\
\hline & {$[0.00]$} & {$[0.01]$} & {$[0.00]$} & {$[0.02]$} & {$[0.04]$} \\
\hline \multirow[t]{3}{*}{$661-700$} & 0.46 & 0.42 & 0.48 & 0.59 & 0.43 \\
\hline & $(0.08)$ & $(0.08)$ & $(0.11)$ & $(0.20)$ & $(0.36)$ \\
\hline & {$[0.00]$} & {$[0.00]$} & {$[0.00]$} & {$[0.00]$} & {$[0.24]$} \\
\hline \multirow[t]{3}{*}{$701-740$} & 0.32 & 0.21 & 0.24 & 0.35 & 0.49 \\
\hline & $(0.08)$ & $(0.09)$ & $(0.10)$ & $(0.16)$ & $(0.44)$ \\
\hline & {$[0.00]$} & {$[0.01]$} & {$[0.02]$} & {$[0.03]$} & {$[0.27]$} \\
\hline \multirow[t]{3}{*}{$>740$} & -0.05 & -0.08 & -0.19 & 0.05 & 0.29 \\
\hline & $(0.06)$ & $(0.08)$ & $(0.14)$ & $(0.20)$ & $(0.39)$ \\
\hline & {$[0.40]$} & {$[0.33]$} & {$[0.17]$} & [0.79] & {$[0.46]$} \\
\hline \multicolumn{6}{|c|}{ Panel C: Cumulative Purchase Volume } \\
\hline \multicolumn{6}{|c|}{ FICO } \\
\hline \multirow[t]{3}{*}{$\leq 660$} & 0.56 & 0.78 & 0.94 & 0.98 & 0.99 \\
\hline & $(0.05)$ & $(0.08)$ & $(0.10)$ & $(0.11)$ & $(0.11)$ \\
\hline & {$[0.00]$} & {$[0.00]$} & {$[0.00]$} & {$[0.00]$} & {$[0.00]$} \\
\hline \multirow[t]{3}{*}{$661-700$} & 0.35 & 0.52 & 0.58 & 0.60 & 0.62 \\
\hline & $(0.02)$ & $(0.04)$ & $(0.05)$ & $(0.05)$ & $(0.05)$ \\
\hline & {$[0.00]$} & {$[0.00]$} & {$[0.00]$} & {$[0.00]$} & {$[0.00]$} \\
\hline \multirow[t]{3}{*}{$701-740$} & 0.33 & 0.47 & 0.56 & 0.60 & 0.60 \\
\hline & $(0.02)$ & $(0.04)$ & $(0.04)$ & $(0.05)$ & $(0.05)$ \\
\hline & {$[0.00]$} & {$[0.00]$} & {$[0.00]$} & {$[0.00]$} & {$[0.00]$} \\
\hline \multirow[t]{3}{*}{$>740$} & 0.22 & 0.31 & 0.36 & 0.40 & 0.44 \\
\hline & $(0.02)$ & $(0.03)$ & $(0.04)$ & $(0.05)$ & $(0.05)$ \\
\hline & [0.00] & {$[0.00]$} & {$[0.00]$} & {$[0.00]$} & {$[0.00]$} \\
\hline
\end{tabular}

Note: Table shows regression discontinuity estimates of the effect of a $\$ 1$ increase in credit limits on borrowing and spending. Panel A shows effects on average daily balances on the treated credit card. Panel B shows effects on total balances across all credit cards held by the account holder. Panel $\mathrm{C}$ shows effects on cumulative purchase volume on the treated credit card. Columns show effects at different time horizons after account origination. Within each panel, rows show effects for different FICO score groups, defined at account origination. Standard errors are constructed by bootstrapping over quasi-experiments, and are shown in parentheses. The corresponding $p$-values are shown in square brackets. 
Table 6: Probability of Deliquency

\begin{tabular}{|c|c|c|c|c|c|}
\hline & \multicolumn{5}{|c|}{ Months After Account Origination } \\
\hline & 12 & 24 & 36 & 48 & 60 \\
\hline \multicolumn{6}{|c|}{ Panel A: 60+ Days Past Due (\%) } \\
\hline \multicolumn{6}{|l|}{ FICO } \\
\hline \multirow[t]{3}{*}{$\leq 660$} & 0.10 & 0.57 & 0.71 & 1.21 & 1.38 \\
\hline & $(0.32)$ & $(0.37)$ & $(0.44)$ & $(0.44)$ & $(0.37)$ \\
\hline & {$[0.76]$} & {$[0.12]$} & {$[0.11]$} & {$[0.01]$} & {$[0.00]$} \\
\hline \multirow[t]{3}{*}{$661-700$} & 0.23 & 0.57 & 0.67 & 0.86 & 0.87 \\
\hline & $(0.15)$ & $(0.18)$ & $(0.21)$ & $(0.21)$ & $(0.21)$ \\
\hline & {$[0.12]$} & {$[0.00]$} & {$[0.00]$} & {$[0.00]$} & {$[0.00]$} \\
\hline \multirow[t]{3}{*}{$701-740$} & 0.28 & 0.55 & 0.63 & 0.68 & 0.67 \\
\hline & $(0.12)$ & $(0.17)$ & $(0.18)$ & $(0.18)$ & $(0.18)$ \\
\hline & {$[0.02]$} & {$[0.00]$} & {$[0.00]$} & {$[0.00]$} & {$[0.00]$} \\
\hline \multirow[t]{3}{*}{$>740$} & -0.19 & -0.16 & -0.20 & -0.32 & -0.33 \\
\hline & $(0.09)$ & $(0.12)$ & $(0.14)$ & $(0.15)$ & $(0.14)$ \\
\hline & {$[0.03]$} & {$[0.20]$} & {$[0.16]$} & {$[0.03]$} & {$[0.02]$} \\
\hline \multicolumn{6}{|c|}{ Panel B: 90+ Days Past Due (\%) } \\
\hline \multicolumn{6}{|c|}{ FICO } \\
\hline \multirow[t]{3}{*}{$\leq 660$} & 0.10 & 0.22 & 0.77 & 1.16 & 1.07 \\
\hline & $(0.27)$ & $(0.40)$ & $(0.42)$ & $(0.38)$ & $(0.34)$ \\
\hline & {$[0.71]$} & {$[0.58]$} & {$[0.07]$} & {$[0.00]$} & {$[0.00]$} \\
\hline \multirow[t]{3}{*}{$661-700$} & 0.19 & 0.42 & 0.68 & 0.80 & 0.74 \\
\hline & $(0.12)$ & $(0.17)$ & $(0.19)$ & $(0.20)$ & $(0.19)$ \\
\hline & {$[0.13]$} & {$[0.02]$} & {$[0.00]$} & {$[0.00]$} & {$[0.00]$} \\
\hline \multirow[t]{3}{*}{$701-740$} & 0.26 & 0.62 & 0.73 & 0.74 & 0.74 \\
\hline & $(0.10)$ & $(0.16)$ & $(0.17)$ & $(0.17)$ & $(0.17)$ \\
\hline & {$[0.01]$} & {$[0.00]$} & {$[0.00]$} & {$[0.00]$} & {$[0.00]$} \\
\hline \multirow[t]{3}{*}{$>740$} & -0.06 & -0.07 & -0.06 & -0.17 & -0.19 \\
\hline & $(0.08)$ & $(0.11)$ & $(0.13)$ & $(0.14)$ & $(0.13)$ \\
\hline & {$[0.46]$} & [0.53] & {$[0.66]$} & {$[0.22]$} & [0.15] \\
\hline
\end{tabular}

Note: Table shows regression discontinuity estimates of the effect of an increase in credit limits on the probability of delinquency. Panel A shows the effects of a $\$ 1,000$ increase in credit limits on the probability that the account is at least 60 days past due (60+ DPD); Panel B shows effects on the probability that the account is at least 90 days past due (90+ DPD). Columns show effects at different time horizons after account origination. Within each panel, rows show effects for different FICO score groups, defined at account origination. Standard errors are constructed by bootstrapping over quasi-experiments, and are shown in parentheses. The corresponding $p$-values are shown in square brackets. 
Table 7: Marginal Effects and Response of Marginal Effects to a \$1,000 Increase in Credit Limits

\begin{tabular}{|c|c|c|c|c|c|c|c|c|c|c|}
\hline & \multicolumn{2}{|c|}{ Total Costs } & \multicolumn{2}{|c|}{ Chargeoffs } & \multicolumn{2}{|c|}{ Total Revenue } & \multicolumn{2}{|c|}{ Fees } & \multicolumn{2}{|c|}{ Profits } \\
\hline & Marginal Effect & $\begin{array}{c}\text { Response of } \\
\text { Marginal Effect } \\
\text { to } \$ 1 \mathrm{~K} \text { Increase }\end{array}$ & Marginal Effect & $\begin{array}{c}\text { Response of } \\
\text { Marginal Effect } \\
\text { to } \$ 1 \mathrm{~K} \text { Increase }\end{array}$ & Marginal Effect & $\begin{array}{c}\text { Response of } \\
\text { Marginal Effect } \\
\text { to } \$ 1 \mathrm{~K} \text { Increase }\end{array}$ & Marginal Effect & $\begin{array}{c}\text { Response of } \\
\text { Marginal Effect } \\
\text { to } \$ 1 \mathrm{~K} \text { Increase }\end{array}$ & Marginal Effect & $\begin{array}{l}\text { Response of } \\
\text { Marginal Effect } \\
\text { to \$1K Increase }\end{array}$ \\
\hline & (1) & $(2)$ & (3) & $(4)$ & $(5)$ & $(6)$ & (7) & $(8)$ & (9) & $(10)$ \\
\hline \multicolumn{11}{|l|}{ FICO } \\
\hline \multirow[t]{3}{*}{$\leq 660$} & 0.296 & 0.075 & 0.216 & 0.080 & 0.238 & -0.129 & 0.027 & -0.102 & 0.002 & -0.136 \\
\hline & $(0.022)$ & $(0.020)$ & $(0.023)$ & $(0.017)$ & $(0.032)$ & (0.039) & $(0.010)$ & $(0.016)$ & $(0.033)$ & $(0.035)$ \\
\hline & {$[0.000]$} & {$[0.000]$} & [0.000] & {$[0.000]$} & {$[0.000]$} & [0.001] & [0.005] & {$[0.000]$} & [0.943] & {$[0.000]$} \\
\hline \multirow[t]{3}{*}{$661-700$} & 0.185 & 0.005 & 0.136 & 0.018 & 0.146 & -0.039 & 0.014 & -0.023 & -0.033 & -0.041 \\
\hline & $(0.013)$ & $(0.004)$ & $(0.012)$ & $(0.004)$ & $(0.008)$ & $(0.004)$ & $(0.002)$ & $(0.002)$ & $(0.012)$ & $(0.004)$ \\
\hline & {$[0.000]$} & {$[0.271]$} & {$[0.000]$} & {$[0.000]$} & {$[0.000]$} & {$[0.000]$} & {$[0.000]$} & {$[0.000]$} & {$[0.007]$} & {$[0.000]$} \\
\hline \multirow[t]{3}{*}{$701-740$} & 0.165 & 0.015 & 0.119 & 0.020 & 0.130 & -0.010 & 0.018 & -0.007 & -0.029 & -0.024 \\
\hline & $(0.011)$ & (0.004) & (0.011) & $(0.003)$ & (0.008) & $(0.003)$ & $(0.002)$ & $(0.001)$ & $(0.010)$ & $(0.003)$ \\
\hline & {$[0.000]$} & {$[0.000]$} & {$[0.000]$} & {$[0.000]$} & {$[0.000]$} & {$[0.002]$} & {$[0.000]$} & {$[0.000]$} & [0.003] & {$[0.000]$} \\
\hline \multirow[t]{3}{*}{$>740$} & 0.060 & -0.013 & 0.037 & -0.005 & 0.055 & -0.014 & 0.008 & -0.003 & -0.004 & -0.002 \\
\hline & (0.009) & $(0.002)$ & $(0.008)$ & $(0.002)$ & $(0.006)$ & $(0.002)$ & $(0.002)$ & $(0.001)$ & $(0.008)$ & $(0.002)$ \\
\hline & {$[0.000]$} & {$[0.000]$} & {$[0.000]$} & {$[0.012]$} & {$[0.000]$} & {$[0.000]$} & {$[0.000]$} & [0.004] & {$[0.652]$} & {$[0.265]$} \\
\hline
\end{tabular}

Note: Table shows marginal effects, and the response of marginal effects to a $\$ 1,000$ increase in credit limits by FICO score group. We show these effects for total costs, chargeoffs (which is an important component of total costs), total revenue, fee revenue (which is an important component of total revenue) and profits (which is defined as total revenue minus total costs). We measure these variables over a time horizon of 48 months after account origination. For each measure, the left column shows the RD estimate of the marginal effect of a $\$ 1$ increase in credit limits at the prevailing equilibrium level, and the right column shows the response of that marginal effect to a $\$ 1,000$ increase in credit limits. Rows show effects for different FICO score groups, defined at account origination. Standard errors are constructed by bootstrapping over quasi-experiments, and are shown in parentheses. The corresponding $p$-values are shown in square brackets. 
Table 8: Marginal Propensity to Lend $\times$ Marginal Propensity to Borrow

\begin{tabular}{|c|c|c|c|c|c|c|}
\hline & \multirow[b]{2}{*}{ MPL } & \multicolumn{5}{|c|}{ MPB Across All Cards } \\
\hline & & 12 Months & 24 Months & 36 Months & 48 Months & 60 Months \\
\hline \multicolumn{7}{|l|}{ FICO } \\
\hline \multirow[t]{3}{*}{$\leq 660$} & 126.75 & 0.59 & 0.54 & 1.00 & 0.96 & 1.27 \\
\hline & (63.84) & 0.12 & 0.19 & 0.26 & 0.41 & 0.63 \\
\hline & {$[0.05]$} & {$[0.00]$} & {$[0.01]$} & {$[0.00]$} & {$[0.02]$} & {$[0.04]$} \\
\hline \multirow[t]{3}{*}{$661-700$} & 273.86 & 0.46 & 0.42 & 0.48 & 0.59 & 0.43 \\
\hline & (57.04) & 0.08 & 0.08 & 0.11 & 0.20 & 0.36 \\
\hline & {$[0.00]$} & {$[0.00]$} & {$[0.00]$} & {$[0.00]$} & {$[0.00]$} & {$[0.24]$} \\
\hline \multirow[t]{3}{*}{$701-740$} & 425.50 & 0.32 & 0.21 & 0.24 & 0.35 & 0.49 \\
\hline & (111.39) & 0.08 & 0.09 & 0.10 & 0.16 & 0.44 \\
\hline & {$[0.00]$} & {$[0.00]$} & {$[0.01]$} & {$[0.02]$} & {$[0.03]$} & {$[0.27]$} \\
\hline \multirow[t]{3}{*}{$>740$} & 2203.04 & -0.05 & -0.08 & -0.19 & 0.05 & 0.29 \\
\hline & $(515.06)$ & 0.06 & 0.08 & 0.14 & 0.20 & 0.39 \\
\hline & {$[0.00]$} & {$[0.40]$} & {$[0.33]$} & {$[0.17]$} & {$[0.79]$} & {$[0.46]$} \\
\hline \multirow[t]{3}{*}{ Weighted Average } & 978.00 & 0.28 & 0.23 & 0.33 & 0.45 & 0.62 \\
\hline & & \multicolumn{5}{|c|}{ MPL X MPB } \\
\hline & & 12 Months & 24 Months & 36 Months & 48 Months & 60 Months \\
\hline \multicolumn{2}{|c|}{ Without Accounting for Correlation } & 274.24 & 223.94 & 327.04 & 438.94 & 609.80 \\
\hline \multicolumn{2}{|c|}{ Accounting for Correlation } & 26.43 & -12.18 & -77.27 & 130.15 & 341.16 \\
\hline \multicolumn{2}{|c|}{ Accounting for Correlation + Lower Bound } & 66.67 & 54.49 & 76.22 & 130.15 & 341.16 \\
\hline
\end{tabular}

Note: Table shows the effect of a reduction in the cost of funds on lending and borrowing. The first column of the top panel shows the effect of a permanent 1 percentage point reduction in the cost of funds on credit limits (MPL), constructed using cumulative profits and borrowing estimates over 48 months after account origination. The remaining columns reproduce the MPB estimates from Table 5 at different time horizons after account origination. Both estimates are shown by FICO score group, defined at account origination. Standard errors are constructed by bootstrapping over quasi-experiments, and are shown in parentheses. The corresponding $p$-values are shown in square brackets. The bottom panel shows the implied stimulative effect at these same time horizons. The estimates that do not account for correlation are calculated as weighted average MPL $\times$ weighted average MPB. The estimates that account for this correlation are constructed by first calculating MPL $\times$ MPB for each FICO score group and then taking the weighted average. In the last row we set the (statistically insignificant) negative coefficient for MPB for high FICO score borrowers to zero. Weighted averages are produced by weighting each group by the share of credit card holders with that FICO score in our data (see Section 1.4 and Appendix Figure A1). 


\title{
Do Banks Pass Through CRedit Expansions? The Marginal PROFITABILITY OF CONSUMER LENDING DURING THE GREAT RECESSION
}

\section{Online Appendix}

\author{
Sumit Agarwal Souphala Chomsisengphet Neale Mahoney Johannes Stroebel
}

\section{A Review of Policy Interventions Partially Aimed at Stimulating Lending}

This appendix describes policy interventions during the Great Recession that were at least partially aimed at encouraging more consumer lending. We analyze the objectives of policies in both the U.S. and in Europe. For the U.S., we consider programs aimed at improving banks' ability to cheaply refinance themselves in short-term funding markets, such as the Term Asset-Backed Securities Loan Facility (TALF) program and the Term Auction Facility (TAF) program (Section A.1). We also discuss programs created to increase the availability of affordable capital for U.S. banks (Section A.2), such as the Capital Purchase Program (CCP) and the Capital Assistance Program (CAP). We document that these programs had at least the partial objective of increasing credit availability for U.S. households. We also discuss the "Funding for Lending Scheme" at the Bank of England (Section A.3) and the Targeted Longer-Term Refinancing Operations (TLTRO) at the European Central Bank (Section A.4).

\section{A.1 U.S. programs focused on short-term funding markets}

In the U.S., a number of programs were set up with the explicit aim of increasing credit availability for households and firms by reducing the costs at which financial institutions could refinance themselves in short-term funding markets. These programs can be viewed within the framework in Section 5 as attempts to reduce the cost of funds, $c$.

The Term Asset-Backed Securities Loan Facility (TALF) was announced on November 25, 2008, and was aimed at supporting the issuance of asset-backed securities (ABS) collateralized by student loans, auto loans, credit card loans, and loans guaranteed by the Small Business Administration. Under TALF, the Federal Reserve Bank of New York lent up to \$200 billion (later expanded to \$1 trillion) to holders of certain AAA-rated ABS backed by newly and recently originated consumer and small business loans. The following sources discuss the anticipated impact of this program on the total supply of credit available to the population. They document that an increase in credit availability (and thus borrowing volumes) was a key policy goal of TALF.

(A) Board of Governors of the Federal Reserve System, Press Release, November 25, 2008: "The Federal Reserve Board on Tuesday announced the creation of the Term Asset-Backed Securities Loan Facility (TALF), a facility that will help market participants meet the credit needs of households and small businesses by supporting the issuance of asset-backed securities (ABS) collateralized by student loans, auto loans, credit card loans, and loans guaranteed by the Small Business Administration (SBA). [... ] New issuance of ABS declined precipitously in September and came to a halt in October. At the same time, interest rate spreads on AAA-rated tranches of ABS soared to levels well outside the range of historical experience, reflecting unusually high risk premiums. The ABS markets historically have funded a substantial share of consumer credit and 
SBA-guaranteed small business loans. Continued disruption of these markets could significantly limit the availability of credit to households and small businesses and thereby contribute to further weakening of U.S. economic activity. The TALF is designed to increase credit availability and support economic activity by facilitating renewed issuance of consumer and small business ABS at more normal interest rate spreads." [Link]

(B) Janet L. Yellen, President and CEO, Federal Reserve Bank of San Francisco, Presentation to the Annual AEA/ASSA Conference, January 4, 2009: "For example, the new Term Asset-Backed Securities Loan Facility (TALF) is a joint program between the Federal Reserve and the Treasury, using TARP funds, and is designed to improve the flow of credit to households and businesses." [Link]

(C) Testimony by Elizabeth A. Duke, Member of the Board of Governors of the Federal Reserve, "Credit availability and prudent lending standards," Committee on Financial Services, U.S. House of Representatives, March 25, 2009: "[T]he Federal Reserve and the Treasury recently launched the Term Asset-Backed Securities Loan Facility (TALF) to facilitate the extension of credit to households and small businesses." [Link]

(D) U.S. Department of the Treasury website, "Credit Market Programs." Accessed July 7, 2015: "The Term Asset-Backed Securities Loan Facility (TALF) is a joint program with the Federal Reserve. The program was launched in March 2009 with the aim of helping to restart the asset-backed securitization (ABS) markets that provide credit to consumers and small businesses. The financial crisis severely impacted these markets. Under this program, the Federal Reserve Bank of New York made non-recourse loans to buyers of AAA-rated asset-backed securities to help stimulate consumer and business lending. Treasury used TARP funds to provide credit support for these loans." [Link]

Similarly, a somewhat more general program - the Term Auction Facility (TAF) - was set up to provide short-term collateralized loans to U.S. financial institutions that are judged to be in sound financial condition by their local reserve banks. TAF ran between December 17, 2007 and March 8, 2010. The Fed described the aims of this program as below:

(A) Board of Governors of the Federal Reserve System, Press Release, October 6, 2008: "Consistent with this increased scope, the Federal Reserve also announced today additional actions to strengthen its support of term lending markets. Specifically, the Federal Reserve is substantially increasing the size of the Term Auction Facility (TAF) auctions, beginning with today's auction of 84-day funds. These auctions allow depository institutions to borrow from the Federal Reserve for a fixed term against the same collateral that is accepted at the discount window; the rate is established in the auction, subject to a minimum set by the Federal Reserve. In addition, the Federal Reserve and the Treasury Department are consulting with market participants on ways to provide additional support for term unsecured funding markets. Together these actions should encourage term lending across a range of financial markets in a manner that eases pressures and promotes the ability of firms and households to obtain credit." [Link] 


\section{A.2 U.S. programs focused on level and cost of bank capital}

In addition to programs aimed at providing liquidity through improving the state of short-term funding markets, U.S. policies also focused on improving the capital position of U.S. banks. Two important programs with that objective, both using resources of the Troubled Asset Relief Program (TARP), were the Capital Purchase Program (CPP) and the Capital Assistance Program (CAP).

Under the first program, the CCP, nine financial institutions received new capital injections on October 28, 2008, with 42 other institutions participating in the CPP through purchases made on November 14, 2008 and November 21, 2008.

(A) U.S. Department of the Treasury website, "Capital Purchase Program." Accessed August 3, 2015: "The Capital Purchase Program (CPP) was launched to stabilize the financial system by providing capital to viable financial institutions of all sizes throughout the nation. Without a viable banking system, lending to businesses and consumers could have frozen and the financial crisis might have spiraled further out of control. Based on market indicators at the time, it became clear that financial institutions needed additional capital to absorb losses and restart the flow of credit to businesses and consumers. In this context, immediate capital injections into financial institutions were necessary to avert a potential collapse of the system." [Link]

(B) Statement by Secretary Henry M. Paulson, Jr. on Capital Purchase Program, October 20, 2008: "We expect all participating banks to continue to strengthen their efforts to help struggling homeowners who can afford their homes avoid foreclosure. Foreclosures not only hurt the families who lose their homes, they hurt neighborhoods, communities and our economy as a whole. [...] Our purpose is to increase confidence in our banks and increase the confidence of our banks, so that they will deploy, not hoard their capital. And we expect them to do so, as increased confidence will lead to increased lending. This increased lending will benefit the U.S. economy and the American people." [Link]

(C) Testimony by Elizabeth A. Duke, Member of the Board of Governors of the Federal Reserve, "Credit availability and prudent lending standards," Committee on Financial Services, U.S. House of Representatives, March 25, 2009: "The U.S. Treasury, the Federal Deposit Insurance Corporation (FDIC), and the Federal Reserve have taken a number of actions to strengthen the financial sector and to promote the availability of credit to businesses and households. This included injecting additional capital into banks, increasing FDIC deposit coverage, providing guarantees of selected senior bank obligations and noninterest-bearing deposits, and establishing new liquidity facilities to financial markets." [Link]

The Treasury's Financial Stability Plan also included an element to improve the capital position of U.S. banks - the Capital Assistance Program (CAP).

(A) Remarks by Treasury Secretary Timothy Geithner, "Introducing the Financial Stability Plan," February 10, 2009: "First, we're going to require banking institutions to go through a carefully designed comprehensive stress test, to use the medical term. We want their balance sheets cleaner, and stronger. [...] Those institutions that need additional capital will be able to access a new funding 
mechanism that uses funds from the Treasury as a bridge to private capital. The capital will come with conditions to help ensure that every dollar of assistance is used to generate a level of lending greater than what would have been possible in the absence of government support." [Link]

\section{A.3 U.K. Funding for Lending Scheme}

Programs aimed at increasing lending of banks to households and firms were not limited to the U.S.; in the U.K., the Bank of England's "Funding for Lending Scheme" (FLS) was set up precisely with the purpose of banks passing through credit expansions to households and firms:

(A) Bank of England, News Release, July 13, 2012: "The FLS is designed to boost lending to the real economy. Banks and building societies that increase lending to UK households and businesses will be able to borrow more in the FLS, and do so at lower cost than those that scale back lending. [...] The FLS is designed to encourage broad participation so that as many institutions as possible have incentives to lend more to the UK real economy through, for example, business loans and residential mortgages, than they otherwise would have. [...] Commenting on the launch of the Scheme, the Governor of the Bank of England said: [...] 'That will encourage banks to make loans to families and businesses both cheaper and more easily available'. The Chancellor of the Exchequer said: 'Today's announcements aim to make mortgages and loans cheaper and more easily available, providing welcome support to businesses that want to expand and families aspiring to own their own home. The Treasury and the Bank of England are taking coordinated action to inject new confidence into our financial system and support the flow of credit to where it is needed in the real economy.'" [Link]

(B) Spencer Dale, Executive Director, Monetary Policy, and Chief Economist, Bank of England, "Limits of Monetary Policy," September 8, 2012: "Most recently, the Bank, together with the Government, has launched the Funding for Lending Scheme (FLS), which provides banks with an alternative cheaper source of funding tied to the extent to which they expand lending to the UK real economy. [...] It is bigger and bolder than any scheme tried so far to get the banks lending. In terms of the cost at which funding is being made available, the maturity of that funding and, most importantly, the strong price incentives it provides to banks to expand their lending. By helping to improve the availability of bank lending to companies and households who previously have been effectively starved of credit, it could have a significant effect on demand. Moreover, if some of the recent poor supply side performance of our economy does stem from the constraints on the flow of credit, it may also help to ease that friction." [Link]

\section{A.4 European Central Bank's Targeted Longer-Term Refinancing Operation}

More recently, the European Central Bank (ECB) also set up programs to support bank lending to the real economy - the targeted longer-term refinancing operations (TLTRO). In these operations, banks are entitled to borrow from the ECB, conditional on their lending to the private non-financial sector, with loans to households for house purchase being excluded.

(A) Mario Draghi, President of the ECB, "Introductory Statement," Hearing at the Committee on Economic and Monetary Affairs of the European Parliament, July 14, 2014: "[O]ur TLTROs are tailored to in- 
centivise bank lending to the real economy in the euro area. The TLTROs will provide long-term funding to participating banks. This should ease their financing costs, allowing banks to pass on such attractive conditions to their customers. This will ease credit conditions and stimulate credit creation. Moreover, the growth of our balance sheet as a result of a significant take-up in our TLTROs will put downward pressure on interest rates in the money markets. This will contribute further to lowering the banking sector's funding costs. However, the TLTROs will not merely provide long-term funding. The TLTROs are targeted operations: the stronger the flows of new net lending to non-financial corporations and consumers (relative to a specified benchmark), the higher the amount that banks will be permitted to borrow from the Eurosystem at very attractive terms and conditions over a period of up to four years. Hence, we have built in strong incentives for banks to expand their lending beyond original plans - both banks with a recent record of positive lending and those that have been deleveraging." [Link]

(B) Peter Praet, Member of the Executive Board of the ECB, "Current Issues of Monetary Policy," July 3, 2014: "In this context, the Governing Council decided last month to adopt several credit easing measures - by which I mean, measures aimed at ensuring that the accommodative policy stance is translated into a corresponding easing in credit conditions. In particular, these measures include a series of targeted longer-term refinancing operations (TLTROs) aimed at easing credit conditions. The TLTROs are expected to ease overly tight lending conditions, lower lending rates and stimulate credit volumes through several channels. The first and most important channel is through a reduction in term funding costs for banks. Funding relief, however, does not per se guarantee better credit conditions for banks' customers, unless the supply of loans shifts in parallel and lending mark-ups are kept constant or even pushed down. This is why the targeted nature of the TLTRO is important: by making funding relief conditional on generation of new lending volumes, the TLTRO will encourage a shift outward in the credit supply curve. By simply moving along the demand schedule, this outward shift will reduce the price for lending while increasing new loans. If banks do not manage to exceed a certain benchmark in terms of net lending, they will not benefit from the TLTRO. This shows that the TLTROs are indeed targeted, rather than a broad-based unconditional provision of liquidity as in the case of the earlier 3-year LTROs." [Link] 
Figure A1: FICO Score, Population Distribution

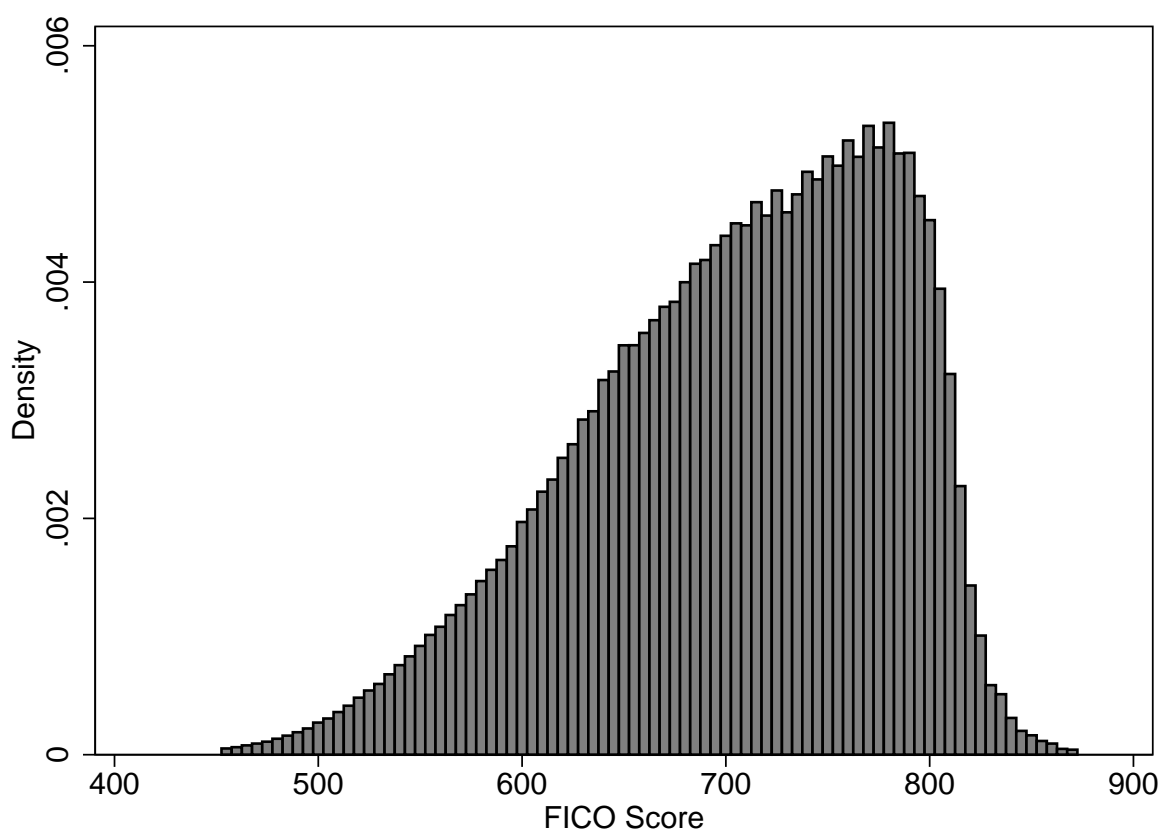

Note: Figure shows the distribution over FICO scores of all credit cards issued by the banks in our sample, averaged over the period January 2008 to December 2013. 
Figure A2: Credit Card Interest Rates vs. Federal Funds Rate

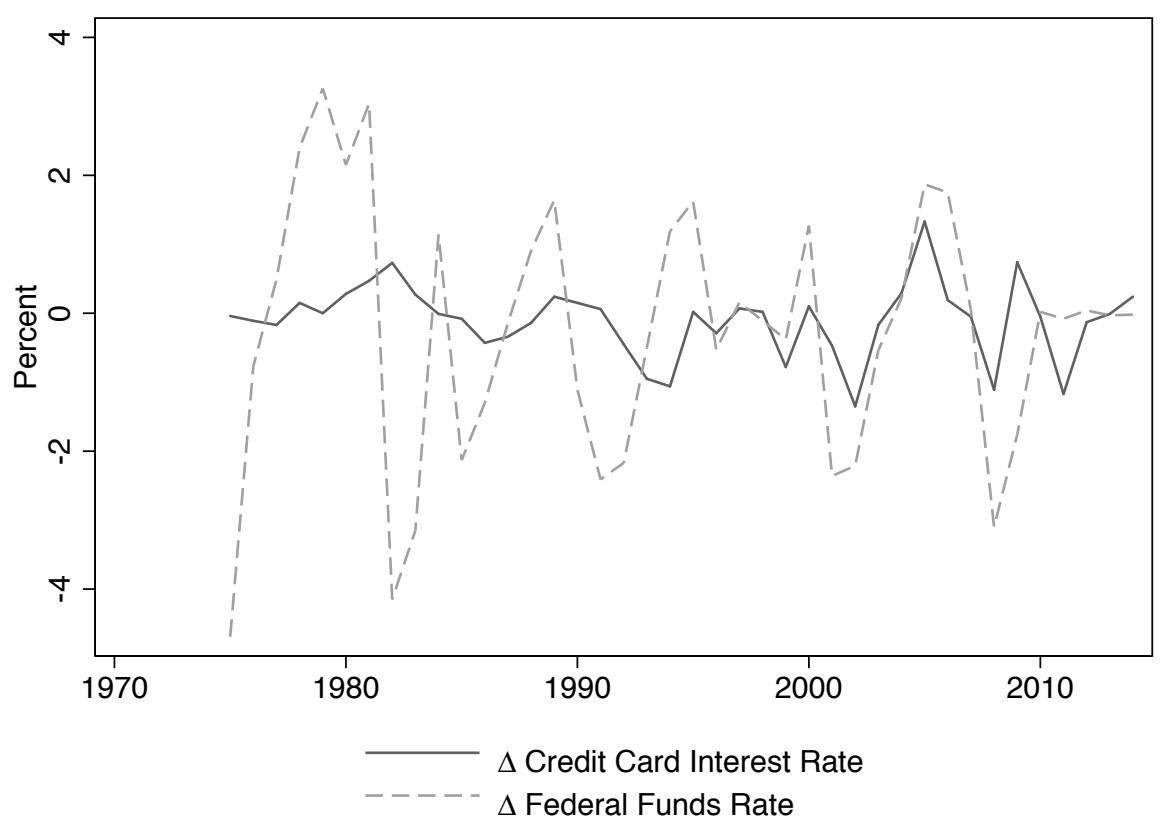

Note: Figure shows the year-on-year change in credit card interest rates and year-on-year change in Federal Funds Rate between 1974 and 2014. Before 1994, credit card interest rates were those reported in the Federal Reserve's "Quarterly Report of Interest Rates on Selected Direct Installment Loans." From 1994 onwards, credit card interest rates are from the Federal Reserve's "Quarterly Report of Credit Card Interest Rates for those credit card holders incurring interest charges." 
Figure A3: Probability of Delinquency at 48 Months After Origination

(A) Probability 60+ DPD

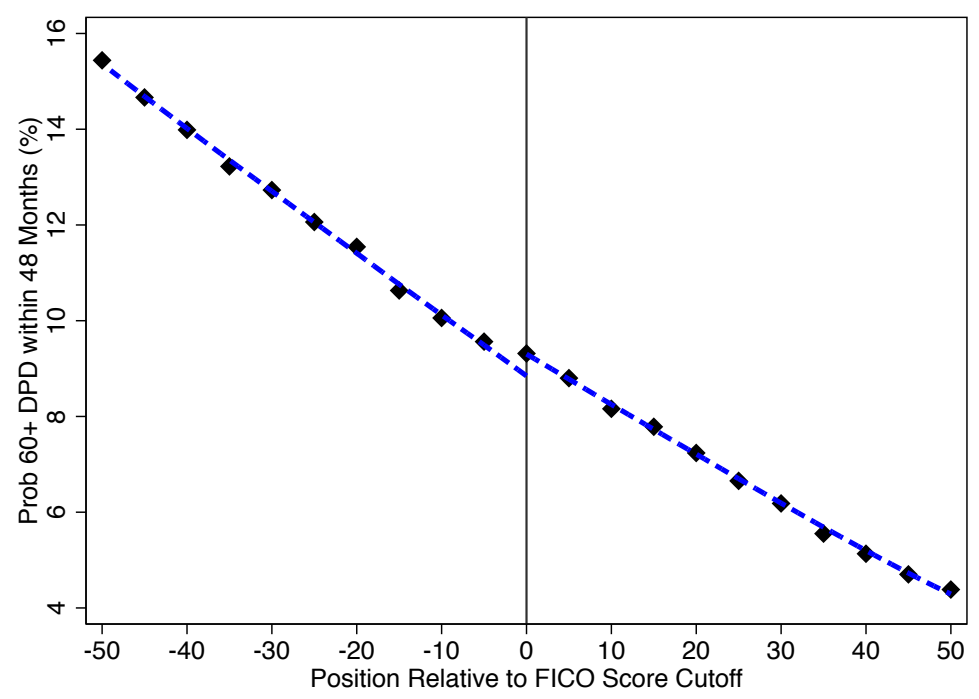

(B) Probability 90+ DPD

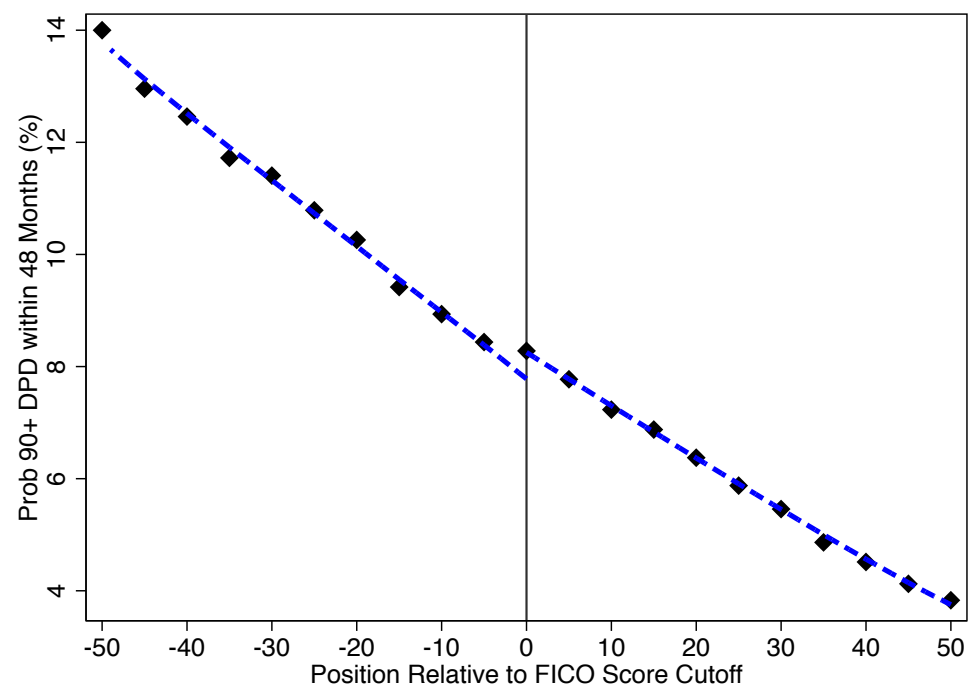

Note: Figure shows the effects of credit limits on the probability of deliquency around our 743 pooled credit limit quasiexperiments. Panel A shows effects on the cumulative probability of an account being more than 60 days past due (60+ DPD); Panel B shows effects on the cumulative probability of being more than 90 days past due (90+ DPD). These plots are constructed as described in Figure 3. 
Figure A4: Total Revenue, Total Cost, and Components

(A) Total Costs

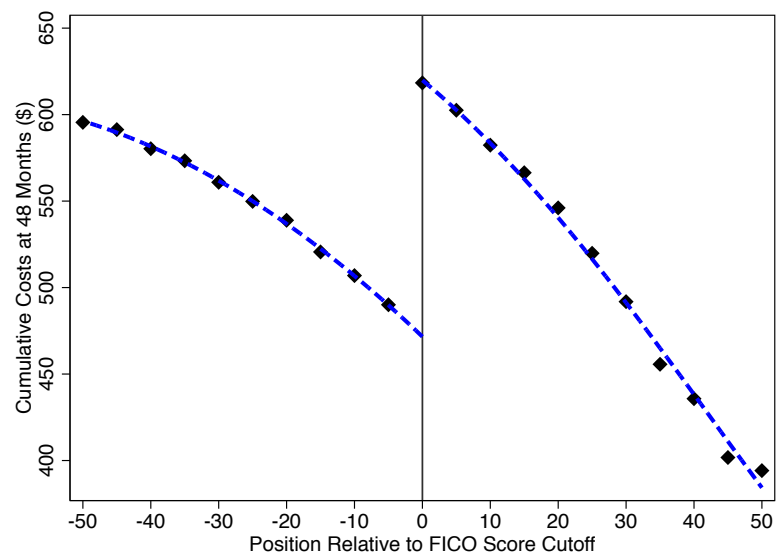

(C) Total Revenue

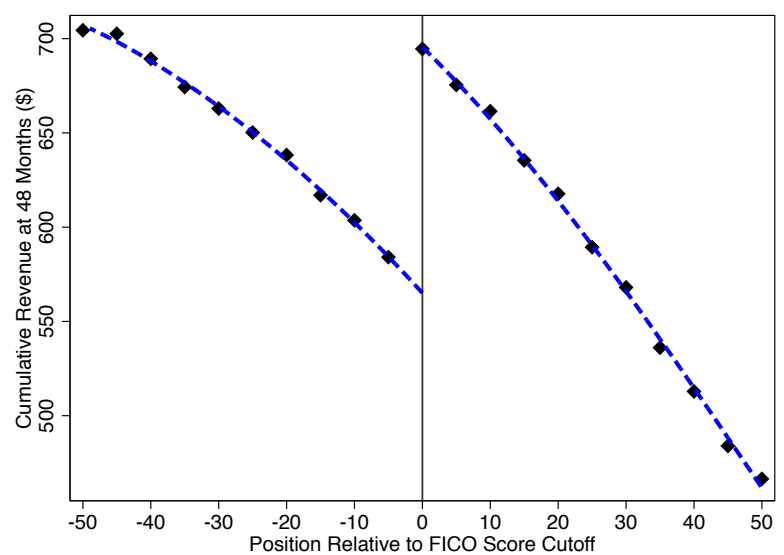

(B) Chargeoffs

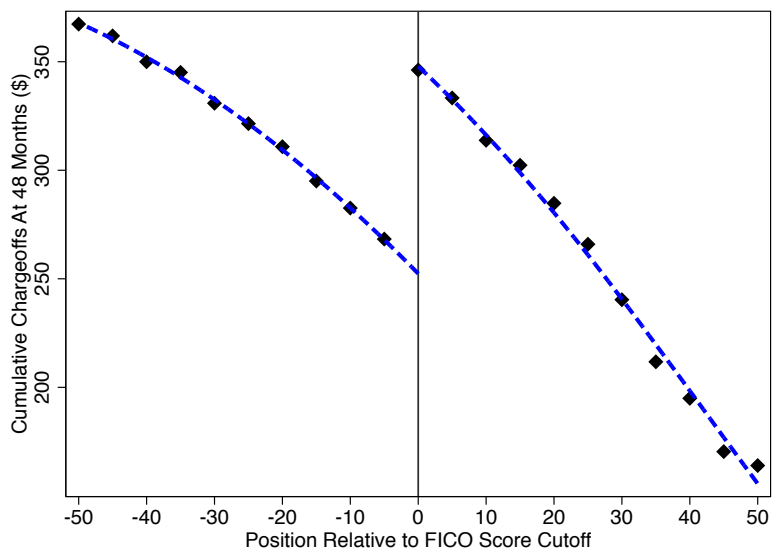

(D) Fee Revenue

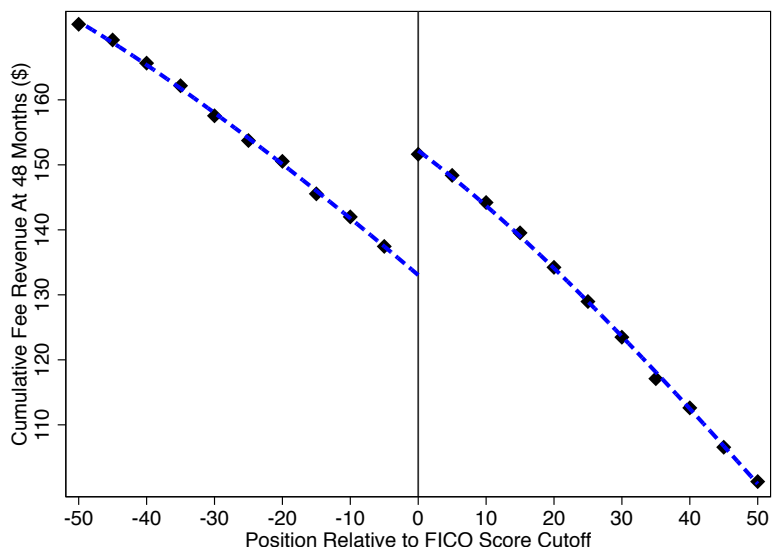

(E) Profits

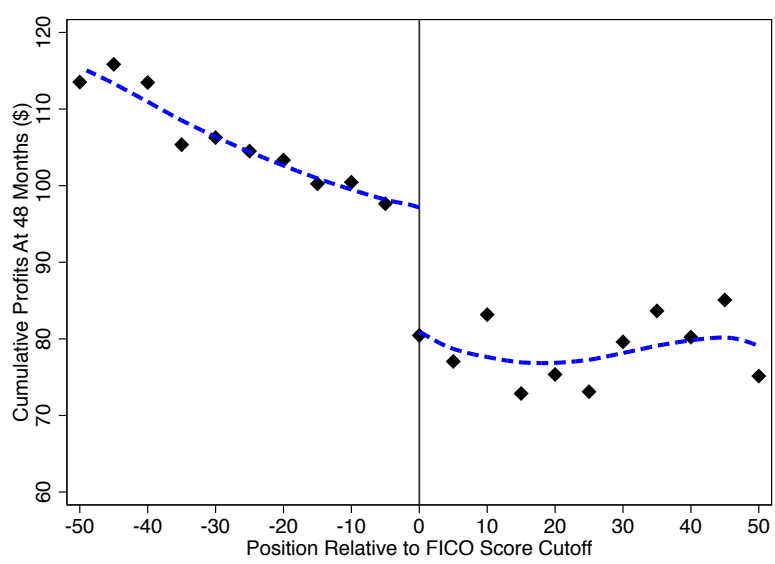

Note: Figure shows the effects of credit limits on cumulative total costs (Panel A), cumulative chargeoffs (Panel B), cumulative total revenue (Panel C), cumulative fee revenue (Panel D), and cumulative profits (Panel E), all measured over the first 48 months after account origination. These plots pool across our 743 credit limit quasi-experiments, and are constructed as described in Figure 3. 